Pacific Northwest

National Laboratory

Operated by Battelle for the

U.S. Department of Energy

\section{Chemical and Radiochemical Composition of Thermally Stabilized Plutonium Oxide from the Plutonium Finishing Plant Considered as Alternate Feedstock for the Mixed Oxide Fuel Fabrication Facility}

\author{
J. M. Tingey \\ S. A. Jones
}

July 2005

Prepared for the U.S. Department of Energy under Contract DE-AC05-76RL01830 


\section{DISCLAIMER}

This report was prepared as an account of work sponsored by an agency of the United States Government. Neither the United States Government nor any agency thereof, nor Battelle Memorial Institute nor any of their employees makes any warranty, express or implied, or assumes any legal liability or responsibility for the accuracy, completeness, or usefulness of any information, apparatus, product, or process disclosed or represents that its use would not infringe privately owned rights. Reference herein to any specific commercial product, process, or service by trade name, trademark, manufacturer, or otherwise does not necessarily constitute or imply its endorsement, recommendation, or favoring by the United States Government or any agency thereof, or Battelle Memorial Institute. The views and opinions of authors expressed herein do not necessarily state or reflect those of the United States Government or any agency thereof.

\section{PACIFIC NORTHWEST NATIONAL LABORATORY operated by \\ BATTELLE \\ for the UNITED STATES DEPARTMENT OF ENERGY under Contract DE-AC05-76RL01830}

Printed in the United States of America Available to DOE and DOE contractors from the Office of Scientific and Technical Information, P.O. Box 62, Oak Ridge, TN 37831-0062;

ph: (865) 576-8401

fax: (865) 576-5728

email: reports@adonis.osti.gov

Available to the public from the National Technical Information Service, U.S. Department of Commerce, 5285 Port Royal Rd., Springfield, VA 22161 ph: (800) 553-6847 fax: (703) 605-6900 email: orders@ntis.fedworld.gov online ordering: http://www.ntis.gov/ordering.htm

This document was printed on recycled paper.

$(8 / 00)$ 


\title{
Chemical and Radiochemical Composition of Thermally Stabilized Plutonium Oxide from the Plutonium Finishing Plant Considered as Alternate Feedstock for the Mixed Oxide Fuel Fabrication Facility
}

\author{
JM Tingey \\ SA Jones
}

July 2005

Prepared for

the U.S. Department of Energy

under Contract DE-AC05-76RL01830

Pacific Northwest National Laboratory

Richland, WA 99352 


\section{Executive Summary}

Eighteen plutonium oxide samples originating from the Plutonium Finishing Plant (PFP) on the Hanford Site were analyzed to provide additional data on the suitability of PFP thermally stabilized plutonium oxides and Rocky Flats oxides as alternate feedstock to the Mixed Oxide Fuel Fabrication Facility (MFFF). Radiochemical and chemical analyses were performed on fusions, acid leaches, and water leaches of these 18 samples. The results from these destructive analyses were compared with nondestructive analyses (NDA) performed at PFP and the acceptance criteria for the alternate feedstock.

The plutonium oxide materials considered as alternate feedstock at Hanford originated from several different sources, including Rocky Flats oxide, scrap from the Remote Mechanical C-Line (RMC) and the Plutonium Reclamation Facility (PRF), and materials from other plutonium conversion processes at Hanford. These materials were initially present at PFP as metals, oxides, and solutions. All of the plutonium considered as alternate feedstock was in the form of plutonium dioxide, $\mathrm{PuO}_{2}$ (and likely also included residual plutonium tetrafluoride, $\mathrm{PuF}_{4}$ ) and had undergone thermal stabilization according to DOE-STD-3013 criteria, generally achieved by heating at $>950^{\circ} \mathrm{C}$ for two hours in an oxidizing environment.

The 18 plutonium oxide samples were grouped into four categories based on their origin. The Rocky Flats oxide was divided into two categories according to their relative chloride concentrations (three lowchloride and seven high-chloride samples). The other two categories were PRF/RMC scrap oxides (six samples), including scrap from both process lines, and oxides produced from solutions (two samples). The two solution samples came from samples that previously had been tested at Pacific Northwest National Laboratory. These samples originated at the PFP and are from relatively pure plutonium nitrate product solutions and double-pass filtrate solutions after they had been precipitated with magnesium hydroxide, filtered, and thermally stabilized according to the 3013 criteria. The remaining plutonium oxide from solutions at PFP, including those obtained by oxalic acid treatment to precipitate plutonium oxalate and subsequent oxalate calcination to produce $\mathrm{PuO}_{2}$, had already been processed and placed in 3013 containers by the start of the testing and thus were not available for characterization.

Samples varied in appearance depending on the original source of material. Rocky Flats items were mostly dark olive green with clumps that crushed easily with a mortar and pestle. PRF/RMC items showed more variability, though most were rust colored. One sample contained white particles that were difficult to crush, and another sample was dark grey with a mixture of fines and large, hard fragments. The appearance and feel of the fragments indicated they might have contained a metallic alloy. The colors of the precipitated and thermally stabilized solution samples were indicative of the impurities they contained. The double-pass filtrate sample was brown, suggesting iron impurities were present; the product nitrate sample was light gray.

Radiochemical analyses, thermal ionization mass spectrometry (TIMS), alpha and gamma energy analysis (AEA and GEA), and kinetic phosphorescence analysis (KPA) indicate that these materials are all weapons-grade plutonium with consistent plutonium isotopics. A small amount of uranium $(<0.14 \mathrm{wt} \%)$ is also present in these samples. The isotopic composition of the uranium varied widely, but was consistent among each category of material. 
The primary water-soluble anions in these samples were $\mathrm{Cl}^{-}, \mathrm{NO}_{3}{ }^{-}, \mathrm{SO}_{4}{ }^{2-}$, and $\mathrm{PO}_{4}{ }^{3-}$. The anion concentrations were determined by ion chromatography on the water leachates of the samples and inductively coupled plasma spectrometry of the samples. The only major anion observed in the Rocky Flats materials was $\mathrm{Cl}^{-}$, but the PRF/RMC samples had significant quantities of all of the observed primary anions. The nondestructive prompt gamma spectral measurements performed at PFP were found to provide a representative analysis of the $\mathrm{Cl}^{-}$concentration in the bulk material. The primary anions observed in the solution samples were $\mathrm{NO}_{3}{ }^{-}$and $\mathrm{PO}_{4}{ }^{3-}$. The anion concentrations did not exceed the mixed oxide (MOX) specification limits.

Metal concentrations were determined by inductively coupled plasma spectrometry and inductively coupled mass spectrometry. Metals found to exceed the MOX specification limits included $\mathrm{Cr}, \mathrm{Fe}, \mathrm{Ni}$, $\mathrm{Al}, \mathrm{Cu}$, and Si. All of the samples exceeded at least the 75 percent specification limit in one element. 


\section{Table of Contents}

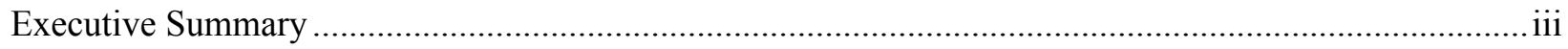

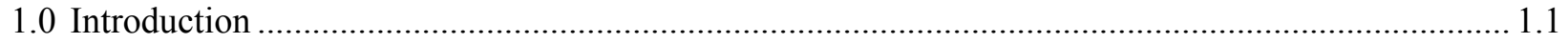

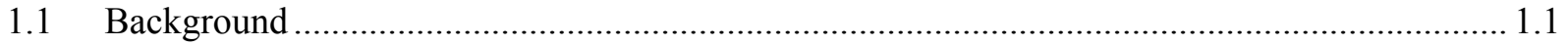

1.2 Alternate Feedstock Specification............................................................................... 1.2

1.3 Potential Alternate Feedstock at Hanford .......................................................................... 1.5

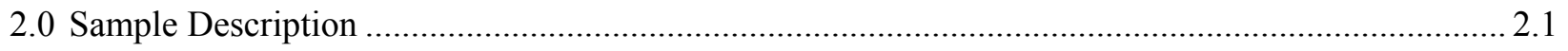

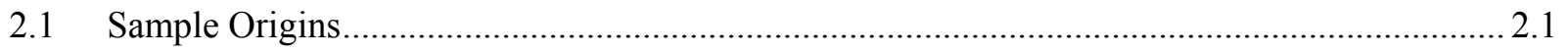

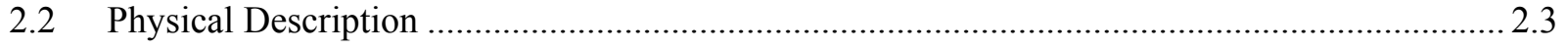

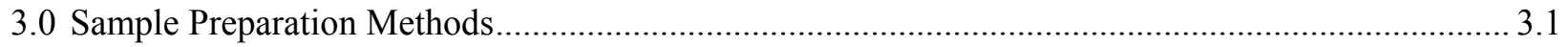

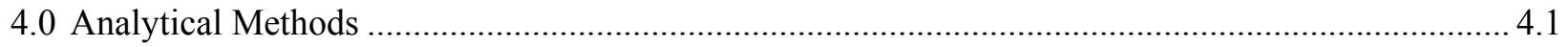

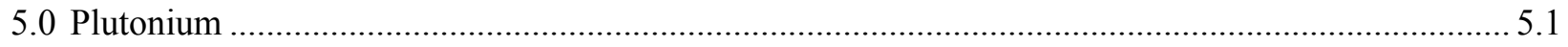

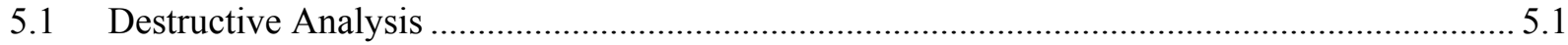

5.2 Comparison of GEA with NDA Observed at PFP …...................................................... 5.2

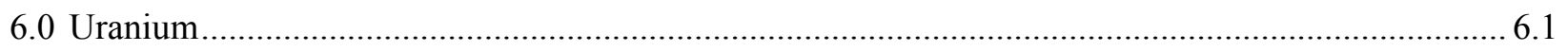

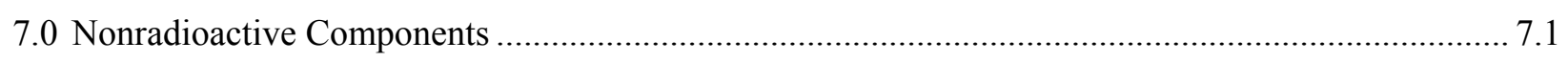

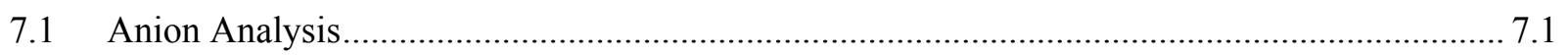

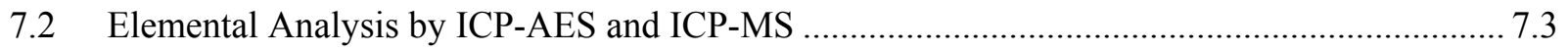

7.3 Prompt Gamma Analysis Compared to Destructive Analyses............................................. 7.7

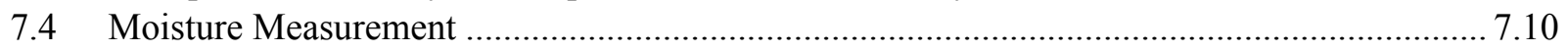

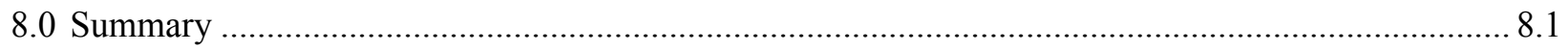

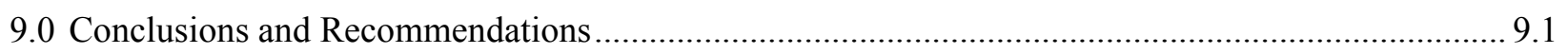

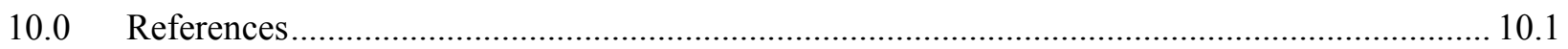

Appendix - ICP-AES and ICP-MS Analyses on Acid Leach and Fusion Fractions ............................... A.1 


\section{Figures}

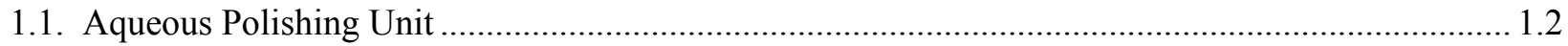

2.1. Photographs of B-5472 Sample with Some of the Larger Particles Separated ............................... 2.3

2.2. Sample Produced by Magnesium Hydroxide Precipitation Process on Double Pass Filtrate ........... 2.4

2.3. Sample Prepared by Magnesium Hydroxide Precipitation of Plutonium from

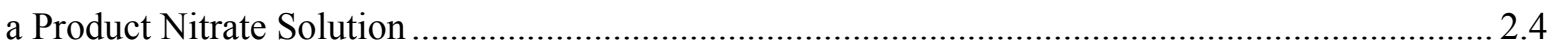

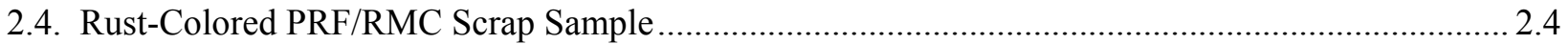

3.1. Sample Preparation and Analysis Flow Diagram .................................................................... 3.1

5.1. Plutonium Measured by Direct GEA/Calorimetry of 3013 Containers Compared

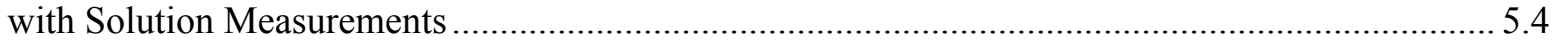

7.1. Chromium Concentration as a Function of Plutonium Content …............................................... 7.3

7.2. Iron Concentration as a Function of Plutonium Content .................................................................. 7.4

7.3. Nickel Concentration as a Function of Plutonium Content .............................................................. 7.4

7.4. Silicon Concentration as a Function of Plutonium Content ........................................................... 7.5

7.5. Molybdenum Concentration as a Function of Plutonium Content ................................................. 7.5

7.6. Aluminum Concentration as a Function of Plutonium Content …..................................................... 7.6

7.7. Copper Concentration as a Function of Plutonium Content.......................................................... 7.6

7.8. Chlorine Measured by PGA in wt $\%$ on Feed Items to 3013 Container Compared with Stabilized Product Sample Measured in Water Leachates ......................................................... 7.9

7.9. Normalized Count Rate for $1274 \mathrm{keV}$ Peak from Prompt Gamma Measurements on Feed Items to 3013 Container Compared with Fluoride Concentration Measured by ISE on Fusion Digest oftabilized Product Sample

7.10. Sodium Measured by PGA in wt $\%$ on Feed Items to 3013 Container Compared with Stabilized Product Sample in Acid Leachates 7.10

7.11. TGA Scan of Rocky Flats Chloride Sample Corresponding to Sample B-5439 


\section{Tables}

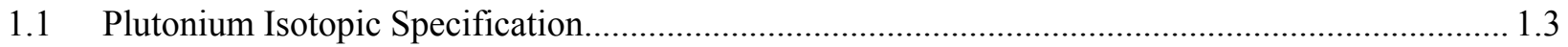

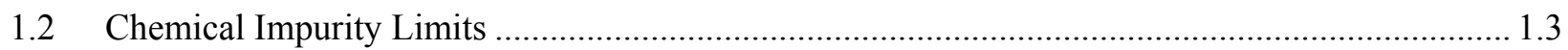

1.3 Groups of Impure Plutonium at Hanford Considered as Potential Alternate Feedstock .................. 1.6

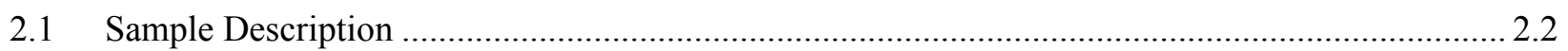

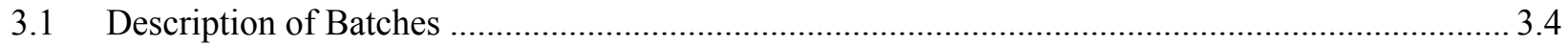

4.1 Analytical Methods Used for Analyses ............................................................................... 4.1

5.1 Plutonium and Americium Found in Oxide Samples Measured by GEA ...................................... 5.1

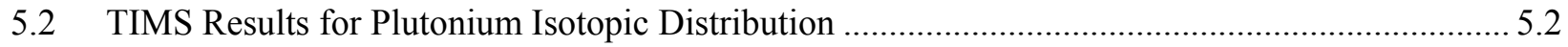

5.3 Total Plutonium Measurement Comparisons ……………………………………………….... 5.3

5.4 Comparison of ${ }^{239} \mathrm{Pu}$ Isotopic Results by Three Analytical Methods ............................................. 5.5

$5.5{ }^{238} \mathrm{Pu}$ Results by Four Analytical Methods ……………............................................................ 5.6

6.1 Uranium Concentrations in Impure Plutonium Oxides ............................................................. 6.1

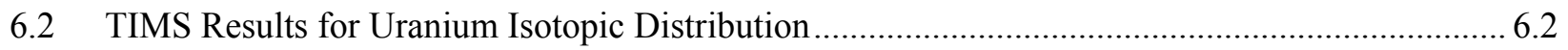

7.1 Concentrations of Anions in the Water Leach of the Samples ..................................................... 7.1

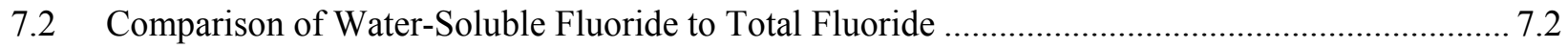

7.3 Chloride Analysis from PGA of Feed Items and IC of Product Wash Sample ……........................ 7.8

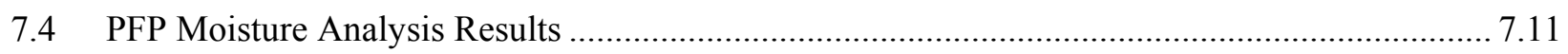

8.1 Major Constituents of the Impure Rocky Flats Oxides .................................................................... 8.2

8.2 Major Constituents of the Impure Plutonium Oxides from Scrap and Solutions ………………..... 8.3

A.1 Analytes Targeted in ICP-AES Acid Leach Fraction........................................................... A.1

A.2 Additional Analytes Detected in ICP-AES Acid Leach Fraction.................................................. A.3

A.3 Analytes Targeted in ICP-AES Fusion Fraction …………................................................ A.5

A.4 Additional Analytes Detected in ICP-AES Fusion Fraction ……........................................... A.7

A.5 Analytes Targeted in ICP-MS Acid Leach Fraction.............................................................. A.9

A.6 Additional Analytes Detected in ICP-MS Acid Leach Fraction ………………………............ A.11

A.7 Analytes Targeted in ICP-MS Fusion Fraction ..................................................................... A.13

A.8 Additional Analytes Detected in ICP-MS Fusion Fraction ......................................................... A.15 


\subsection{Introduction}

Eighteen plutonium oxide samples originating from the Plutonium Finishing Plant (PFP) on the Hanford Site were analyzed to provide additional data on the suitability of PFP thermally stabilized plutonium oxides and Rocky Flats oxides as alternate feedstock to the Mixed Oxide Fuel Fabrication Facility (MFFF). Radiochemical and chemical analyses were performed on acid digestions, fusions, and water leaches of these samples. The results from the destructive analyses were compared with the nondestructive analyses (NDA) performed at PFP and acceptance criteria for alternate feedstock (DCS 2001).

\subsection{Background}

In September 2000, the United States and the Russian Federation signed a Plutonium Management and Disposition Agreement (PMDA) by which each party agreed to dispose of 34 metric tons (MT) of weapons-grade plutonium. In this agreement the United States declared that $25 \mathrm{MT}$ of plutonium as pits and clean metal and 0.57 MT of plutonium as oxide was designated as no longer required for defense purposes and would be disposed of by irradiation. They also declared that 2.70 MT of plutonium as impure metal and 5.73 MT of plutonium as oxide would be immobilized. The disposition strategy associated with this agreement included converting 25.57 MT of plutonium to mixed-oxide (MOX) fuel and irradiating it in commercial reactors. The remaining 8.43 MT of plutonium would be immobilized for eventual disposal in a geological repository. The U.S. Department of Energy (DOE) amended the Records of Decision (ROD) relating to this agreement in April 2002 and canceled the immobilization portion of the disposition strategy, resulting in a new disposition strategy where all 34 MT of weaponsgrade plutonium would be converted to MOX fuel and irradiated in commercial power reactors.

Based on this new strategy, the MFFF will receive two separate feedstocks of plutonium to be mixed with uranium to produce MOX fuel. The two feedstocks are 1) the plutonium oxide product from the Pit Disassembly and Conversion Facility (PDCF) and the ARIES Demonstration at Los Alamos National Laboratory (LANL) and 2) the alternate feedstock that may come from several DOE sites. The PDCF and ARIES Demonstration will process pits and clean metal to produce plutonium oxide suitable for use in MOX. Alternate feedstock will include stabilized plutonium oxide in 3013 containers that may include a significant quantity of impurities. Both feedstocks will be purified in the Aqueous Polishing Unit (AP) at the MFFF. This purification includes dissolution, solvent extraction, precipitation, and calcination. A flow diagram of the AP is provided in Figure 1.1.

Plutonium oxide powder (containing alloying materials and ${ }^{241} \mathrm{Am}$ from PDCF and ARIES processes and other impurities in the alternate feedstock) is stabilized by heating it in an oxidizing environment (such as with $\mathrm{He} / \mathrm{O}_{2}$ ) at $950^{\circ} \mathrm{C}$ for at least two hours (DOE-STD-3013-2004, Section 6.1.2). This heating process removes water and other volatile species but not the impurities. (a) Samples of blended plutonium oxide will be analyzed at MFFF to ensure that it will meet the feed specifications.

(a) Plutonium tetrafluoride, $\mathrm{PuF}_{4}$, if present in material sent to alternate feedstock, will remain as $\mathrm{PuF}_{4}$ even after thermal stabilization according to DOE-STD-3013. The stabilized plutonium is referred to as plutonium oxide in this report, even though some plutonium may be present in other phases such as $\mathrm{PuF}_{4}$. 


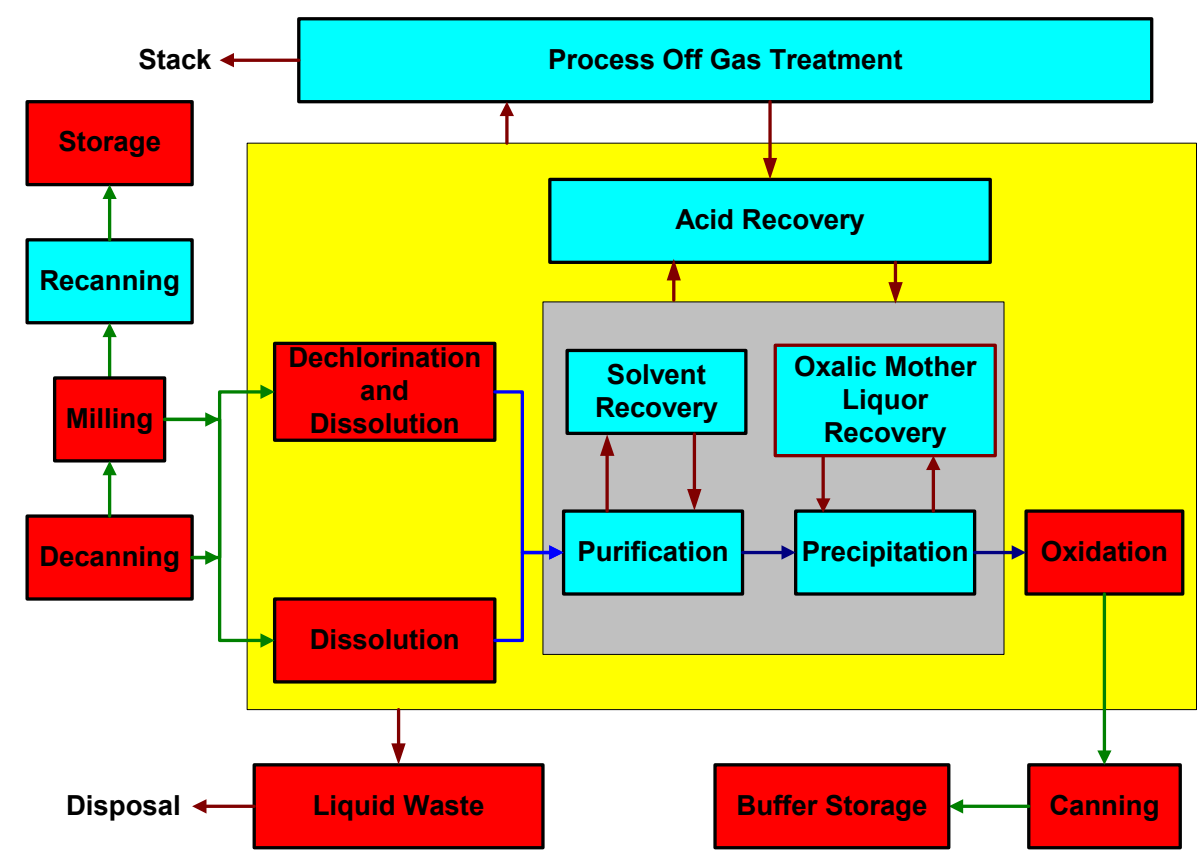

Figure 1.1. Aqueous Polishing Unit

NDA has been performed on the stabilized plutonium oxide that has been placed in 3013 containers at Rocky Flats and Hanford. The NDA suite for plutonium oxide characterization included calorimetry, neutron coincidence counting, and isotopic assay. These NDA methods provide data on the plutonium concentration and isotopic ratios and the activity of radionuclide impurities and daughter products of the plutonium. Because NDA is performed on the entire container of plutonium, sampling error does not affect the accuracy of the results, but inhomogeneity at a macroscopic level in the material can have a significant effect if the source is collimated or the radioactive species are layered in the container.

Prompt gamma measurements were also made on the material fed to thermal stabilization at Hanford to screen impure oxides containing sodium and potassium chlorides and direct these feeds containing corrosive chloride salts to lower temperature thermal stabilization. Lower-temperature stabilization of plutonium oxides from Rocky Flats that contain sodium and potassium chloride from electrorefining (ER) processes has been approved $\left(750^{\circ}\right.$ instead of $\left.950^{\circ} \mathrm{C}\right)$ based on demonstration of technical equivalency of the 3013 standard's stabilization goals (Boak et al. 2003). The prompt gamma measurements used to identify the presence of ER salts also provide qualitative data on other elements that may exist as chemical impurities in the Hanford alternate feedstocks, including aluminum, beryllium, chromium, copper, fluorine, iron, magnesium, silicon, and tantalum (Fazzari 2003).

\subsection{Alternate Feedstock Specification}

Interface requirements for the plutonium oxide powder from the alternate feedstock that is to be polished by AP have been defined in a document prepared by MFFF design team (Brossard 2002). The pertinent requirements from this interface guideline document are summarized in this section. These requirements include plutonium isotopic composition, uranium and americium content, and impurity content. 
The range of acceptable plutonium isotopic compositions for the alternate feedstock is listed in Table 1.1. This is the same range that is acceptable for the $\mathrm{PuO}_{2}$ product from PDCF. The amount of $\mathrm{U}$ impurity is significantly higher for the alternate feedstock than for the PDCF product. Alternate feedstock may contain up to $30 \mathrm{wt} \%$ enriched uranium with an annual maximum of $50 \mathrm{~kg}$. The amount of depleted and natural uranium impurities has not been established for the majority of the alternate feedstock, but 2 percent of the items may contain as much as 50 percent depleted or natural uranium.

Table 1.1. Plutonium Isotopic Specification

\begin{tabular}{|c|c||}
\hline Isotope & Acceptable Range \\
\hline $\mathrm{Pu}-236$ & $<1 \mathrm{ppb}$ \\
\hline $\mathrm{Pu}-238$ & $<0.05 \%$ \\
\hline $\mathrm{Pu}-239$ & 90 to $95 \%$ \\
\hline $\mathrm{Pu}-240$ & 5 to $9 \%$ \\
\hline $\mathrm{Pu}-241$ & $<1 \%$ \\
\hline $\mathrm{Pu}-242$ & $<0.1 \%$ \\
\hline
\end{tabular}

Information about the $\mathrm{Pu}$ isotopic distribution of the material processed at the MFFF is also published in the MFFF Construction Authorization Request (CAR) (DCS 2002) and Final Safety Evaluation Report (FSER) (NRC 2005). In sections on criticality safety and radiation protection of the DSER and CAR, source terms for safety calculations are proposed. The same range of values as is presented in the interface requirements document (Table 1.1) with the exception of ${ }^{242} \mathrm{Pu}(<0.02$ percent in the CAR) is reported. These isotopics assume that the time since separation of the plutonium is less than 45 years.

A limit was also imposed on the ${ }^{241} \mathrm{Am}$ and $\mathrm{Np}$ content. Most of the plutonium (approximately 75 percent of the items) is required to contain less than $7000 \mathrm{ppm}{ }^{241} \mathrm{Am}$ and $500 \mathrm{ppm} \mathrm{Np}$. All but a few percent of the remaining items need to contain less than $11,000 \mathrm{ppm}{ }^{241} \mathrm{Am}$ and $1000 \mathrm{ppm} \mathrm{Np}$.

Similar limits were set on chemical impurities. All of the elements in the periodic table were considered. The limits are provided in Table 1.2. The first set is for the majority of the plutonium oxide items (approximately 75 percent), and the second set is the maximum impurity level except for a few exceptional cases (less than 2 percent of the items). Limits for some of the primary anionic compounds likely to be present in the items (nitrate and sulfate) are also included in this table of elements.

Table 1.2. Chemical Impurity Limits

\begin{tabular}{||c|c|c||}
\hline \multirow{2}{*}{ Analyte } & \multicolumn{2}{|c|}{ MOX Specifications } \\
\cline { 2 - 3 } & $\mathbf{7 5 \%}$ Items & $\mathbf{9 8 \%}$ Items \\
\hline $\mathrm{Ag}$ & $\mathrm{NA}$ & 10,000 \\
\hline $\mathrm{Al}$ & 4,000 & 15,000 \\
\hline $\mathrm{As}$ & $\mathrm{NA}$ & 100 \\
\hline $\mathrm{Au}$ & $\mathrm{NA}$ & 100 \\
\hline $\mathrm{B}$ & 100 & 1,000 \\
\hline $\mathrm{Ba}$ & 5,000 & 10,000 \\
\hline
\end{tabular}


Table 1.2 (contd)

\begin{tabular}{|c|c|c|}
\hline \multirow{2}{*}{ Analyte } & \multicolumn{2}{|c|}{ MOX Specifications } \\
\hline & $75 \%$ Items & $98 \%$ Items \\
\hline $\mathrm{Be}$ & 100 & 5,000 \\
\hline $\mathrm{Bi}$ & 1,000 & 1,000 \\
\hline $\mathrm{C}$ & 2,000 & 10,000 \\
\hline $\mathrm{Cd}$ & 1,000 & 1,000 \\
\hline $\mathrm{Ca}$ & 120,000 & $\begin{array}{c}(\mathrm{Ca}+\mathrm{Mg}+\mathrm{Na}+\mathrm{K}) \\
<40 \% \text { net weight } \\
\end{array}$ \\
\hline $\mathrm{Ce}$ & NA & 500 \\
\hline $\mathrm{Cl}^{-}$ & 200,000 & 330,000 \\
\hline $\mathrm{Co}$ & 5,000 & 10,000 \\
\hline $\mathrm{Cr}$ & 3,000 & 8,000 \\
\hline $\mathrm{Cu}$ & 500 & 3,000 \\
\hline Er & NA & 500 \\
\hline $\mathrm{F}^{-}$ & 1,000 & 7,000 \\
\hline $\mathrm{Fe}$ & 5,000 & 18,000 \\
\hline $\mathrm{Ga}$ & 12,000 & 15,000 \\
\hline $\mathrm{Gd}$ & 250 & 250 \\
\hline $\mathrm{Ge}$ & NA & 100 \\
\hline Hf & 50 & 1,000 \\
\hline $\mathrm{Hg}$ & NA & 100 \\
\hline $\mathrm{I}^{-}$ & NA & 100 \\
\hline In & 20 & 2,500 \\
\hline K & 220,000 & $\begin{array}{c}(\mathrm{Ca}+\mathrm{Mg}+\mathrm{Na}+\mathrm{K}) \\
<40 \% \text { net weight }\end{array}$ \\
\hline $\mathrm{La}$ & NA & 5,000 \\
\hline $\mathrm{Li}$ & 5,000 & 10,000 \\
\hline $\mathrm{Mg}$ & 70,000 & $\begin{array}{c}(\mathrm{Ca}+\mathrm{Mg}+\mathrm{Na}+\mathrm{K}) \\
<40 \% \text { net weight }\end{array}$ \\
\hline $\mathrm{Mn}$ & 1,000 & 2,000 \\
\hline Mo & 100 & $(\mathrm{Mo}+\mathrm{Zr})<5,000$ \\
\hline $\mathrm{N}$ & 400 & 5,000 \\
\hline $\mathrm{NO}_{3}{ }^{-}$ & NA & 5,000 \\
\hline $\mathrm{Na}$ & 130,000 & $\begin{array}{c}(\mathrm{Ca}+\mathrm{Mg}+\mathrm{Na}+\mathrm{K}) \\
<40 \% \text { net weight }\end{array}$ \\
\hline $\mathrm{Nb}$ & 100 & 3,500 \\
\hline $\mathrm{Ni}$ & 5,000 & 15,000 \\
\hline $\mathrm{Np}$ & 500 & 1,000 \\
\hline $\mathrm{P}$ & 1,000 & $\begin{array}{c}(\mathrm{P}+\mathrm{S}) \\
<1 \% \text { net weight }\end{array}$ \\
\hline $\mathrm{Pb}$ & 200 & 5,000 \\
\hline $\mathrm{Pd}$ & NA & 100 \\
\hline $\mathrm{Pt}$ & NA & 100 \\
\hline $\mathrm{Pu}$ & & \\
\hline $\mathrm{Rb}$ & 100 & 5,000 \\
\hline
\end{tabular}


Table 1.2 (contd)

\begin{tabular}{|c|c|c|}
\hline \multirow{2}{*}{ Analyte } & \multicolumn{2}{|c|}{ MOX Specifications } \\
\cline { 2 - 3 } & $\mathbf{7 5 \%}$ Items & $\mathbf{9 8 \% \text { Items }}$ \\
\hline \multirow{2}{*}{$\mathrm{S}$} & 330 & $\begin{array}{c}(\mathrm{P}+\mathrm{S}) \\
<1 \% \text { net weight }\end{array}$ \\
\hline $\mathrm{SO}_{4}{ }^{2-}$ & $\mathrm{NA}$ & 5,000 \\
\hline $\mathrm{Sb}$ & $\mathrm{NA}$ & 100 \\
\hline $\mathrm{Si}$ & 5,000 & 10,000 \\
\hline $\mathrm{Sn}$ & 1,000 & 10,000 \\
\hline $\mathrm{Sr}$ & 5,000 & 10,000 \\
\hline $\mathrm{Ta}$ & 4,000 & 10,000 \\
\hline $\mathrm{Th}$ & 100 & 300 \\
\hline $\mathrm{Ti}$ & 100 & 3,000 \\
\hline $\mathrm{Tl}$ & $\mathrm{NA}$ & 100 \\
\hline & $\mathrm{EU}<30 \%$ net & EU $<30 \%$ net weight \\
$\mathrm{U}$ & weight & DU: 500,000 \\
& $\mathrm{DU} \& \mathrm{NU}$ TBC & 1,000 \\
\hline $\mathrm{V}$ & 300 & 10,000 \\
\hline $\mathrm{W}$ & 4,000 & 10,000 \\
\hline $\mathrm{Y}$ & 200 & 10,000 \\
\hline $\mathrm{Zn}$ & 1,000 & $(\mathrm{Mo}+\mathrm{Zr})<5,000$ \\
\hline $\mathrm{Zr}$ & 50 &
\end{tabular}

\subsection{Potential Alternate Feedstock at Hanford}

Potential alternative feedstock materials exist at Hanford, Rocky Flats, Savannah River, and Los Alamos. This characterization activity focused on plutonium oxide stored on the Hanford Site. All of the plutonium on the Hanford Site that is considered as alternate feedstock is stored at the PFP. Before stabilization and packaging of the plutonium at PFP, the inventory of special nuclear material included metal, alloys, oxides, plutonium-uranium mixed oxides, fuel pins, solutions, polycubes (plutonium oxide powder dispersed in polystyrene cubes), other combustibles, ash, reduction residues, radiation sources, research plutonium compounds, and other miscellaneous items. A subset of these items was thermally stabilized and is potential alternate feedstock. At least a portion of the metal, alloys, oxides, mixed oxides, solutions, sources, polycubes, other combustibles, plutonium compounds, and other miscellaneous items were thermally stabilized.

Many of the metals and alloys were brushed and repackaged as metal in 3013 containers and were not available for sampling. Some of the low-plutonium-content alloys were packaged and sent to the Waste Isolation Pilot Plant (WIPP) in New Mexico as waste along with much of the reduction residue, ash, and other such materials with less than $30 \mathrm{wt} \%$ plutonium. Much of the $\mathrm{Pu}-\mathrm{U}$ mixed oxide contains fuelsgrade plutonium or has low plutonium concentration and does not meet the specifications for alternate feedstock. The polycubes were also fuels-grade plutonium $\left(18\right.$ percent $\left.{ }^{240} \mathrm{Pu}\right)$, and their stabilized products are not acceptable as alternate feedstock. The fuel pins and sources were packaged to be shipped to SRS in their current forms and are not considered alternate feedstock. The other combustibles, plutonium compounds, and miscellaneous items account for less than 2 percent of the net weight of the plutonium available at PFP. 
Initial characterization of material at Hanford indicated that the majority of the potential alternate feedstock material came from plutonium oxide from stabilization of metal, oxides, and solutions. The oxide from metal and solution stabilization had already been packaged except for two oxide samples left from solution stabilization lots after unrelated characterization testing at Pacific Northwest National Laboratory (PNNL). Therefore, the samples obtained for the present characterization activity included sixteen oxide samples from thermal stabilization of oxides at PFP and the two samples of oxide already at PNNL that were left from previous characterization of solution stabilization product.

The oxide materials that were thermally stabilized at Hanford originated from Rocky Flats oxides sent to Hanford in the 1980s for plutonium recovery, scrap from the PFP's RMC Line and PRF, oxide from Hanford's PUREX plant, and oxide from other plutonium conversion processes at the PFP. The oxides were grouped into several categories based on their origin. The material groups, the number of 3013 cans produced from these groups, and the percentage of the total plutonium mass in the materials considered as potential alternative feedstock are presented in Table 1.3. The five material groups listed in Table 1.3 (Rocky Flats oxide, RMC scrap, stabilized PRF scrap, other PFP scrap, and solutions) make up more than 98 percent of the plutonium mass at PFP that meets the alternative feedstock requirements for ${ }^{240} \mathrm{Pu}, \mathrm{U}$, and total $\mathrm{Pu}$ concentration. The percentage of the five material categories that had already been processed and placed in 3013 cans before May 2003 - and thus were not available for sampling in the present program - are indicated in fourth column of Table 1.3. Though all of the material in the solutions group had been processed by May 2003, PNNL had two solutions product samples that were available for characterization. Metal, alloys, and the high-purity fuels-grade plutonium oxide are not included in the table because they are not considered alternate feedstock and had already been placed in 3013 containers.

Table 1.3. Groups of Impure Plutonium at Hanford Considered as Potential Alternate Feedstock

\begin{tabular}{|l|c|c|c|}
\hline \multicolumn{1}{|c|}{ Group } & $\begin{array}{c}\text { Number of 3013 } \\
\text { Containers }\end{array}$ & $\begin{array}{c}\text { Percent of } \\
\text { Pu Mass }\end{array}$ & $\begin{array}{c}\text { Percent Processed into } \\
\mathbf{3 0 1 3 s}, \text { May 2003 }\end{array}$ \\
\hline Rocky Flats Oxide & 450 & 64.1 & 2 \\
\hline PRF Scrap & 20 & 2.9 & 80 \\
\hline RMC Scrap & 34 & 7.3 & 65 \\
\hline Other PFP Scrap & 79 & 2.5 & 24 \\
\hline Solutions & 315 & 21.3 & 100 \\
\hline Total & $\mathbf{8 9 8}$ & $\mathbf{9 8 . 1}$ & $\mathbf{4 2}$ \\
\hline
\end{tabular}

The largest number of items and most of the plutonium mass ( $\sim 64$ percent) comes from the Rocky Flats oxides. The Rocky Flats oxides also constituted over 99 percent of the weapons grade plutonium that had not been packaged in 3013 containers prior to the sampling activities. Because of the cost and loss of plant resources during a time of intense schedule pressure, the 3013 containers were not opened, sampled, and resealed; the samples obtained for this characterization effort could come only from stabilized plutonium oxide that were being packaged in 3013 containers.

All tested Rocky Flats oxide items had been found to contain at least $1 \mathrm{wt} \%$ salt. Therefore, the population of available Rocky Flats oxides was split into batches containing both low ER chloride salt impurities and high ER chloride salt impurities. Prompt gamma analyses of the original items in each 
thermal stabilization batch were used to sort Rocky Flats oxides by their chloride concentration and the presence of equimolar $\mathrm{NaCl} / \mathrm{KCl}$ ER salts.

Scrap from across the DOE complex, including scrap from all the plutonium processes at Hanford, was sent to PFP for plutonium recovery. The scrap materials sent to PFP included oxides, liquids, mixed plutonium-uranium oxides, alloys, and scrap containing low concentrations of plutonium. This purification was performed at the Plutonium Reclamation Facility (PRF). Impurities, plutonium content, and plutonium isotopic compositions in the PRF scrap vary widely, and samples to be tested as candidate alternate feedstock were taken only from items that were weapons-grade plutonium and contained greater than $50 \mathrm{wt} \%$ plutonium.

The RMC, sometimes referred to as C-Line, converted plutonium nitrate solutions to metal. Defensegrade metal as well as nondefense-grade metal and oxides were produced in this processing line.

Other PFP scrap includes laboratory recycle and materials of either RMC or PRF origin but with indeterminate inventory codes. The same criteria were used for selecting samples for this category of alternate feedstock as were used for RMC and PRF scrap. However, because the inventory codes were not reliable of process origin in the PRF, RMC, and other PFP scrap, these three groups were considered as one for sampling purposes in the present characterization testing.

The plutonium in the solutions was converted to oxide in two distinctly different precipitation processes. One process used oxalic acid as the precipitating agent, while the other used magnesium hydroxide. The form and amount of impurities introduced by these two processes differ widely. The oxalic acid precipitating agent is relatively selective for plutonium while leaving most other metals in solution. The magnesium hydroxide precipitating agent is less discriminate and precipitates plutonium and other multi-charged metals such as aluminum, iron, and calcium. Magnesium hydroxide also contributes significant magnesium as well from excess magnesium hydroxide and the entrained magnesium nitrate solution present in the precipitate cake. Therefore, it would be best to characterize those solutions processed by magnesium hydroxide precipitation separately from those prepared by oxalate precipitation. Unfortunately, the plutonium from solutions processing was already recovered and packaged in 3013 containers before the sampling effort, and samples for the solution group of material could only be obtained from some small samples already present at PNNL. Both of the samples at PNNL had originated from the magnesium hydroxide precipitation process. One sample was from product nitrate solution and the other was a double-pass filtrate. The double-pass filtrate feed solutions were less pure than the product nitrate solutions. No samples from the oxalic acid precipitation processing were available for characterization. 


\subsection{Sample Description}

Sixteen samples of stabilized plutonium oxide were obtained at the PFP. The samples were drawn after thermal stabilization but before 3013 canning. Operations and management at the PFP cooperated with this characterization effort by authorizing sampling of these materials for characterization at PNNL at the same time samples were taken for the required moisture analyses. Two additional samples from magnesium hydroxide-treated solutions were obtained from PFP for previous testing performed at PNNL and were available for this characterization.

All of the Rocky Flats oxides had been thermally stabilized at a lower temperature than was specified in DOE-STD-3013-2004 $\left(>750^{\circ} \mathrm{C}\right.$ instead of $\left.>950^{\circ} \mathrm{C}\right)$. The decision to stabilize the material at lower temperatures was based on arguments maintaining that technical equivalency to the goals of DOE-3013 could be achieved for these problematic high-chloride materials at the lower stabilization temperature (Boak et al. 2003). Rocky Flats items to be stabilized at lower temperature were identified in part by prompt gamma assay of the chloride concentration. The remaining samples originated from materials that had undergone thermal stabilization at temperatures greater than $950^{\circ} \mathrm{C}$.

\subsection{Origins of Samples}

The eighteen samples were grouped into categories as having originated from low-chloride Rocky Flats oxides, high-chloride Rocky Flats oxide, PRF/RMC scrap, and solutions, as shown in Table 2.1. The prompt gamma analysis estimates of chloride concentrations in the Rocky Flats oxides also are given in Table 2.1 as are the plutonium concentrations as determined by nondestructive assay techniques.

Items with identification numbers beginning with ARF- originated at the Rocky Flats Plant. These items were residues from a molten salt electrorefining process that used a eutectic mixture of sodium and potassium chloride salts. Calcium and/or magnesium chloride also could be present in these residues. Sample B-5701 also originated at the Rocky Flats Plant and initially had an identification number beginning with ARF- but was transferred to the Plutonium Process Support Laboratory (PPSL) at PFP for additional characterization. Though this item received a new identification number once it was transferred to PPSL, its composition was not altered and was still representative of residues from the electrorefining process. After the PPSL characterization was complete, the item was returned to the RMC line for thermal stabilization.

PRF/RMC scrap originated at Hanford's PFP in either the PRF or RMC. Item description codes (IDC) indicate the types of materials present in PFP inventory items, including those from PRF and RMC. IDC numbers 5, 10, and 61 through 64 indicate that the material was PFP scrap. The item number 66-00XX-XXX indicates that these materials were previously stabilized at PFP in 2000 and placed in the vaults. All of these items were sampled for thermogravimetric analysis (TGA) to determine the moisture content of the materials. If these items met the specification for water content, no additional thermal stabilization was performed before placing the material in a 3013 container. Prompt gamma analysis was not performed on these items prior to canning. 
Table 2.1. Sample Description

\begin{tabular}{|c|c|c|c|c|}
\hline Sample & Input Items & Category & $\begin{array}{c}\text { Prompt Gamma } \\
\text { wt\% Cl }\end{array}$ & $\begin{array}{c}\mathrm{Pu} \\
\mathrm{wt} \%\end{array}$ \\
\hline \multirow{2}{*}{ B-5497 } & ARF-102-86-416 & Rocky Flats oxide--(similar to ER salt) & 5.42 & \multirow{2}{*}{54.07} \\
\hline & ARF-102-85-181 & Rocky Flats oxide--(similar to ER salt) & 6.19 & \\
\hline \multirow{2}{*}{ B-5526 } & ARF-102-85-972 & Rocky Flats oxide--(similar to ER salt) & 8.09 & \multirow{2}{*}{76.46} \\
\hline & ARF-102-85-730 & Rocky Flats oxide & 1.85 & \\
\hline \multirow{2}{*}{ B-5524 } & ARF-102-85-719 & Rocky Flats oxide--(similar to ER salt) & 6.54 & \multirow{2}{*}{72.36} \\
\hline & ARF-102-85-731 & Rocky Flats oxide & 4.25 & \\
\hline \multirow{2}{*}{ B-5534 } & ARF-102-86-150 & Rocky Flats oxide--(similar to ER salt) & 0.46 & \multirow{2}{*}{77.29} \\
\hline & ARF-102-85-665 & Rocky Flats oxide--(similar to ER salt) & 1.71 & \\
\hline \multirow{2}{*}{ B-5439 } & ARF-102-85-980 & Rocky Flats oxide--(similar to ER salt) & 11.7 & \multirow{2}{*}{64.66} \\
\hline & ARF-102-85-486 & Rocky Flats oxide--(similar to ER salt) & 6.73 & \\
\hline \multirow{2}{*}{ B-5532 } & ARF-102-85-713 & Rocky Flats oxide--(similar to ER salt) & 6.73 & \multirow{2}{*}{68.65} \\
\hline & ARF-102-85-721 & Rocky Flats oxide--(similar to ER salt) & 6.46 & \\
\hline \multirow{2}{*}{ B-5495 } & ARF-102-86-393 & Rocky Flats oxide--(similar to ER salt) & 12.8 & \multirow{2}{*}{62.74} \\
\hline & ARF-102-85-385 & Rocky Flats oxide--(similar to ER salt) & 9.89 & \\
\hline \multirow{2}{*}{ B-5680 } & ARF-102-86-192 & Rocky Flats oxide--(similar to ER salt) & 4.99 & \multirow{2}{*}{74.24} \\
\hline & ARF-102-85-469 & Rocky Flats oxide--(similar to ER salt) & 4.72 & \\
\hline \multirow{2}{*}{ B-5703 } & ARF-102-86-376 & Rocky Flats oxide--(similar to ER salt) & 12.0 & \multirow{2}{*}{65.38} \\
\hline & ARF-102-86-496 & Rocky Flats oxide--(similar to ER salt) & 8.34 & \\
\hline \multirow{2}{*}{ B-5701 } & PPSL-518 & Rocky Flats oxide--(similar to ER salt) & 9.27 & \multirow{2}{*}{73.51} \\
\hline & ARF-102-86-116 & Rocky Flats oxide--(similar to ER salt) & 3.15 & \\
\hline \multirow{2}{*}{ B-5456 } & $62-00-08-261$ & \multirow{2}{*}{ PRF/RMC scrap (IDC 64/63) } & $\mathrm{N} / \mathrm{M}^{(\mathrm{a})}$ & \multirow{2}{*}{67.1} \\
\hline & $62-00-07-191$ & & $\mathrm{~N} / \mathrm{M}$ & \\
\hline B-5472 & $62-00-09-273$ & PRF/RMC scrap (IDC 10) & $\mathrm{N} / \mathrm{M}$ & 76.7 \\
\hline \multirow{2}{*}{ B-5470 } & $62-00-09-300$ & \multirow{2}{*}{ PRF/RMC scrap (IDC 64/5/10) } & $\mathrm{N} / \mathrm{M}$ & \multirow{2}{*}{73.9} \\
\hline & $62-00-08-253$ & & $\mathrm{~N} / \mathrm{M}$ & \\
\hline \multirow{2}{*}{ B-5471 } & $62-00-09-300$ & \multirow{2}{*}{ PRF/RMC scrap (IDC 64/X) } & $\mathrm{N} / \mathrm{M}$ & \multirow{2}{*}{74.5} \\
\hline & $62-00-08-253$ & & $\mathrm{~N} / \mathrm{M}$ & \\
\hline B-5457 & $62-00-08-210$ & PRF/RMC scrap (IDC 64) & $\mathrm{N} / \mathrm{M}$ & 79.1 \\
\hline \multirow{2}{*}{ B-5501 } & $62-00-07-182$ & PRF/RMC scran (IDC 61/62/63/64) & $\mathrm{N} / \mathrm{M}$ & 582 \\
\hline & $62-00-07-200$ & PRF/RIVIC scrap (IDC 01/02/03/04) & $\mathrm{N} / \mathrm{M}$ & 58.2 \\
\hline $\mathrm{R}-418$ & & Plutonium nitrate solution & $\mathrm{N} / \mathrm{M}$ & $\mathrm{N} / \mathrm{M}$ \\
\hline $\mathrm{R}-419$ & & Plutonium nitrate solution & $\mathrm{N} / \mathrm{M}$ & $\mathrm{N} / \mathrm{M}$ \\
\hline
\end{tabular}

Samples R-418 and R-419 are the two already at PNNL. These samples originated at the PFP from precipitation of plutonium nitrate product and double-pass filtrate solutions using the magnesium hydroxide process. Magnesium hydroxide was used briefly in a PFP process designed to stabilize plutonium-bearing solutions. Magnesium hydroxide was added to nitric acid solutions containing plutonium. As the solution $\mathrm{pH}$ increased due to neutralization of the acid, plutonium(IV) hydrous oxides precipitated. Additionally, other metal ions with limited solubility in nearly neutral solutions (e.g., iron, chromium, calcium, aluminum) precipitated. Magnesium hydroxide was added in excess to ensure complete precipitation of plutonium. The resulting solids were filtered, dried, and calcined at $950^{\circ} \mathrm{C}$. 
The final stabilized solids from this process had low density and relatively low plutonium concentrations because of the excess magnesium as well as low-solubility tramp metals. Neither prompt gamma nor calorimetry was performed on these two samples; therefore, no nondestructive assay was available on the chloride or plutonium concentrations in the two tested solution products.

\subsection{Physical Description}

Samples varied in appearance depending on the original source of material. Chloride items from Rocky Flats were mostly dark olive green with some clumps. The clumps were fairly easily crushed with the mortar and pestle. The PRF/RMC items showed more variability. These items were mostly the color of rust. Item B-5456, one of the PRF/RMC scrap samples, was rust-colored but contained white pieces that were difficult to break. Photographs of B-5472, another PRF/RMC scrap sample, are shown in Figure 2.1. This material was a very dark grey with a mixture of fines and large, hard fragments. The larger pieces were unbreakable and dense. The two fractions pictured represent a 35 to 65 percent distribution of the sample that was weighed. The appearance and feel of the large pieces indicated they might be an alloy. These larger chunks were not analyzed separately.
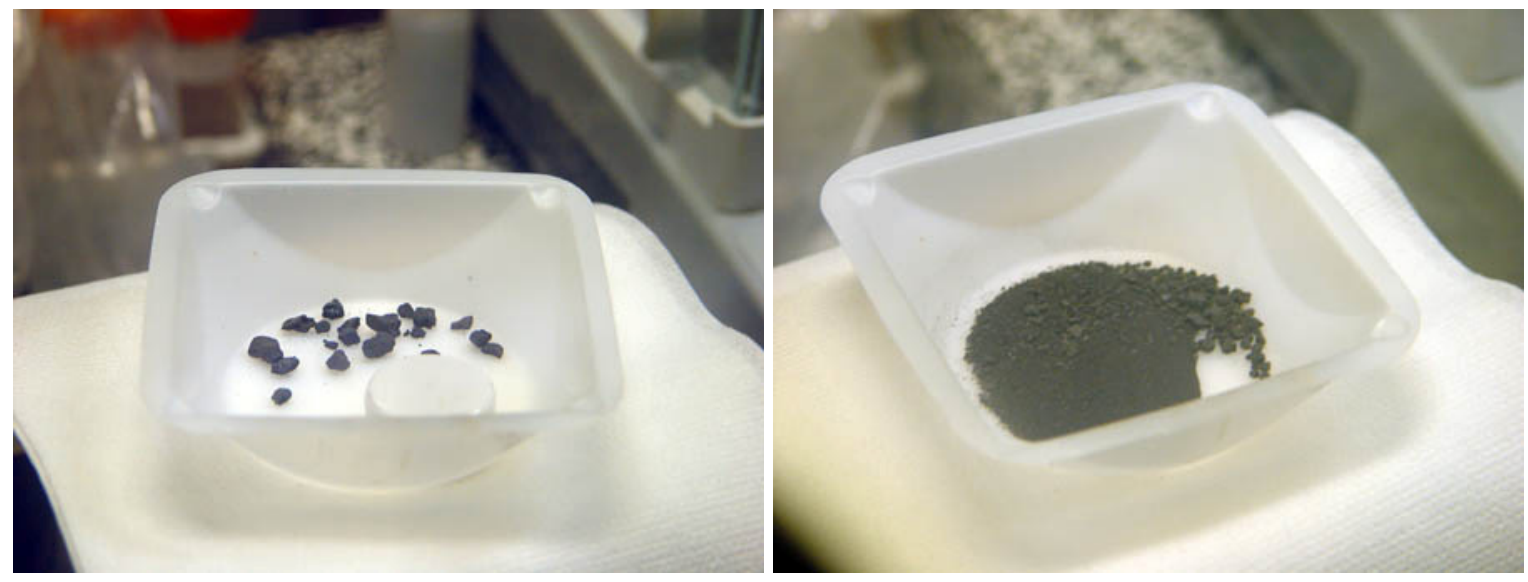

Figure 2.1. Photographs of B-5472 Sample with Some of the Larger Particles Separated (left)

Figures 2.2, 2.3, and 2.4 are photographs of 10 grams each of three samples containing different material types. Figure 2.2 displays the precipitate from magnesium hydroxide neutralization of a PRF double-pass filtrate solution. Filtrate originated in the PFP RMC during oxalate precipitation of plutonium. The resulting filtrate solution contained impurity elements such as iron and chromium plus traces of plutonium. During plutonium production, the filtrate was recycled in the PRF by first adding permanganate to destroy the oxalate and then concentrating the solution through evaporation. Dilute acid was added to the concentrated solution, and the resulting solution was concentrated a second time to produce double-pass filtrate. Plutonium in these solutions was then separated from the impurities through extraction with tributyl phosphate (TBP). With the shutdown of plutonium metal production at PFP, these impure filtrate solutions were stored in stainless steel vessels without further processing and needed to be stabilized. Using magnesium hydroxide to neutralize the acid in filtrate solutions and hydrolyze the plutonium produced solids that contained most of the impurity elements, especially the transition metals, hydrous plutonium oxide as well as excess $\mathrm{Mg}(\mathrm{OH})_{2}$ and entrained magnesium nitrate solution. During thermal stabilization, excess water is lost, nitrates decompose, and the corresponding metal oxides form. 


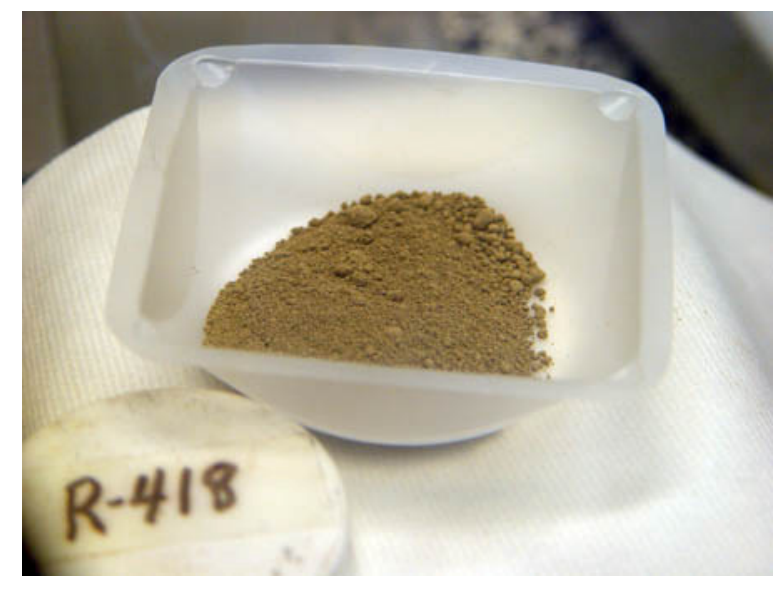

Figure 2.2. Sample R-418 Produced by the Magnesium Hydroxide Precipitation Process on Double Pass Filtrate. The color comes from plutonium, iron, and other impurities.

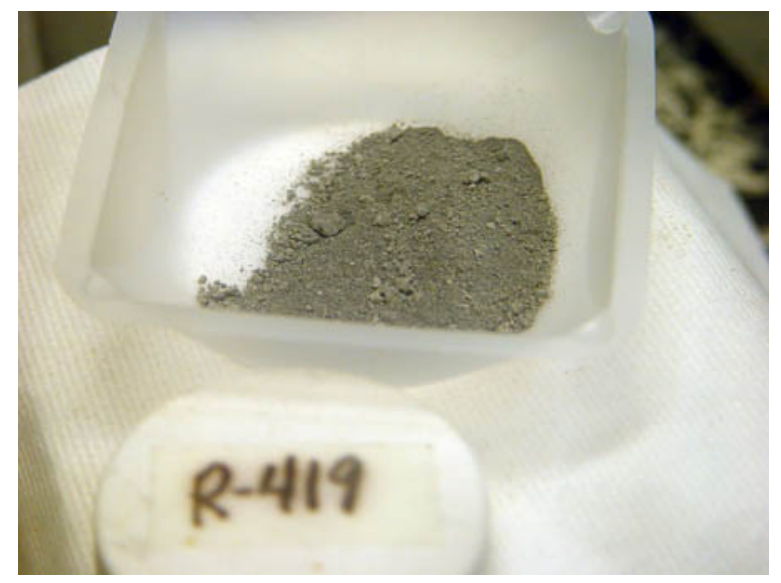

Figure 2.3. Sample R-419 Prepared by the Magnesium Hydroxide Precipitation of Plutonium from a Product Nitrate Solution

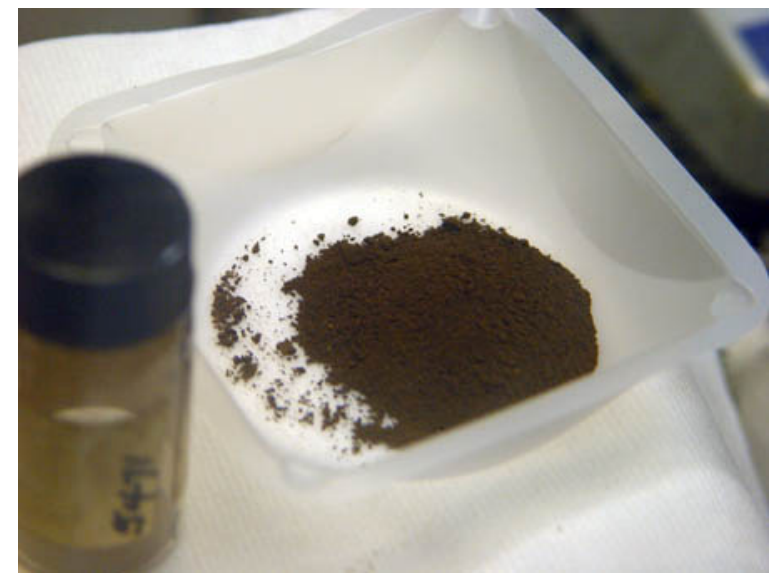

Figure 2.4. Rust-Colored PRF/RMC Scrap Sample B-5471 
The sample shown in Figure 2.3 also was produced by the magnesium hydroxide precipitation process. This solution was a product plutonium nitrate solution from the PUREX process and contained a higher concentration of plutonium in $\mathrm{HNO}_{3}$ and lower concentrations of impurities than observed for the double-pass filtrate. The thermally stabilized samples contain $\mathrm{PuO}_{2}, \mathrm{MgO}$, and trace impurity metal oxides (some arising from corrosion of the stainless steel vessels in which the high-purity PUREX product nitrate was stored). The initial purified plutonium nitrate solutions typically contained 1000 to $10,000 \mathrm{ppm}$ total metallic impurities, where the impurity concentrations are with respect to the contained plutonium weight. Impurities typically present in the 100 to $1000 \mathrm{ppm}$ range are $\mathrm{U}, \mathrm{Th}, \mathrm{Fe}, \mathrm{Cr}, \mathrm{Ni}$, and Ti. These solids were denser than the material in Figure 2.2.

The stabilized RMC/PRF scrap shown in Figure 2.4 originated from various processes in the RMC and PRF. The scrap material was stored until it could be processed through PRF to recover plutonium. With the shutdown of production, such items were thermally stabilized without purification. The most notable physical characteristic of this material was that it looked and felt like rust. Crushing the larger pieces of orange-brown colored sample produced a burnt orange-colored powder. 


\subsection{Sample Preparation Methods}

Chemical and radiochemical analyses of these solid samples first require that the analytes of interest be dissolved. Three techniques (water leach, acid digestion, and a fusion followed by dissolution of the fused sample in nitric acid) were used to solubilize the targeted analytes. A process flow diagram of the sample preparation and analyses for these samples is provided Figure 3.1.

The processes inside the cross-hatched areas represent the procedures completed in the glovebox. The remaining processes were completed either on the benchtop or in fume hoods. Size reduction of the samples was performed by hand with an agate mortar and pestle, after which the sample was split and subsamples used for each preparation method. Samples were subdivided for direct aliquots using coneand-quartering. (a) Subsamples were placed in vials with a known mass, and the mass of each subsample was measured using a calibrated balance.

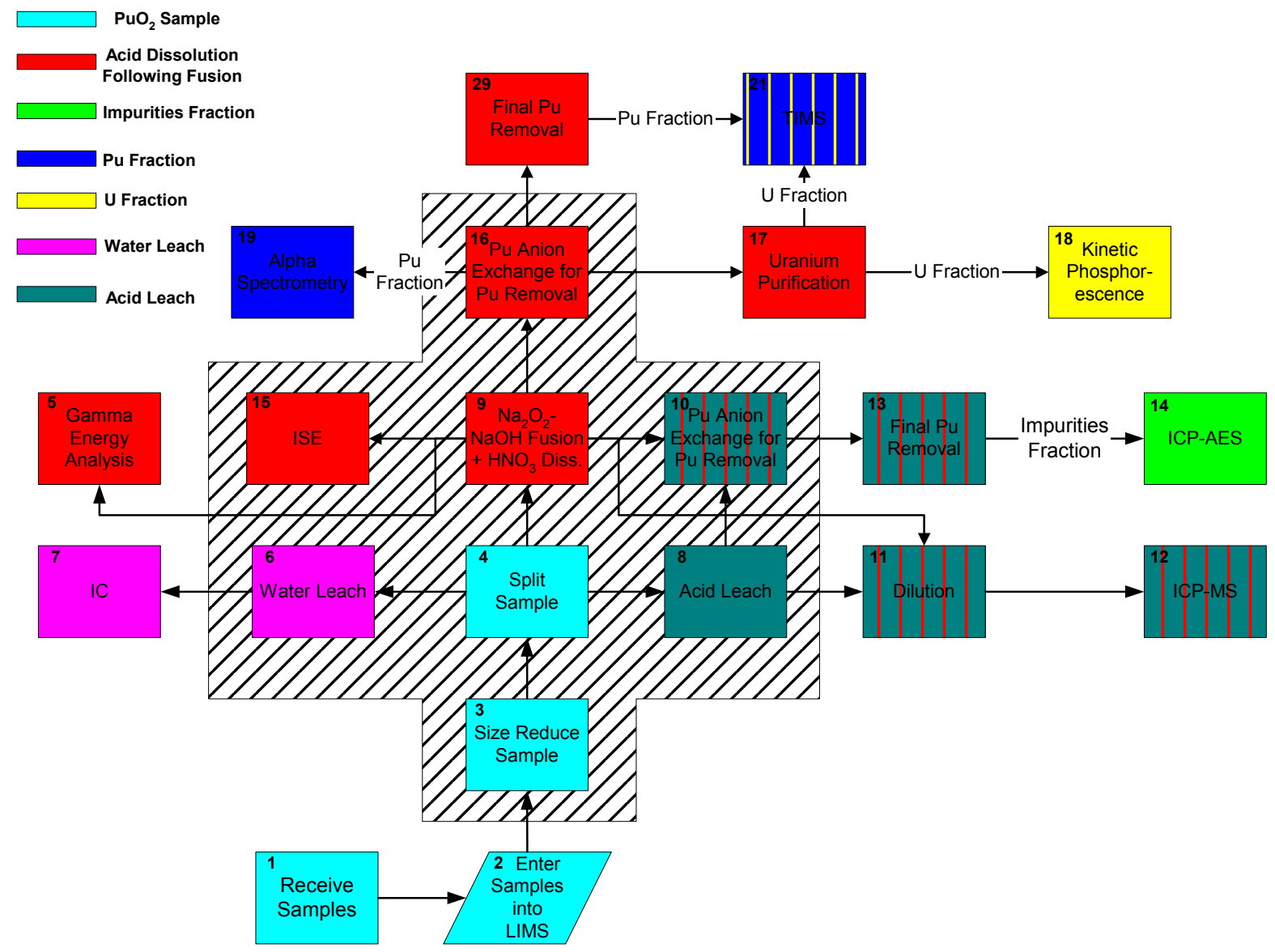

Figure 3.1. Sample Preparation and Analysis Flow Diagram (see text for definitions of acronyms)

(a) The cone-and-quarter technique is used to provide representative split subsamples of heterogeneous solids such as soils for subsequent analyses. In this technique, the particulate sample is poured carefully into a radially symmetric cone-shaped pile. A spatula is used to slice the pile into two equal parts. The two fractions are scraped away from each other and sliced evenly $90^{\circ}$ from the first split to form four equal piles. The technique can be repeated with each pile to produce subsamples of the selected amount. 
Water-soluble inorganic contaminants in the plutonium oxide samples were dissolved by a water leach. The water soluble analytes of interest included the anions chloride, fluoride, nitrate, phosphate, and sulfate. Approximately $100 \mathrm{mg}$ of sample was mixed with $10 \mathrm{~mL}$ of deionized water. The water leach was stirred and allowed to settle. The sample was then filtered to remove the insoluble solids, and the filtrate was analyzed by ion chromatography (IC) to determine the concentration of the water soluble anions in the plutonium oxide sample.

Because many fluoride salts have low water solubility, fluoride analyses were also performed on the caustic fusion of each of the samples to determine the total fluoride present in the sample. An ion selective electrode (ISE) using the method of standard additions was used to measure the fluoride ion concentration. The $\mathrm{pH}$ of the acid solution from the fusion was adjusted to minimize the amount of hydrofluoric acid (HF) in the sample that is not detected by the ISE and the concentration of hydroxide in the sample that interferes with the fluoride measurement.

Metals analyses were performed on both caustic fusion digestates and acid leaches of the subsamples. The acid leach method is patterned after the Environmental Protection Agency (EPA) method for analysis of total recoverable elements (EPA Method 200.2). The procedure used for this leach was optimized for glovebox operation; therefore, some changes were made to the EPA method to reduce radioactive dose to the analyst. Approximately $100 \mathrm{mg}$ of the plutonium oxide sample was weighed into a Teflon tube and mixed with $15 \mathrm{~mL}$ of concentrated nitric acid. The acid was refluxed for several hours. After cooling, the solution was brought to a final volume of $50 \mathrm{~mL}$ with dilute nitric acid. The nitric acid solution was filtered through a 0.45 -micron filter prior to analysis.

A sodium peroxide fusion was used to solubilize the entire sample, including the plutonium oxide. Approximately $100 \mathrm{mg}$ of size-reduced sample was weighed into a zirconium crucible. Sodium hydroxide was added as an aqueous solution. The sample was heated to dryness on a hot plate, solid sodium peroxide was added, and the crucible was transferred to a muffle furnace. The sample and sodium hydroxide/peroxide flux were heated to melting at approximately $350^{\circ} \mathrm{C}$ for 45 to 60 minutes. The crucible and melt were removed part way through the digest to swirl the contents for improved reagent contact with the sample. After removing the crucible and partially cooling the sample, the contents were dissolved in water and transferred to a Nalgene volumetric flask. The crucible was rinsed with nitric acid and all rinses combined. The acid concentration of the resulting solution was adjusted to achieve a final nitrate concentration of $8 \underline{\mathrm{M}}$ and a total volume of $50 \mathrm{~mL}$. The fusion appeared to completely dissolve all samples; therefore, chemical analysis of the insoluble solids by X-ray diffraction (XRD) was not required. The acid dissolution of the fusion was used for metals analysis, total fluoride, plutonium and uranium content, and plutonium and uranium isotopic determinations. Plutonium and uranium content were determined by alpha spectrometry and kinetic phosphorescence analysis (KPA), respectively. Thermal ionization mass spectrometry (TIMS) was used to measure the plutonium and uranium isotopic compositions. Metals analysis was performed by inductively coupled plasma-mass spectrometry (ICP-MS) and inductively coupled plasma-atomic emission spectroscopy (ICP-AES). Total fluoride was measured with an ion selective electrode after adjusting the $\mathrm{pH}$ with sodium hydroxide.

Anion exchange was performed on a fraction of the acid digestion and acid dissolution of the fusion to remove plutonium from these solutions. Plutonium was removed from these solutions to minimize its interference, produce samples that would meet fume hood and benchtop limits, and obtain pure uranium aliquots for the total uranium and uranium isotopic measurements. The plutonium fraction from these 
separations was used for alpha spectrometry and plutonium isotopic analyses. A strong-base anion exchange resin was used for this separation. Related ion exchange processes were used to collect uranium and plutonium samples for subsequent isotopic analyses. ${ }^{238} \mathrm{U}$ and ${ }^{238} \mathrm{Pu}$ are indistinguishable in the TIMS without a chemical separation prior to analysis. Similarly, ${ }^{241} \mathrm{Am}$ interferes with the ${ }^{238} \mathrm{Pu}$ energy in the alpha energy analysis. Ion exchange separation was used to minimize these interferences. The effectiveness of the plutonium removal was ensured by liquid scintillation measurements before removing ICP samples from the glovebox.

Three batches were prepared for analysis to maximize throughput and still determine the effectiveness of the analytical scheme. The first batch was a single sample, followed by a batch of eight samples and finally a batch of nine samples. A duplicate sample was prepared from each category of samples; therefore, two duplicates were added to each batch except the first. A single blank and a standard were also processed with each batch. A spike on the acid digestion and the dissolution of the fusion were processed with each batch of samples. The critical analytes included in the spike were $\mathrm{Mn}, \mathrm{Ni}, \mathrm{Cr}, \mathrm{Fe}$, $\mathrm{Be}, \mathrm{Si}, \mathrm{Ta}$, and W. A total of 22 samples plus the blank, standard, and spike for each batch were prepared in the glovebox. Post-digestion spikes, including spikes for the separations, were performed on the sample after removing them from the glovebox.

Table 3.1 describes the samples in each batch including the quality control samples. The preparation methods included for each sample are also listed in this table. 
Table 3.1. Description of Batches

\begin{tabular}{|c|c|c|c|c|c|}
\hline \multirow{2}{*}{ Sample ID } & \multirow{2}{*}{ Category } & \multirow{2}{*}{ Water Leach } & \multirow{2}{*}{ Acid Leach } & \multicolumn{2}{|c|}{ Pu Anion Exchange } \\
\hline & & & & Fusion & Acid Leach \\
\hline \multicolumn{6}{|c|}{ Batch 1} \\
\hline B-5526 & Low-Chloride Rocky Flats & $\mathrm{X}$ & $\mathrm{X}$ & $\mathrm{X}$ & $\mathrm{X}$ \\
\hline B-5526 Duplicate & Quality Control & $\mathrm{X}$ & $\mathrm{X}$ & $\mathrm{X}$ & $\mathrm{X}$ \\
\hline B-PNNL Standard & Quality Control & $\mathrm{X}$ & $\mathrm{X}$ & $\mathrm{X}$ & $\mathrm{X}$ \\
\hline Blank & Quality Control & $\mathrm{X}$ & $\mathrm{X}$ & $\mathrm{X}$ & $\mathrm{X}$ \\
\hline \multicolumn{6}{|c|}{ Batch 2} \\
\hline B-5497 & High-Chloride Rocky Flats & $\mathrm{X}$ & $\mathrm{X}$ & $\mathrm{X}$ & $\mathrm{X}$ \\
\hline B-5524 & High-Chloride Rocky Flats & $\mathrm{X}$ & $\mathrm{X}$ & $X$ & $\mathrm{X}$ \\
\hline B-5534 & Low-Chloride Rocky Flats & $\mathrm{X}$ & $\mathrm{X}$ & $\mathrm{X}$ & $\mathrm{X}$ \\
\hline B-5439 & High-Chloride Rocky Flats & $\mathrm{X}$ & $\mathrm{X}$ & $\mathrm{X}$ & $\mathrm{X}$ \\
\hline B-5532 & High-Chloride Rocky Flats & $\mathrm{X}$ & $\mathrm{X}$ & $\mathrm{X}$ & $\mathrm{X}$ \\
\hline B-5680 & Low-Chloride Rocky Flats & $\mathrm{X}$ & $\mathrm{X}$ & $\mathrm{X}$ & $\mathrm{X}$ \\
\hline B-5703 & High-Chloride Rocky Flats & $\mathrm{X}$ & $\mathrm{X}$ & $\mathrm{X}$ & $\mathrm{X}$ \\
\hline B-5703 Duplicate & Quality Control & $\mathrm{X}$ & $X$ & $\mathrm{X}$ & $\mathrm{X}$ \\
\hline B-5701 & High-Chloride Rocky Flats & $\mathrm{X}$ & $\mathrm{X}$ & $\mathrm{X}$ & $\mathrm{X}$ \\
\hline B-PNNL Standard & \begin{tabular}{|l|} 
Quality Control \\
\end{tabular} & $\mathrm{X}$ & $\mathrm{X}$ & $\mathrm{X}$ & $\mathrm{X}$ \\
\hline Blank & Quality Control & $\mathrm{X}$ & $\mathrm{X}$ & $\mathrm{X}$ & $\mathrm{X}$ \\
\hline \multicolumn{6}{|c|}{ Batch 3} \\
\hline B-5456 & PRF/RMC Scrap & $\mathrm{X}$ & $\mathrm{X}$ & $X$ & $X$ \\
\hline B-5456 Duplicate & Quality Control & $\mathrm{X}$ & $\mathrm{X}$ & $\mathrm{X}$ & $\mathrm{X}$ \\
\hline B-5472 & PRF/RMC Scrap & $\mathrm{X}$ & $\mathrm{X}$ & $\mathrm{X}$ & $\mathrm{X}$ \\
\hline B-5470 & PRF/RMC Scrap & $\mathrm{X}$ & $\mathrm{X}$ & $\mathrm{X}$ & $\mathrm{X}$ \\
\hline B-5471 & PRF/RMC Scrap & $\mathrm{X}$ & $\mathrm{X}$ & $\mathrm{X}$ & $\mathrm{X}$ \\
\hline B-5457 & PRF/RMC Scrap & $\mathrm{X}$ & $\mathrm{X}$ & $\mathrm{X}$ & $\mathrm{X}$ \\
\hline B-5501 & PRF/RMC Scrap & $\mathrm{X}$ & $\mathrm{X}$ & $\mathrm{X}$ & $\mathrm{X}$ \\
\hline B-5495 & High-Chloride Rocky Flats & $\mathrm{X}$ & $\mathrm{X}$ & $\mathrm{X}$ & $\mathrm{X}$ \\
\hline $\mathrm{R}-418$ & Pu Nitrate Solutions & $\mathrm{X}$ & $\mathrm{X}$ & $\mathrm{X}$ & $\mathrm{X}$ \\
\hline $\mathrm{R}-419$ & $\mathrm{Pu}$ Nitrate Solutions & $\mathrm{X}$ & $\mathrm{X}$ & $\mathrm{X}$ & $\mathrm{X}$ \\
\hline R-419 Duplicate & Quality Control & $\mathrm{X}$ & $\mathrm{X}$ & $\mathrm{X}$ & $\mathrm{X}$ \\
\hline B-PNNL Standard & Quality Control & $\mathrm{X}$ & $X$ & $X$ & $\mathrm{X}$ \\
\hline Blank & Quality Control & $\mathrm{X}$ & $\mathrm{X}$ & $\mathrm{X}$ & $\mathrm{X}$ \\
\hline
\end{tabular}




\subsection{Analytical Methods}

The composition of the plutonium oxide samples was determined using several analytical methods and solutions from several preparation methods. The analytical methods used and the solutions provided to the analysts for each method are shown in the sample flow diagram (Figure 3.1). Each analysis was performed using a procedure that had been developed at PNNL for analyzing radioactive materials. Analytical method, PNNL procedure number, and title of procedure are provided in Table 4.1.

Table 4.1. Analytical Methods Used for Analyses

\begin{tabular}{|l|l|l||}
\hline \multicolumn{1}{|c|}{ Method } & \multicolumn{1}{|c|}{ Procedure \# } & \multicolumn{1}{c|}{ Title } \\
\hline TIMS & $\begin{array}{l}\text { PNL-MA-599 } \\
\text { PNNL-98523-264 }\end{array}$ & Mass spectrometer isotopic analyses \\
\hline KPA & RPG-CMC-4014 & Uranium by kinetic phosphorescence analysis \\
\hline ICP-AES & RPG-CMC-211 & $\begin{array}{l}\text { Determination of elements by inductively coupled argon } \\
\text { plasma atomic emission spectrometry (ICP-AES) }\end{array}$ \\
\hline ICP-MS & $329-O P-S C 01$ & Inductively coupled plasma-mass spectrometry analysis \\
\hline IC & PNL-ALO-212 & Determination of inorganic anions by ion chromatography \\
\hline Gamma energy analysis & RPG-CMC-450 & $\begin{array}{l}\text { Gamma energy analysis and low energy photon } \\
\text { spectrometry }\end{array}$ \\
\hline Alpha spectrometry & RPG-CMC-422 & Pu and Am/Cm derived from the alpha AEA results \\
\hline
\end{tabular}

Thermal ionization MS for plutonium and uranium isotopic distribution was performed on both the uranium and plutonium fractions of the anion exchange separation process described in Section 3 . The solutions for this separation were generated by an $\mathrm{HNO}_{3}$ dissolution of the $\mathrm{Na}_{2} \mathrm{O}_{2}-\mathrm{NaOH}$ fusion. A CEC 21-703 single-stage MS equipped with an electron multiplier detector capable of nanogram detection limits was used for these measurements. A single filament source provided the mechanism for producing the ions that were separated by the MS and detected by the electron multiplier. Approximately $10 \mu \mathrm{L}$ of sample solution was dried on a rhenium filament and installed in the MS. Electrical current was supplied to the filament and ions extracted for analysis. Each isotope was measured two times per cycle and the measurements averaged. A typical analysis consisted of nine cycles, with the isotope measurement of all cycles averaged to calculate the final result.

KPA was performed on the uranium fraction of the anion exchange separation process on the solution from the $\mathrm{HNO}_{3}$ dissolution of the $\mathrm{Na}_{2} \mathrm{O}_{2}-\mathrm{NaOH}$ fusion. The sample preparation and anion exchange processes are described in Section 3. A Chemcheck KPA-11M kinetic phosphorescence analyzer was used to measure the total uranium in the samples. KPA is a proven technique for rapid, precise, and accurate determinations of uranium in aqueous solutions. A laser source is used to excite the uranium in solution, and the intensity of the phosphorescence created by the relaxation of the excited uranium back to its ground state is measured as a function of time to determine the uranium concentration in solution.

Metals analysis was performed by both ICP-AES and ICP-MS on both the acid dissolution of the fusion and the acid leach of the plutonium oxide samples. Both techniques use inductively-coupled argon plasma to vaporize the sample and excite the element, but each system uses a different detection system to measure the concentration of the analyte in the vaporized sample. 
Atomic emission spectroscopy (AES) has been the standard for routine analysis of metal ions. In AES the light derived from the vaporized, excited material is dispersed into its component parts in the spectrometer, and the intensity of the light is detected by a photodetector. Because each element produces a series of spectral lines of specific wavelengths, the identification of an element is possible by studying the lines according to their respective wavelengths. The concentration of the analyte is determined by the intensity of those lines. Plutonium has a large number of intense spectral lines; therefore, more accurate determination of the concentrations of the impurities in the plutonium oxide samples was made by removing the plutonium in the acid dissolution of the fused sample and in the filtrate of the acid dissolution. A Thermo Jarrell Ash Model ICP-61 ICP-AES system was used for the analysis of these samples.

In MS, both positive and negative gas phase ions are detected after they are separated according to their charge-to-mass ratio. Because the elements are separated by their atomic mass, interferences from the plutonium in the analyzed solution are minimized, and greater sensitivity is achieved for many analytes. The inductively coupled argon plasma produces the gas phase ions, and the MS separates and detects the ions. A Thermo Elemental VG PQ ExCell ICP-MS was used for the analysis of these samples.

Water-soluble anions were measured by IC on the water leach of the plutonium oxide samples. IC is a rapid, multi-ion method for analyzing anions in a sample solution. Separation of the anions is accomplished by an anion exchange column, and a conductivity cell is used to detect the anions. The anions are identified by their retention time on the anion exchange column, and the anion concentrations are determined by comparison with detector responses from standard solutions. A Dionex ICS-2500 modular IC system was used to quantify the amount of $\mathrm{F}^{-}, \mathrm{Cl}^{-}, \mathrm{Br}^{-}, \mathrm{NO}_{2}{ }^{-}, \mathrm{NO}_{3}{ }^{-}, \mathrm{PO}_{4}{ }^{3-}, \mathrm{SO}_{4}{ }^{2-}$, and $\mathrm{C}_{2} \mathrm{O}_{4}{ }^{2-}$ in the water leach.

Alpha energy analysis (AEA) and gamma energy analysis (GEA) identify the isotopes in a sample and quantify the activity of those isotopes by measuring the energy and frequency of the alpha particles and gamma rays emitted from the sample. The energy of the alpha or gamma radiation identifies the isotope, and the frequency at which the alpha particles or gamma rays occur (disintegrations/unit time) represents the activity and consequently the concentration of that particular isotope. GEA was measured on an aliquot of the direct plutonium oxide sample. The isotope of interest for this analysis was americium-241, but all isotopes that were detected were reported. Canberra Genie-ESP software was used for the spectral analysis of the GEA data collected by high-purity germanium detectors with efficiencies ranging from 40 to 100 percent. Similar software was used for the analysis of the AEA data, which was obtained with multiple solid-state surface barrier silicon detectors. The target isotope for this analysis was plutonium-238, but all alpha-emitting isotopes detected were reported. 


\subsection{Plutonium}

\subsection{Destructive Analysis}

Following total dissolution of a sample aliquot using sodium hydroxide-sodium peroxide fusion, an aliquot of the dilution was analyzed by GEA. The concentrations of plutonium isotopes and americium241 were determined using this method and may be seen in Table 5.1. Additional measurements were made on Quality Control (QC) subsamples (duplicate samples and samples with spikes added) and were reported in Table 5.1. No other gamma-emitting isotopes were detected.

Table 5.1. Plutonium and Americium Found in Oxide Samples Measured by GEA

\begin{tabular}{|c|c|c|c|c|c|}
\hline \multirow[b]{2}{*}{ Sample } & \multicolumn{5}{|c|}{ Activity in $\mu \mathrm{Ci} / \mathrm{g}$} \\
\hline & ${ }^{238} \mathbf{P u}$ & ${ }^{239} \mathrm{Pu}$ & ${ }^{240} \mathrm{Pu}$ & ${ }^{241} \mathrm{Pu}$ & ${ }^{241} \mathrm{Am}$ \\
\hline \multicolumn{6}{|c|}{ Rocky Flats Oxides (low chloride) } \\
\hline B-5526 & $1.06 \times 10^{3}$ & $3.57 \times 10^{4}$ & $8.27 \times 10^{3}$ & $5.68 \times 10^{4}$ & $4.99 \times 10^{3}$ \\
\hline B-5526-Dup & $1.04 \times 10^{3}$ & $3.46 \times 10^{4}$ & $8.12 \times 10^{3}$ & $5.41 \times 10^{4}$ & $4.70 \times 10^{3}$ \\
\hline B-5526-Spike & $1.00 \times 10^{3}$ & $4.06 \times 10^{4}$ & $8.31 \times 10^{3}$ & $6.70 \times 10^{4}$ & $5.98 \times 10^{3}$ \\
\hline B-5534 & $2.00 \times 10^{3}$ & $3.66 \times 10^{4}$ & $8.63 \times 10^{3}$ & $8.26 \times 10^{4}$ & $4.29 \times 10^{3}$ \\
\hline B-5680 & $2.00 \times 10^{3}$ & $3.80 \times 10^{4}$ & $1.01 \times 10^{4}$ & $6.10 \times 10^{4}$ & $4.28 \times 10^{3}$ \\
\hline \multicolumn{6}{|c|}{ Rocky Flats Oxides (high chloride) } \\
\hline B-5439 & $5.80 \times 10^{2}$ & $3.08 \times 10^{4}$ & $8.03 \times 10^{3}$ & $3.12 \times 10^{4}$ & $2.42 \times 10^{3}$ \\
\hline B-5495 & $2.00 \times 10^{3}$ & $3.41 \times 10^{4}$ & $9.09 \times 10^{3}$ & $5.18 \times 10^{4}$ & $3.96 \times 10^{3}$ \\
\hline B-5497 & $6.72 \times 10^{2}$ & $2.62 \times 10^{4}$ & $9.34 \times 10^{3}$ & $4.60 \times 10^{4}$ & $2.87 \times 10^{3}$ \\
\hline B-5524 & $9.18 \times 10^{2}$ & $3.56 \times 10^{4}$ & $6.84 \times 10^{3}$ & $6.37 \times 10^{4}$ & $6.96 \times 10^{3}$ \\
\hline B-5532 & $6.36 \times 10^{2}$ & $3.30 \times 10^{4}$ & $6.95 \times 10^{3}$ & $3.95 \times 10^{4}$ & $2.36 \times 10^{3}$ \\
\hline B-5701 & $7.31 \times 10^{2}$ & $3.03 \times 10^{4}$ & $7.51 \times 10^{3}$ & $4.31 \times 10^{4}$ & $3.03 \times 10^{3}$ \\
\hline B-5703 & $1.47 \times 10^{3}$ & $3.37 \times 10^{4}$ & $9.62 \times 10^{3}$ & $1.07 \times 10^{5}$ & $6.28 \times 10^{3}$ \\
\hline B-5703-Dup & $1.07 \times 10^{3}$ & $3.60 \times 10^{4}$ & $1.29 \times 10^{4}$ & $1.18 \times 10^{5}$ & $6.59 \times 10^{3}$ \\
\hline B-5703-Spike & $1.71 \times 10^{3}$ & $3.17 \times 10^{4}$ & $1.22 \times 10^{4}$ & $9.78 \times 10^{4}$ & $5.77 \times 10^{3}$ \\
\hline \multicolumn{6}{|c|}{ PRF/RMC Scrap } \\
\hline B-5456 & $1.44 \times 10^{3}$ & $3.15 \times 10^{4}$ & $6.36 \times 10^{3}$ & $6.12 \times 10^{4}$ & $4.22 \times 10^{3}$ \\
\hline \begin{tabular}{|l|} 
B-5456-Dup \\
\end{tabular} & $2.00 \times 10^{3}$ & $3.30 \times 10^{4}$ & $7.05 \times 10^{3}$ & $6.69 \times 10^{4}$ & $4.39 \times 10^{3}$ \\
\hline B-5457 & $2.00 \times 10^{3}$ & $4.30 \times 10^{4}$ & $1.78 \times 10^{4}$ & $9.22 \times 10^{4}$ & $5.08 \times 10^{3}$ \\
\hline B-5470 & $2.08 \times 10^{3}$ & $3.97 \times 10^{4}$ & $1.21 \times 10^{4}$ & $1.44 \times 10^{5}$ & $6.57 \times 10^{3}$ \\
\hline B-5471 & $1.70 \times 10^{3}$ & $4.35 \times 10^{4}$ & $1.12 \times 10^{4}$ & $1.11 \times 10^{5}$ & $7.54 \times 10^{3}$ \\
\hline B-5472 & $2.85 \times 10^{3}$ & $3.94 \times 10^{4}$ & $1.81 \times 10^{4}$ & $1.74 \times 10^{5}$ & $8.67 \times 10^{3}$ \\
\hline B-5501 & $2.00 \times 10^{3}$ & $3.27 \times 10^{4}$ & $7.71 \times 10^{3}$ & $9.29 \times 10^{4}$ & $5.83 \times 10^{3}$ \\
\hline \multicolumn{6}{|c|}{ Pu Solutions } \\
\hline $\mathrm{R}-418$ & $2.00 \times 10^{3}$ & $1.52 \times 10^{4}$ & $4.82 \times 10^{3}$ & $7.51 \times 10^{4}$ & $2.84 \times 10^{3}$ \\
\hline $\mathrm{R}-419$ & $2.77 \times 10^{3}$ & $3.60 \times 10^{4}$ & $1.39 \times 10^{4}$ & $1.92 \times 10^{5}$ & $7.81 \times 10^{3}$ \\
\hline R-419-Dup & $3.00 \times 10^{3}$ & $3.61 \times 10^{4}$ & $1.18 \times 10^{4}$ & $2.03 \times 10^{5}$ & $7.78 \times 10^{3}$ \\
\hline
\end{tabular}


Aliquots of the same fusion fraction used in the GEA were also analyzed by TIMS. These solutions were first purified by ion exchange chromatography to separate uranium and plutonium. The uranium fraction was analyzed separately. The normalized plutonium isotopic distribution was determined and is reported in Table 5.2. Too little plutonium was obtained from the ion exchange processes to obtain accurate isotopic results for B-5470 and ${ }^{238} \mathrm{Pu}$ and ${ }^{242} \mathrm{Pu}$ for B-5501. Because the results for the other samples were so consistent, additional samples were not generated for these analyses.

Table 5.2. TIMS Results for Plutonium Isotopic Distribution

\begin{tabular}{|c|c|c|c|c|c|}
\hline Sample & ${ }^{238} \mathrm{Pu}$ atom\% & ${ }^{2339} \mathrm{Pu}$ atom\% & 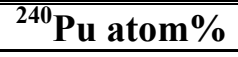 & 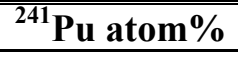 & ${ }^{242} \mathrm{Pu}$ atom\% \\
\hline \multicolumn{6}{|c|}{ Rocky Flats Oxide (low chloride) } \\
\hline B-5526 & 0.008 & 94.0 & 5.8 & 0.088 & 0.026 \\
\hline B-5526-dup & 0.006 & 94.1 & 5.8 & 0.088 & 0.023 \\
\hline B-5534 & 0.038 & 94.1 & 5.7 & 0.109 & 0.031 \\
\hline B-5680 & 0.074 & 94.0 & 5.6 & 0.071 & 0.181 \\
\hline \multicolumn{6}{|c|}{ Rocky Flats Oxide (high chloride) } \\
\hline B-5439 & 0.007 & 94.2 & 5.7 & 0.064 & 0.023 \\
\hline B-5495 & 0.076 & 94.2 & 5.5 & 0.188 & 0.087 \\
\hline B-5497 & 0.002 & 94.2 & 5.7 & 0.069 & 0.027 \\
\hline B-5524 & 0.011 & 94.1 & 5.8 & 0.100 & 0.027 \\
\hline B-5532 & 0.010 & 94.5 & 5.4 & 0.072 & 0.017 \\
\hline B-5701 & 0.008 & 94.1 & 5.8 & 0.084 & 0.020 \\
\hline B-5701-dup & 0.007 & 93.9 & 5.9 & 0.076 & 0.021 \\
\hline B-5703 & 0.013 & 93.7 & 6.1 & 0.176 & 0.034 \\
\hline B-5703-dup & 0.021 & 94.0 & 5.7 & 0.130 & 0.081 \\
\hline \multicolumn{6}{|c|}{ PRF/RMC Scrap } \\
\hline B-5456 & 0.011 & 93.7 & 6.2 & 0.101 & 0.040 \\
\hline B-5456-dup & 0.016 & 93.7 & 6.0 & 0.151 & 0.073 \\
\hline B-5457 & 0.182 & 93.7 & 6.0 & 0.104 & 0.056 \\
\hline B-5470 & -- & -- & -- & -- & -- \\
\hline B-5471 & 0.494 & 93.1 & 5.7 & 0.570 & 0.126 \\
\hline B-5472 & 0.118 & 93.6 & 5.8 & 0.439 & 0.060 \\
\hline B-5501 & -- & 96.6 & 3.7 & 0.396 & -- \\
\hline \multicolumn{6}{|c|}{ Pu Solutions } \\
\hline $\mathrm{R}-418$ & 0.117 & 94.0 & 5.5 & 0.328 & 0.044 \\
\hline $\mathrm{R}-419$ & 0.043 & 93.7 & 6.0 & 0.318 & 0.027 \\
\hline R-419-dup & 0.113 & 94.0 & 5.6 & 0.253 & 0.032 \\
\hline
\end{tabular}

\subsection{Comparison of GEA with NDA Observed at PFP}

Using results from the direct GEA of complete dissolution of the samples in the peroxide fusion preparation, the total plutonium fraction in the sample was determined. In Table 5.3, the GEA results of these sample analyses are compared with the measured values of plutonium on the 3013 containers. The PFP measurements were determined using gamma isotopic analysis coupled with calorimetry. In Figure 5.1 the bias between the methods is clearly seen. 
Table 5.3. Total Plutonium Measurement Comparisons

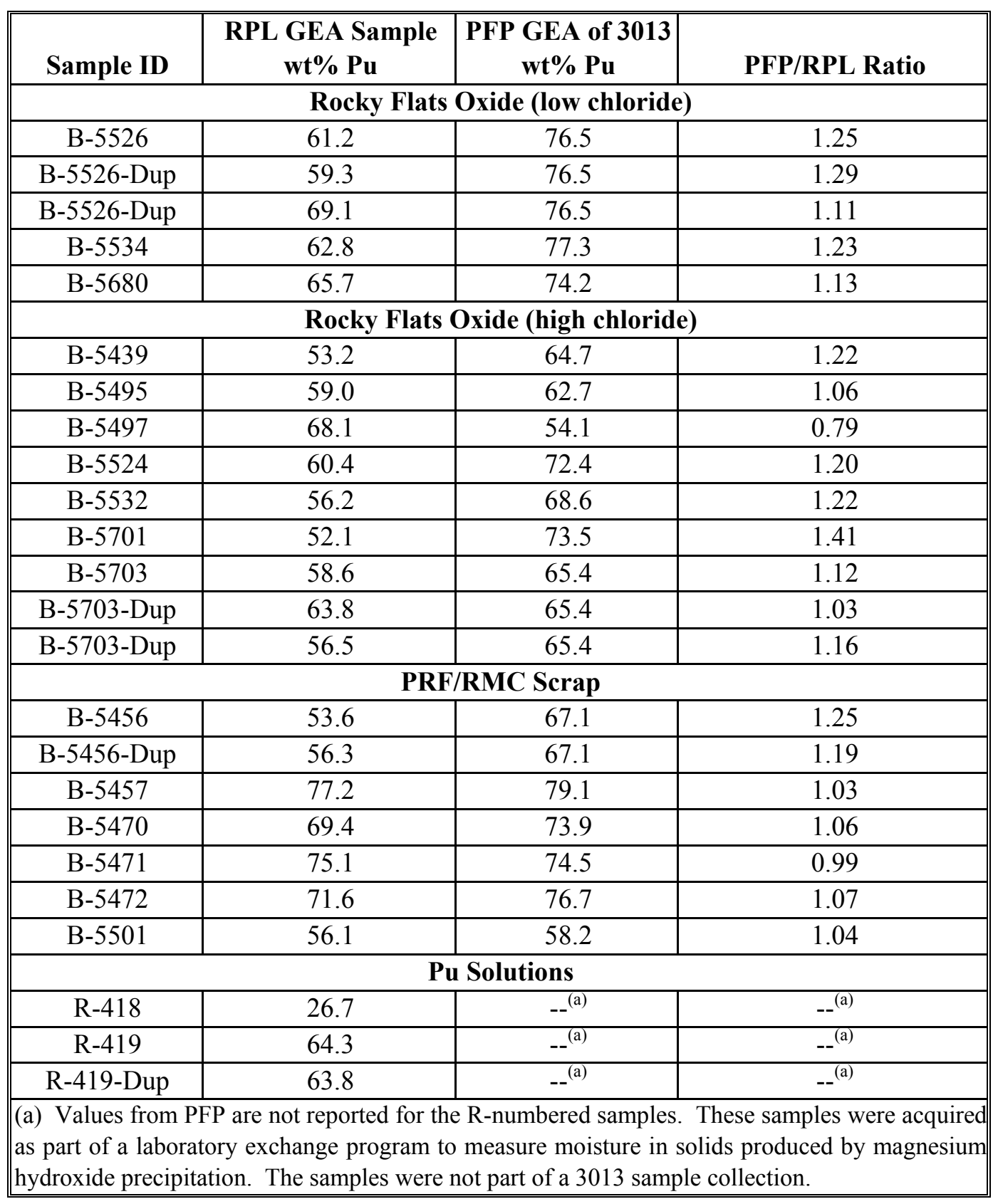




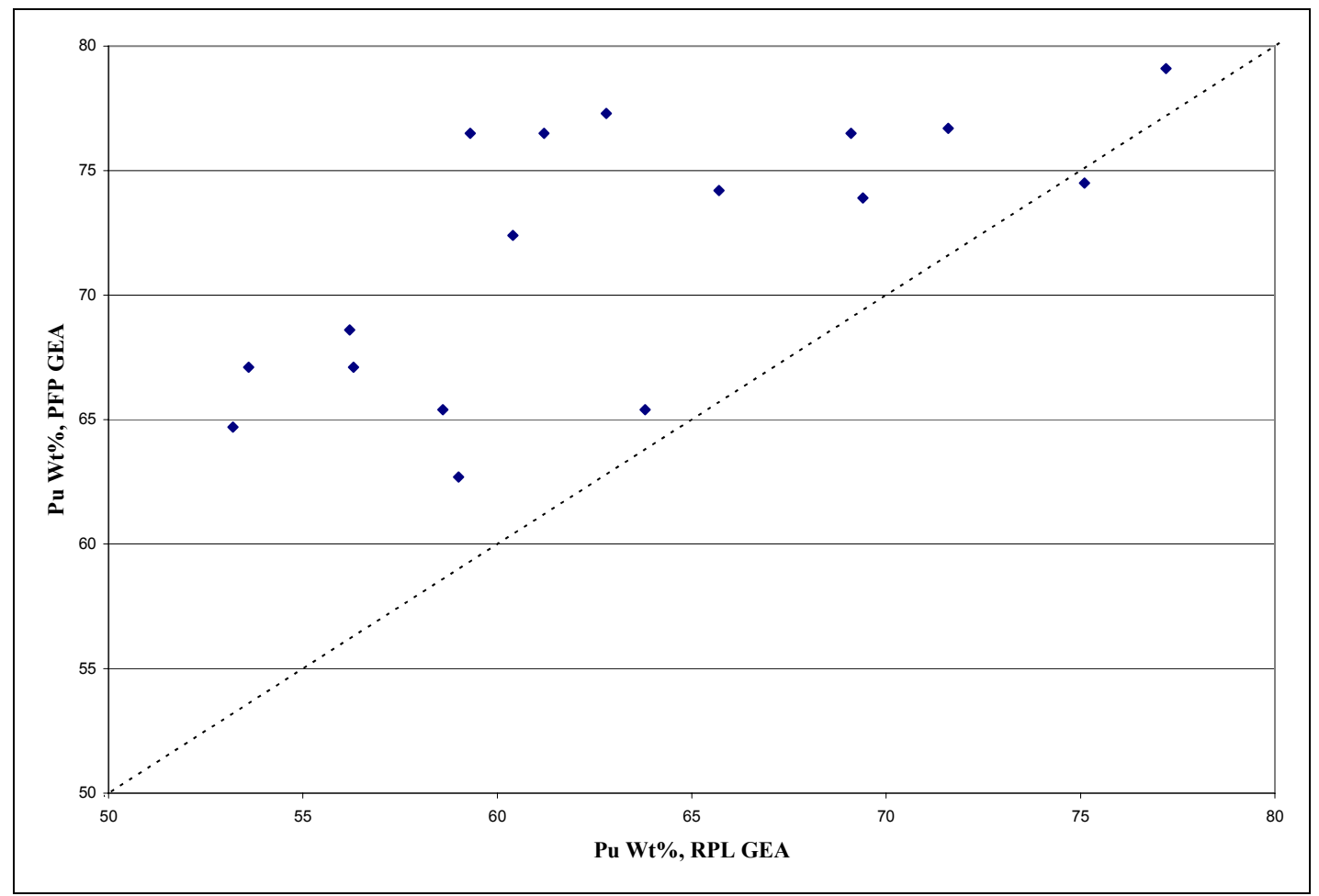

Figure 5.1. Plutonium Measured by Direct GEA/Calorimetry of 3013 Containers Compared with Solution Measurements

GEA of plutonium-bearing material is complicated by energy interferences through coincident or overlapping spectral peaks. To correct for these interferences, methods specifically designed for plutonium have been used at PFP — specialized spectral analysis and deconvolution software - that were not available at the Radiochemical Processing Laboratory (RPL) at PNNL. Spectral interferences may explain the differences reported in Table 5.4 for the ${ }^{239} \mathrm{Pu}$ ratios measured by GEA in the RPL compared with TIMS and GEA performed at PFP.

Ion exchange was used to separate plutonium, uranium, and americium fractions. Aliquots of the plutonium solutions were mounted for alpha spectroscopy by coprecipitation on $50 \mu \mathrm{g}$ of $\mathrm{NdF}_{3}$ on a membrane filter, then counted by alpha spectroscopy to determine ${ }^{238} \mathrm{Pu}$. Because ${ }^{239} \mathrm{Pu}$ and ${ }^{240} \mathrm{Pu}$ appear as a single peak in the alpha energy spectrum, the isotopic distribution of these isotopes as measured by TIMS was used in combination with the AEA to calculate ${ }^{238} \mathrm{Pu}$. The peak from ${ }^{241} \mathrm{Am}$ is indistinguishable from ${ }^{238} \mathrm{Pu}$. Three samples were rerun due to anomalously high percentages of ${ }^{238} \mathrm{Pu}$. These same samples had been rerun previously using larger sample aliquots due to insufficient activity in the first run. Results from the AEA determination of ${ }^{238} \mathrm{Pu}$ are listed in Table 5.5 along with the results from analyses by TIMS and GEA both at RPL on the fusion solutions and at PFP on the entire 3013 containers. Values in the TIMS samples run higher, likely due to interference from ${ }^{238} \mathrm{U}$ in the same samples in which AEA sample cleanup had been difficult.

Throughout the remainder of this report, the plutonium concentration reported is the value determined by PFP on the 3013 cans. The plutonium isotopic compositions reported are the values measured by TIMS with the exception of ${ }^{238} \mathrm{Pu}$ which is the value measured by AEA. 
Table 5.4. Comparison of ${ }^{239} \mathrm{Pu}$ Isotopic Results by Three Analytical Methods

\begin{tabular}{|c|c|c|c|}
\hline \multirow{2}{*}{ Sample } & \multicolumn{3}{|c|}{${ }^{2339} \mathrm{Pu} w \mathrm{w} \%$} \\
\hline & TIMS & GEA at RPL & GEA at PFP \\
\hline \multicolumn{4}{|c|}{ Rocky Flats Oxide (low chloride) } \\
\hline B-5526 & 94.000 & 93.966 & 94.090 \\
\hline B-5526-Dup & 94.100 & 93.895 & -- \\
\hline B-5534 & 94.100 & 94.918 & 93.996 \\
\hline B-5680 & 94.000 & 94.500 & 94.097 \\
\hline \multicolumn{4}{|c|}{ Rocky Flats Oxide (high chloride) } \\
\hline B-5439 & 94.200 & 93.823 & 94.221 \\
\hline B-5495 & 94.200 & 93.128 & 93.941 \\
\hline B-5497 & 94.200 & 94.618 & 94.174 \\
\hline B-5524 & 94.100 & 91.047 & 94.055 \\
\hline B-5532 & 94.500 & 93.305 & 94.388 \\
\hline B-5701 & 94.100 & 90.929 & 94.183 \\
\hline B-5701-Dup & 93.900 & 93.588 & -- \\
\hline B-5703 & 93.700 & 93.144 & 93.690 \\
\hline B-5703-Dup & 94.000 & 92.602 & -- \\
\hline \multicolumn{4}{|c|}{ PRF/RMC Scrap } \\
\hline B-5456 & 93.700 & 94.663 & 93.879 \\
\hline B-5456 & 93.700 & 94.368 & -- \\
\hline B-5457 & 93.700 & 89.742 & 93.874 \\
\hline B-5470 & -- & 92.127 & 93.715 \\
\hline B-5471 & 93.100 & 93.295 & 93.678 \\
\hline B-5472 & 93.600 & 88.641 & 93.735 \\
\hline B-5501 & 96.600 & 93.791 & 93.681 \\
\hline \multicolumn{4}{|c|}{ Pu Solutions } \\
\hline $\mathrm{R}-418$ & 94.000 & 91.752 & $--^{(a)}$ \\
\hline $\mathrm{R}-419$ & 93.700 & 90.192 & $--^{\text {(a) }}$ \\
\hline R-419-Dup & 94.000 & 91.509 & $--^{\text {(a) }}$ \\
\hline \multicolumn{4}{|c|}{ Statistical Evaluation (all categories) } \\
\hline Average & 94.055 & 92.763 & 93.962 \\
\hline RSD & $0.7 \%$ & $1.9 \%$ & $0.2 \%$ \\
\hline
\end{tabular}


Table 5.5. ${ }^{238} \mathrm{Pu}$ Results by Four Analytical Methods

\begin{tabular}{|c|c|c|c|c|}
\hline & \multicolumn{4}{|c|}{${ }^{238} \mathrm{Pu}$ wt\% } \\
\hline Sample & AEA & TIMS & GEA at RPL & GEA at PFP \\
\hline \multicolumn{5}{|c|}{ Rocky Flats Oxide (low chloride) } \\
\hline B-5526 & -- & 0.008 & 0.010 & 0.0073 \\
\hline B-5526 & 0.0066 & 0.006 & 0.010 & -- \\
\hline B-5534 & 0.0095 & 0.038 & 0.009 & 0.0090 \\
\hline B-5680 & 0.0185 & 0.074 & 0.007 & 0.0091 \\
\hline Average & 0.012 & 0.032 & 0.009 & 0.008 \\
\hline RSD & $53 \%$ & $101 \%$ & $19 \%$ & $10 \%$ \\
\hline \multicolumn{5}{|c|}{ Rocky Flats Oxide (high chloride) } \\
\hline B-5439 & 0.0063 & 0.007 & 0.019 & 0.0077 \\
\hline B-5495 & 0.0095 & 0.076 & 0.020 & 0.0093 \\
\hline B-5497 & 0.0061 & 0.002 & 0.008 & 0.0074 \\
\hline B-5524 & 0.0064 & 0.011 & 0.008 & 0.0088 \\
\hline B-5532 & 0.0066 & 0.010 & 0.006 & 0.0077 \\
\hline B-5701 & 0.0078 & 0.008 & 0.010 & 0.0078 \\
\hline B-5701 & 0.0093 & 0.007 & 0.008 & 0.0078 \\
\hline B-5703 & 0.0088 & 0.013 & 0.018 & 0.0165 \\
\hline B-5703 & 0.0142 & 0.021 & 0.015 & 0.0165 \\
\hline Average & 0.0083 & 0.017 & 0.012 & 0.010 \\
\hline RSD & $31 \%$ & $132 \%$ & $42 \%$ & $33 \%$ \\
\hline \multicolumn{5}{|c|}{ PRF/RMC Scrap } \\
\hline B-5456 & 0.0099 & 0.011 & 0.016 & 0.0110 \\
\hline B-5456 & 0.0242 & 0.016 & 0.021 & 0.0110 \\
\hline B-5457 & 0.0100 & 0.182 & 0.015 & 0.0116 \\
\hline B-5470 & -- & -- & 0.018 & 0.0185 \\
\hline B-5471 & 0.0152 & 0.494 & 0.013 & 0.0170 \\
\hline B-5472 & 0.0244 & 0.118 & 0.023 & 0.0244 \\
\hline B-5501 & 0.0139 & -- & 0.021 & 0.0153 \\
\hline Average & 0.0163 & 0.164 & 0.018 & 0.016 \\
\hline RSD & $40 \%$ & $121 \%$ & $20 \%$ & $30 \%$ \\
\hline \multicolumn{5}{|c|}{ Pu Solutions } \\
\hline $\mathrm{R}-418$ & 0.0270 & 0.117 & 0.044 & Not Measured \\
\hline R-419 & 0.0295 & 0.043 & 0.025 & Not Measured \\
\hline $\mathrm{R}-419$ & 0.0290 & 0.113 & 0.028 & Not Measured \\
\hline Average & 0.029 & 0.091 & 0.032 & -- \\
\hline RSD & $5 \%$ & $46 \%$ & $31 \%$ & -- \\
\hline \multicolumn{5}{|c|}{ Statistical Evaluation (all categories) } \\
\hline Average & 0.014 & 0.065 & 0.016 & 0.012 \\
\hline RSD & $58 \%$ & $169 \%$ & $54 \%$ & $43 \%$ \\
\hline
\end{tabular}




\subsection{Uranium}

Following removal of plutonium by anion exchange in $\mathrm{HCl}$, the total uranium concentration was measured by kinetic phosphorescence analysis (KPA) on sample aliquots from the fusion preparation. The results in Table 6.1 show that the highest observed uranium concentration was $0.14 \mathrm{wt} \%$ of the original dry sample (B-5701).

Table 6.1. Uranium Concentrations in Impure Plutonium Oxides

\begin{tabular}{|c|c|}
\hline Sample & $\begin{array}{c}\text { Uranium } \\
\mu \mathrm{g} \text { per gram sample }\end{array}$ \\
\hline \multicolumn{2}{|c|}{ Rocky Flats Oxide (low chloride) } \\
\hline B-5526 & $2.88 \times 10^{2}$ \\
\hline B-5526-Dup & $1.82 \times 10^{2}$ \\
\hline B-5534 & $7.03 \times 10^{2}$ \\
\hline B-5680 & $8.24 \times 10^{2}$ \\
\hline \multicolumn{2}{|c|}{ Rocky Flats Oxide (high chloride) } \\
\hline B-5439 & $8.56 \times 10^{2}$ \\
\hline B-5495 & $3.34 \times 10^{2}$ \\
\hline B-5497 & $5.49 \times 10^{2}$ \\
\hline B-5524 & $7.99 \times 10^{2}$ \\
\hline B-5532 & $8.49 \times 10^{2}$ \\
\hline B-5701 & $1.36 \times 10^{3}$ \\
\hline B-5703 & $1.15 \times 10^{3}$ \\
\hline B-5703-Dup & $1.05 \times 10^{3}$ \\
\hline \multicolumn{2}{|c|}{ PRF/RMC Scrap } \\
\hline B-5456 & $8.79 \times 10^{2}$ \\
\hline B-5456-Dup & $9.35 \times 10^{2}$ \\
\hline B-5457 & $1.30 \times 10^{3}$ \\
\hline B-5470 & $5.80 \times 10^{2}$ \\
\hline B-5471 & $7.85 \times 10^{2}$ \\
\hline B-5472 & $3.91 \times 10^{2}$ \\
\hline B-5501 & $8.28 \times 10^{2}$ \\
\hline \multicolumn{2}{|c|}{ Pu Solutions } \\
\hline $\mathrm{R}-418$ & $1.02 \times 10^{3}$ \\
\hline $\mathrm{R}-419$ & $6.28 \times 10^{2}$ \\
\hline R-419-Dup & $7.02 \times 10^{2}$ \\
\hline
\end{tabular}


Isotopic analysis of the uranium by TIMS showed a wide range of values, as listed in Table 6.2. Compared with the origin of the material stabilized, the isotopic distributions correlate well within a family of items except for the varied scrap material from the PRF/RMC.

Table 6.2. TIMS Results for Uranium Isotopic Distribution

\begin{tabular}{|c|c|c|c|c|c|}
\hline & ${ }^{233} \mathrm{U}$ atom\% & ${ }^{2334}$ U atom\% & ${ }^{235} \mathrm{U}$ atom $\%$ & ${ }^{2336} \mathrm{U}$ atom\% & 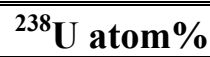 \\
\hline \multicolumn{6}{|c|}{ Rocky Flats Oxide (low chloride) } \\
\hline B-5526 & -- & 0.75 & 65.1 & 11.2 & 22.9 \\
\hline B-5526-Dup & -- & 0.50 & 66.0 & 13.2 & 21.8 \\
\hline B-5534 & 0.110 & 1.94 & 74.8 & 13.7 & 9.4 \\
\hline B-5680 & 0.023 & 1.91 & 75.7 & 16.0 & 6.4 \\
\hline \multicolumn{6}{|c|}{ Rocky Flats Oxide (high chloride) } \\
\hline B-5439 & 0.280 & 1.81 & 73.4 & 16.0 & 8.4 \\
\hline B-5439-Dup & 0.120 & 1.67 & 75.0 & 16.0 & 7.1 \\
\hline B-5495 & 4.340 & 3.85 & 63.8 & 16.3 & 11.7 \\
\hline B-5497 & -- & 1.69 & 73.0 & 15.9 & 9.4 \\
\hline B-5524 & 0.010 & 1.78 & 73.1 & 14.7 & 10.4 \\
\hline B-5532 & 0.220 & 1.89 & 74.6 & 16.3 & 7.0 \\
\hline B-5701 & 0.062 & 1.79 & 74.5 & 15.8 & 7.8 \\
\hline B-5703 & 0.066 & 2.24 & 71.1 & 11.3 & 15.3 \\
\hline B-5703-Dup & 0.024 & 2.30 & 72.7 & 12.2 & 12.8 \\
\hline \multicolumn{6}{|c|}{ PRF/RMC Scrap } \\
\hline B-5456 & -- & 1.50 & 45.1 & 8.3 & 45.2 \\
\hline B-5456-Dup & 0.246 & 1.50 & 44.0 & 8.1 & 46.2 \\
\hline B-5457 & 2.350 & 1.80 & 36.0 & 6.3 & 53.5 \\
\hline B-5470 & 1.15 & 4.00 & 51.7 & 11.6 & 31.6 \\
\hline B-5471 & 0.232 & 2.46 & 74.1 & 9.8 & 40.4 \\
\hline B-5472 & 0.057 & 5.40 & 67.6 & 16.4 & 10.6 \\
\hline B-5501 & 1.650 & 2.26 & 33.6 & 7.3 & 55.2 \\
\hline \multicolumn{6}{|c|}{ Pu Solutions } \\
\hline $\mathrm{R}-418$ & 0.047 & 1.16 & 21.6 & 3.1 & 74.1 \\
\hline $\mathrm{R}-419$ & 0.040 & 1.64 & 19.3 & 4.2 & 74.9 \\
\hline $\mathrm{R}-419$ & 0.038 & 1.67 & 19.1 & 4.1 & 75.2 \\
\hline
\end{tabular}




\subsection{Nonradioactive Components}

\subsection{Anion Analysis}

Anions that were leachable with water from the solid, impure plutonium oxide material were determined by IC. Results of these anion analyses are listed in Table 7.1. Blank cells in the table indicate that the analyte was below the detection limit of the system. All results are reported in parts per million (ppm) in the original solid sample.

Table 7.1. Concentrations of Anions in the Water Leach of the Samples (ppm) ${ }^{(\mathrm{a})}$

\begin{tabular}{|c|c|c|c|c|c|c|c|c|}
\hline Sample & $\overline{\mathbf{F}^{-}}$ & $\mathrm{Cl}^{-}$ & $\mathrm{NO}_{2}^{-}$ & $\mathrm{Br}^{-}$ & $\mathrm{NO}_{3}^{-}$ & $\mathrm{PO}_{4}{ }^{3-}$ & $\mathrm{SO}_{4}{ }^{2-}$ & $\mathrm{C}_{2} \mathrm{O}_{4}{ }^{2-}$ \\
\hline \multicolumn{9}{|c|}{ Rocky Flats Oxides (low chloride) } \\
\hline B-5526 & -- & 44,878 & -- & - & - & -- & $765^{(\mathrm{a})}$ & -- \\
\hline B-5526-Dup & -- & 45,159 & -- & -- & -- & -- & $842^{(a)}$ & -- \\
\hline B-5534 & -- & 16,324 & -- & $\mathrm{V}$ & $927^{(\mathrm{a})}$ & -- & $715^{(a)}$ & -- \\
\hline B-5680 & -- & 53,959 & -- & -- & $209^{(a)}$ & -- & $1,173^{(\mathrm{a})}$ & -- \\
\hline \multicolumn{9}{|c|}{ Rocky Flats Oxides (high chloride) } \\
\hline B-5439 & -- & 112,645 & -- & -- & -- & -- & -- & - \\
\hline B-5495 & - & 120,200 & - & -- & - & - & - & - \\
\hline B-5497 & -- & 85,817 & -- & -- & -- & -- & -- & -- \\
\hline B-5524 & - & 76,908 & - & -- & - & -- & - & - \\
\hline B-5532 & - & 79,123 & - & -- & - & -- & $553^{(\mathrm{a})}$ & - \\
\hline B-5701 & -- & 53,261 & -- & -- & -- & -- & - & -- \\
\hline B-5703 & -- & 102,353 & -- & -- & -- & -- & -- & - \\
\hline B-5703-Dup & -- & 101,877 & -- & -- & -- & -- & - & -- \\
\hline \multicolumn{9}{|c|}{ PRF/RMC Scrap } \\
\hline B-5456 & 697 & $10^{\text {(a) }}$ & 26.7 & -- & 1,084 & 541 & 225 & $19^{(\mathrm{a})}$ \\
\hline B-5456-Dup & 802 & $10^{(\mathrm{a})}$ & 36.6 & -- & 1,021 & 659 & 275 & $22^{(\mathrm{a})}$ \\
\hline B-5457 & -- & $4.4^{(\mathrm{a})}$ & & -- & 325 & & 26.2 & $6.9^{(\mathrm{a})}$ \\
\hline B-5470 & 314 & 164 & 62.8 & -- & 1,149 & 632 & 440 & 28.2 \\
\hline B-5471 & 510 & 286 & 60.3 & -- & 1,195 & 758 & 632 & $10^{(\mathrm{a})}$ \\
\hline B-5472 & 1,677 & 33.1 & & - & 630 & -- & 25.4 & $22^{(\mathrm{a})}$ \\
\hline B-5501 & -- & 26.8 & 34.6 & -- & 887 & -- & 1,647 & $15^{(\mathrm{a})}$ \\
\hline \multicolumn{9}{|c|}{ Pu Solutions } \\
\hline R-418 & 106 & 89.3 & 161 & -- & 1,475 & 41.9 & 4,201 & - \\
\hline $\mathrm{R}-419$ & -- & 35.4 & 238 & -- & 1,340 & & 1,060 & -- \\
\hline R-419-Dup & -- & 38.3 & 239 & -- & 1,333 & & 77.4 & -- \\
\hline
\end{tabular}

(a) Result is greater than minimum detectible level but less than estimated quantitation limit.

None of the samples contained water-soluble anions that exceeded the specification for alternate feedstock. The highest concentration of water-soluble anion was observed in the Rocky Flats Oxide samples with chloride as the predominant anion. The combined mass of all other water-soluble anions in any of the samples is less than 1 percent of the total mass of the sample. Nitrate, sulfate, phosphate, and fluoride were the primary anions observed in the PRF/RMC scrap samples, but quantifiable 
concentrations of all of the measured anions except bromide were observed in the PRF/RMC scrap samples. The concentration of these anions varied widely in the samples from this category. Nitrate and sulfate were the primary anions in the solution samples. Nitrite was present only in samples that also contained nitrate. When quantifiable, nitrite composed about 3 to 6 percent of the nitrate concentration.

Some anions likely were not soluble in the water leach. In particular, fluoride present as a plutonium fluoride would not be soluble in the water leach. Therefore, fluoride analysis was also performed on a $\mathrm{pH}$-adjusted sample from the caustic fusion. Fluoride results obtained on the water leach and caustic fusion fractions of each sample are compared in Table 7.2.

The results in Table 7.2 indicate that a significant amount of fluoride is present as insoluble fluoride. The fusion digest results from sample B-5472, indicating $\sim 67 \mathrm{wt} \%$ fluorine, obviously are biased high (i.e., even $\mathrm{PuF}_{4}$ is only $24 \mathrm{wt} \%$ fluorine), but prompt gamma results on the 3013 can from which this sample was taken confirm that significant quantities of fluoride are present. The prompt gamma results on this material indicate that the fluoride is probably intimately mixed with plutonium, likely as a compound such as $\mathrm{PuF}_{4}$.

Table 7.2. Comparison of Water-Soluble Fluoride to Total Fluoride

\begin{tabular}{|c|c|c|}
\hline \multirow{2}{*}{ Sample } & \multicolumn{2}{|c|}{$\mathbf{F}^{-}(\mathbf{p p m})$} \\
\hline & Water-Soluble & Total \\
\hline \multicolumn{3}{|c|}{ Rocky Flats Oxides (low chloride) } \\
\hline B-5526 & & 11,462 \\
\hline B-5526-Dup & & 10,681 \\
\hline B-5534 & & 16,929 \\
\hline B-5680 & & 4,242 \\
\hline \multicolumn{3}{|c|}{$\begin{array}{l}\text { Rocky Flats Oxides (high chloride) } \\
\end{array}$} \\
\hline B-5439 & & 4,951 \\
\hline B-5495 & & 10,847 \\
\hline B-5497 & & 23,989 \\
\hline B-5524 & & 8,870 \\
\hline B-5532 & & 4,119 \\
\hline B-5701 & & 7,020 \\
\hline B-5703 & & 8,224 \\
\hline B-5703-Dup & & 9,069 \\
\hline \multicolumn{3}{|c|}{ PRF/RMC Scrap } \\
\hline B-5456 & 697 & 57,727 \\
\hline B-5456-Dup & 802 & 53,212 \\
\hline B-5457 & & 5,546 \\
\hline B-5470 & 314 & 57,220 \\
\hline B-5471 & 510 & 11,878 \\
\hline B-5472 & 1,677 & 669,796 \\
\hline B-5501 & & 102,512 \\
\hline \multicolumn{3}{|c|}{ Pu Solutions } \\
\hline $\mathrm{R}-418$ & 106 & 26,114 \\
\hline $\mathrm{R}-419$ & & 3,113 \\
\hline R-419-Dup & & 4,214 \\
\hline
\end{tabular}




\subsection{Elemental Analysis by ICP-AES and ICP-MS}

Concentrations of acid-soluble metals were measured by ICP-MS and ICP-AES on the acid leach from each sample. Analysis was also performed on the caustic fusion of these samples to obtain a measurement of the total impurities in the samples. Prior to ICP-AES analysis, plutonium was removed from the caustic fusion fraction by anion exchange. The results from these analyses are reported in the appendix. Some analytes were measured in both the ICP-MS and ICP-AES, while others were measured in one of the two systems depending on the sensitivities of the respective instruments to the analyte.

Impurities above the MOX specification limit were observed in each of the samples. The metals of greatest concern were chromium, iron, nickel, silicon, aluminum, molybdenum, and copper. In Figures 7.1 through 7.7, the concentrations of these impurities in $\mu \mathrm{g}$ of impurity per gram of sample $(\mathrm{ppm})$ are plotted as a function of plutonium concentration for each category of material. The solid lines are the MOX specification. The specification varies with plutonium concentration because the unit for these specifications is in $\mu \mathrm{g}$ of impurity per gram of plutonium instead of per gram of sample. All of the analyses were based on one gram of sample, and further error would be incorporated into the data by reporting the data in $\mu \mathrm{g}$ of impurity per gram of plutonium.

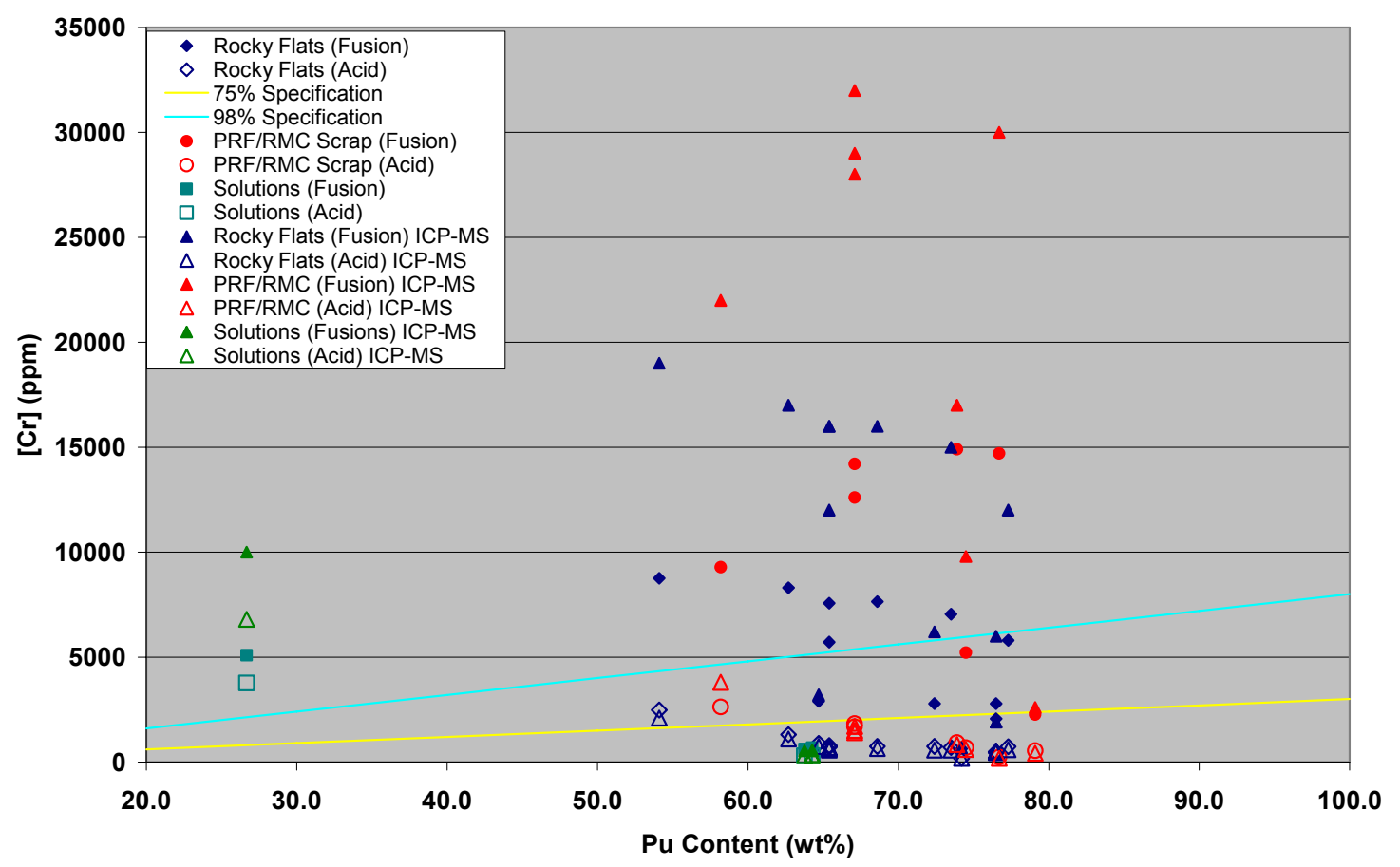

Figure 7.1. Chromium Concentration as a Function of Plutonium Content.

Concentrations are reported in $\mu \mathrm{g} / \mathrm{g}$ of sample. 


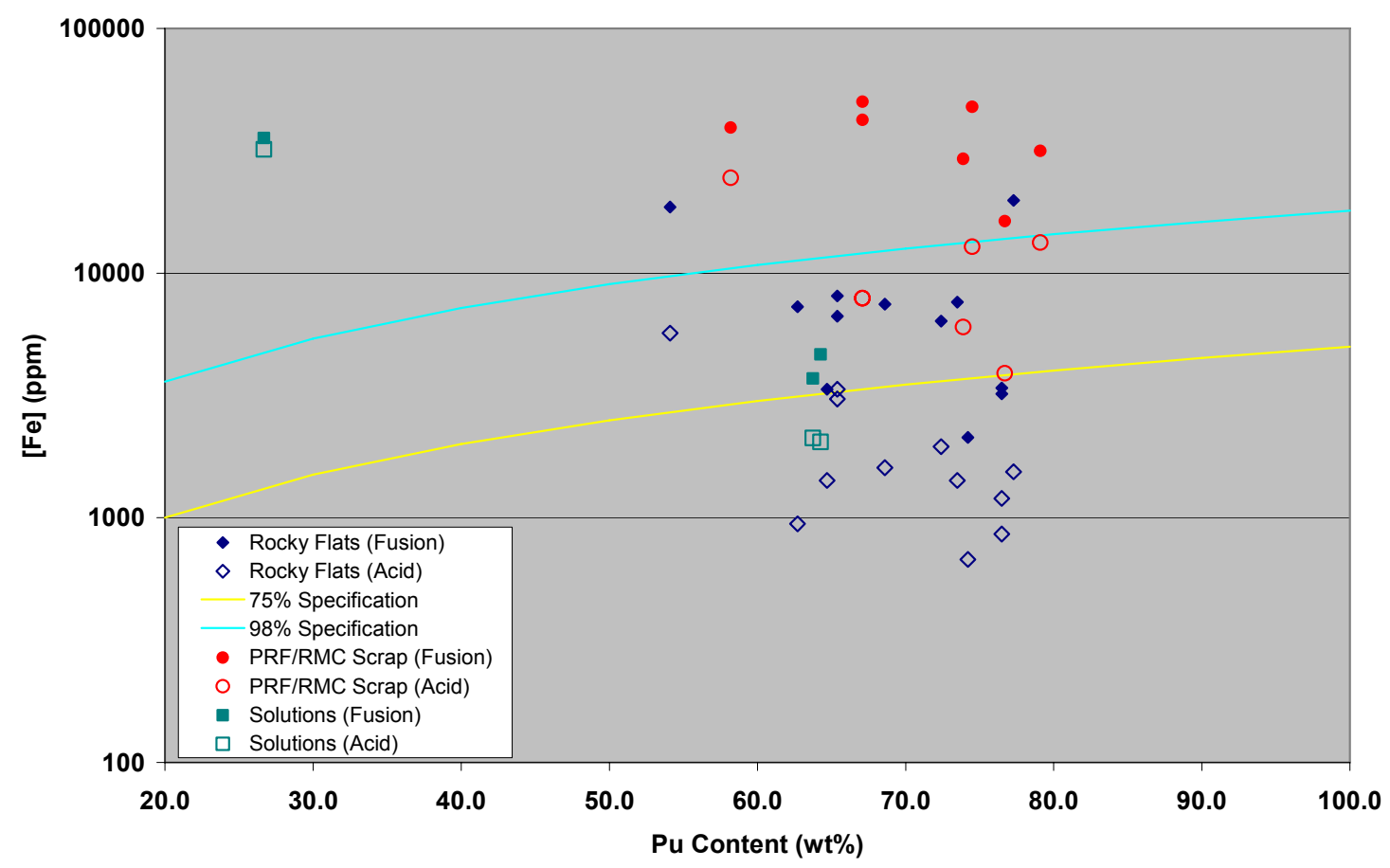

Figure 7.2. Iron Concentration as a Function of Plutonium Content. Concentrations are reported in $\mu \mathrm{g} / \mathrm{g}$ of sample and plotted on a log scale. Data are from ICP-AES measurements only.

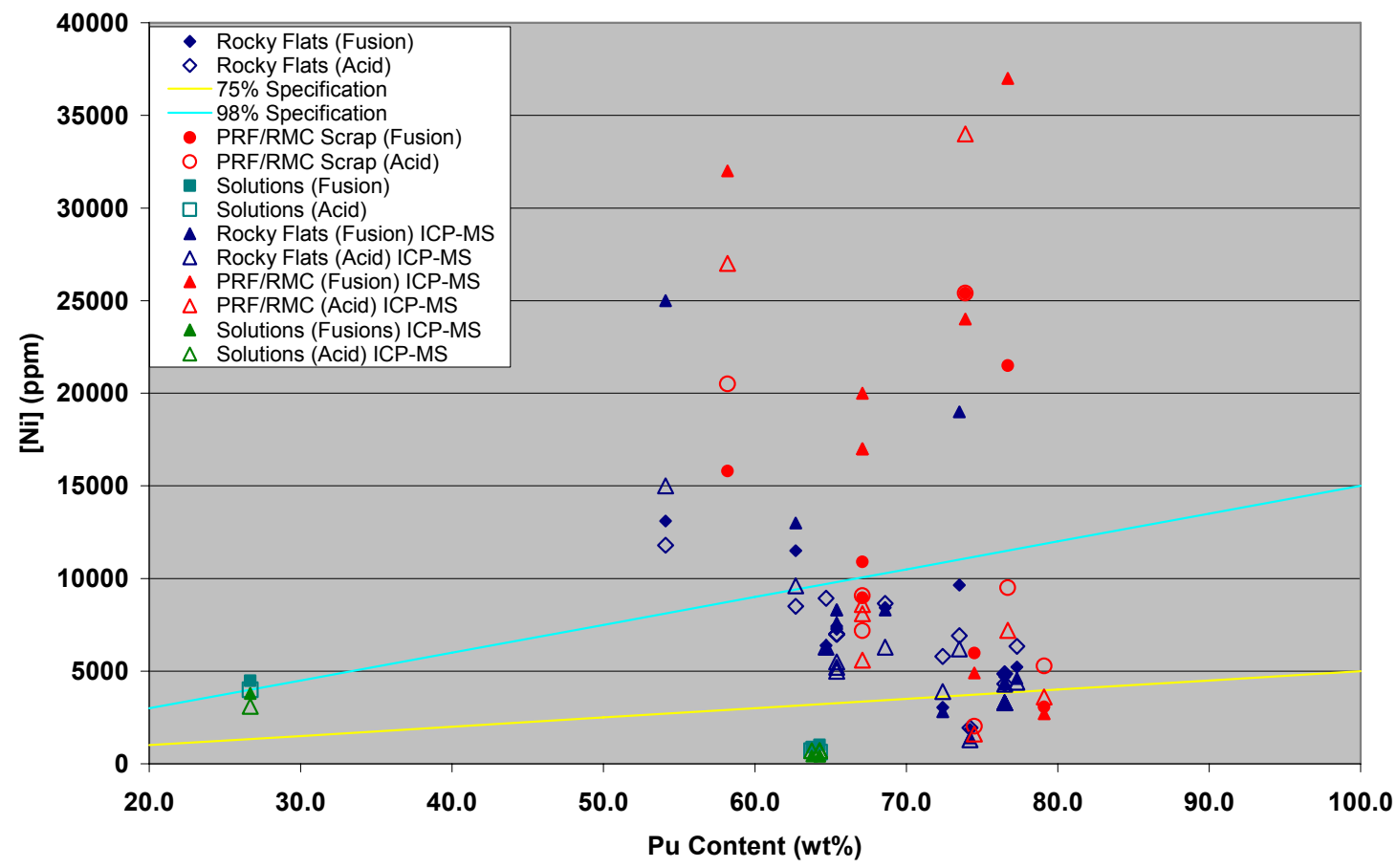

Figure 7.3. Nickel Concentration as a Function of Plutonium Content. Concentrations are reported in $\mu \mathrm{g} / \mathrm{g}$ of sample. 


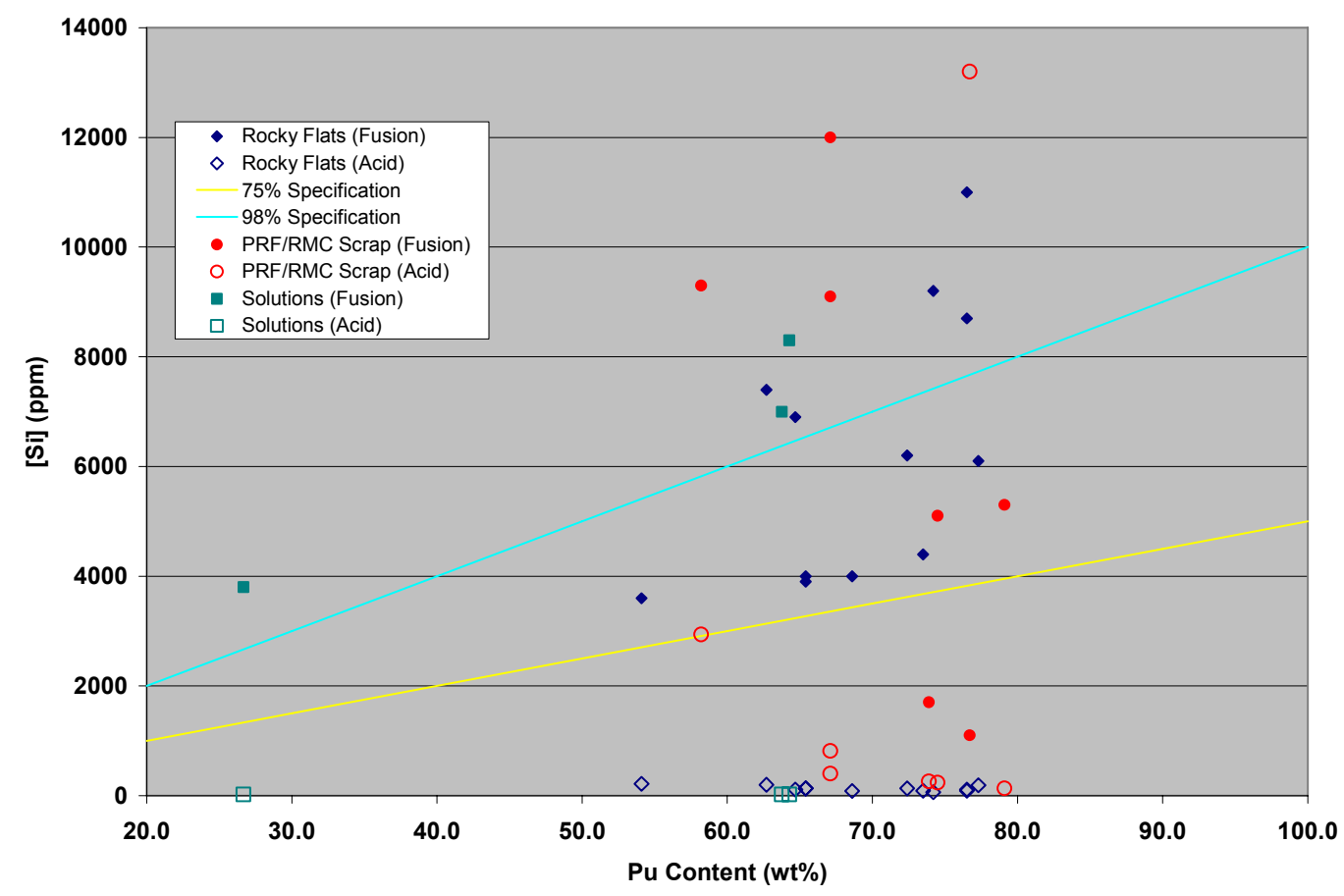

Figure 7.4. Silicon Concentration as a Function of Plutonium Content. Concentrations are reported in $\mu \mathrm{g} / \mathrm{g}$ of sample; data are from ICP-AES measurements only.

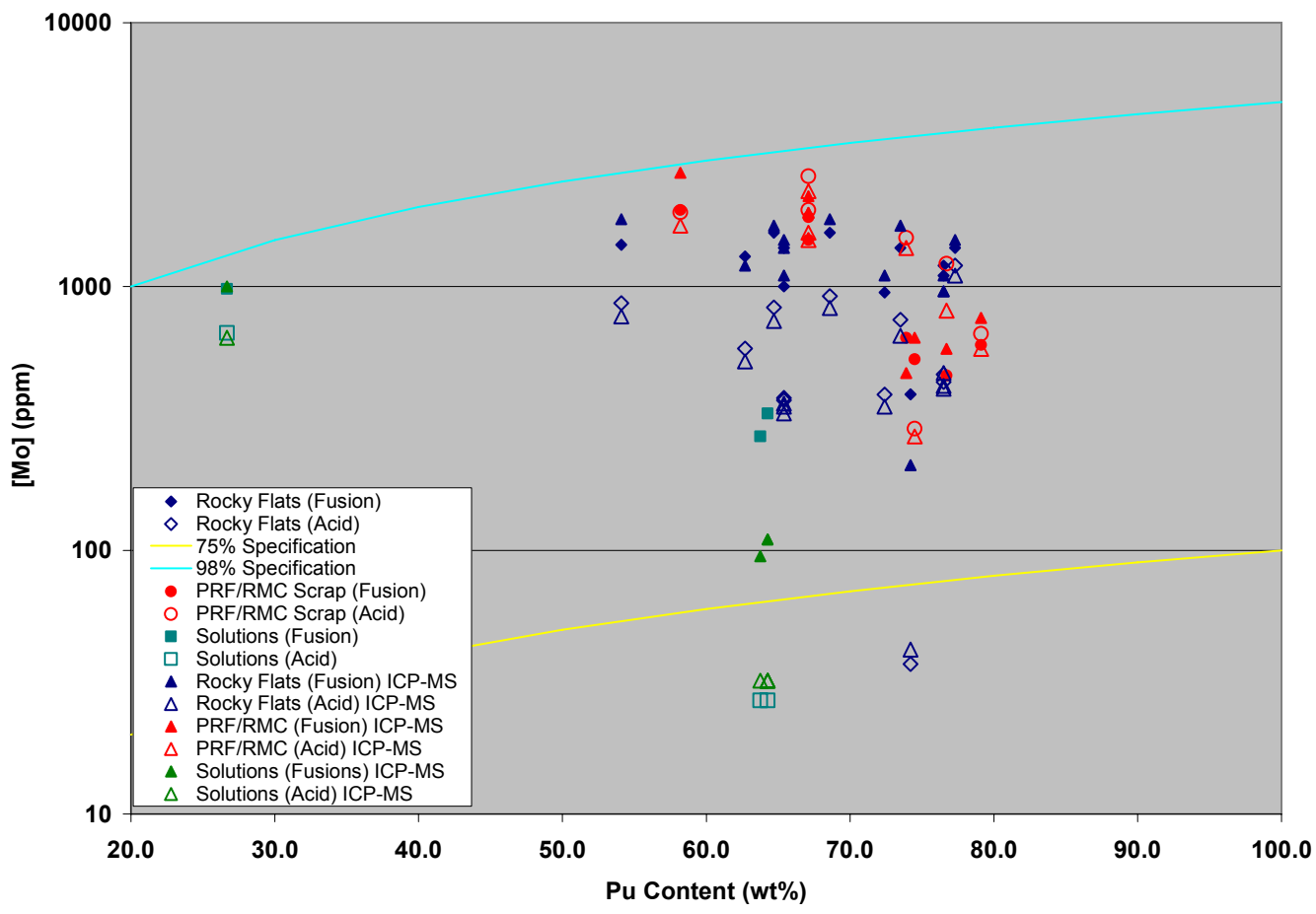

Figure 7.5. Molybdenum Concentration as a Function of Plutonium Content. Concentrations are reported in $\mu \mathrm{g} / \mathrm{g}$ of sample and are plotted on a log scale. 


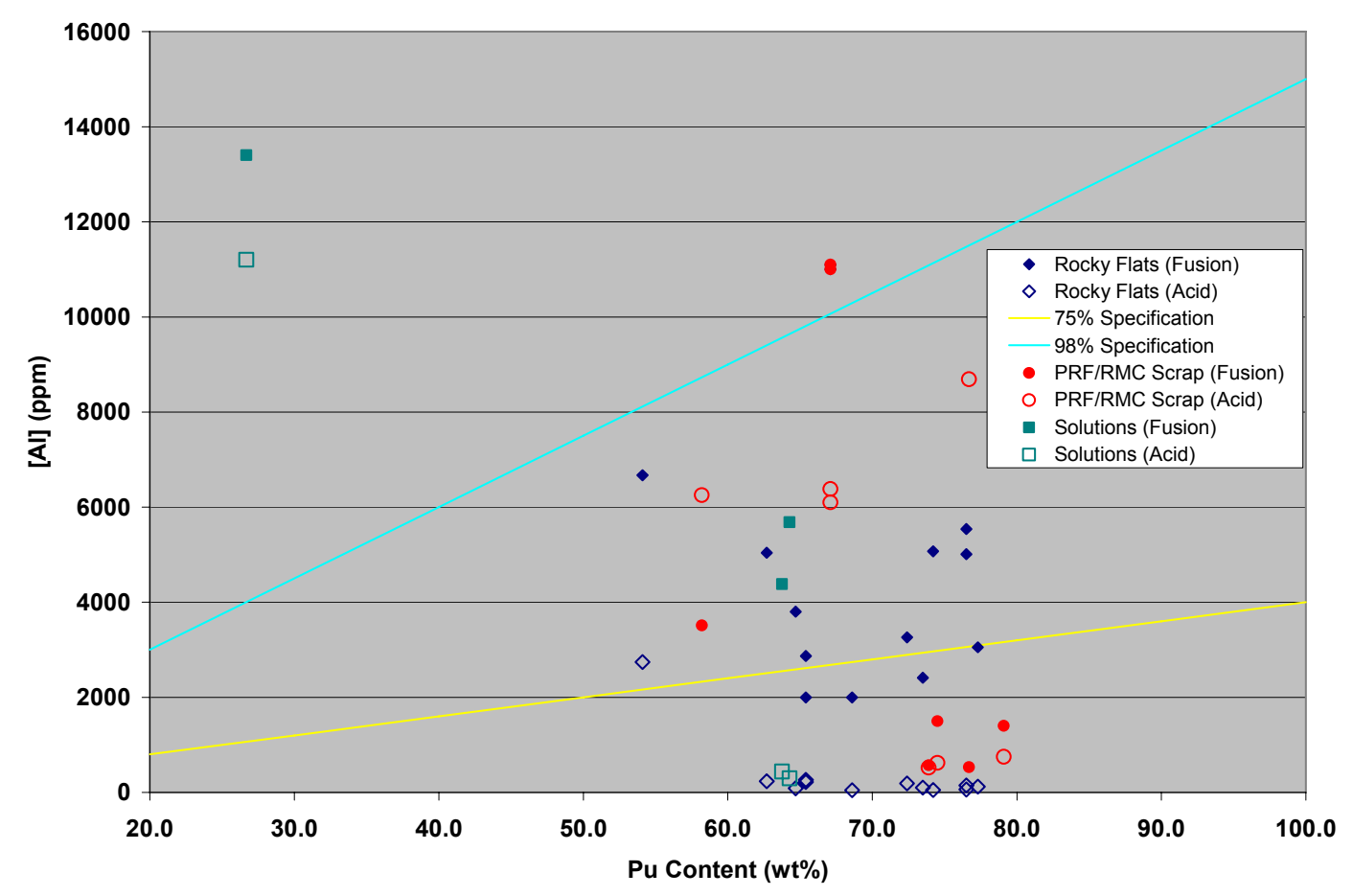

Figure 7.6. Aluminum Concentration as a Function of Plutonium Content. Concentrations are reported in $\mu \mathrm{g} / \mathrm{g}$ of sample; data are from ICP-AES measurements only.

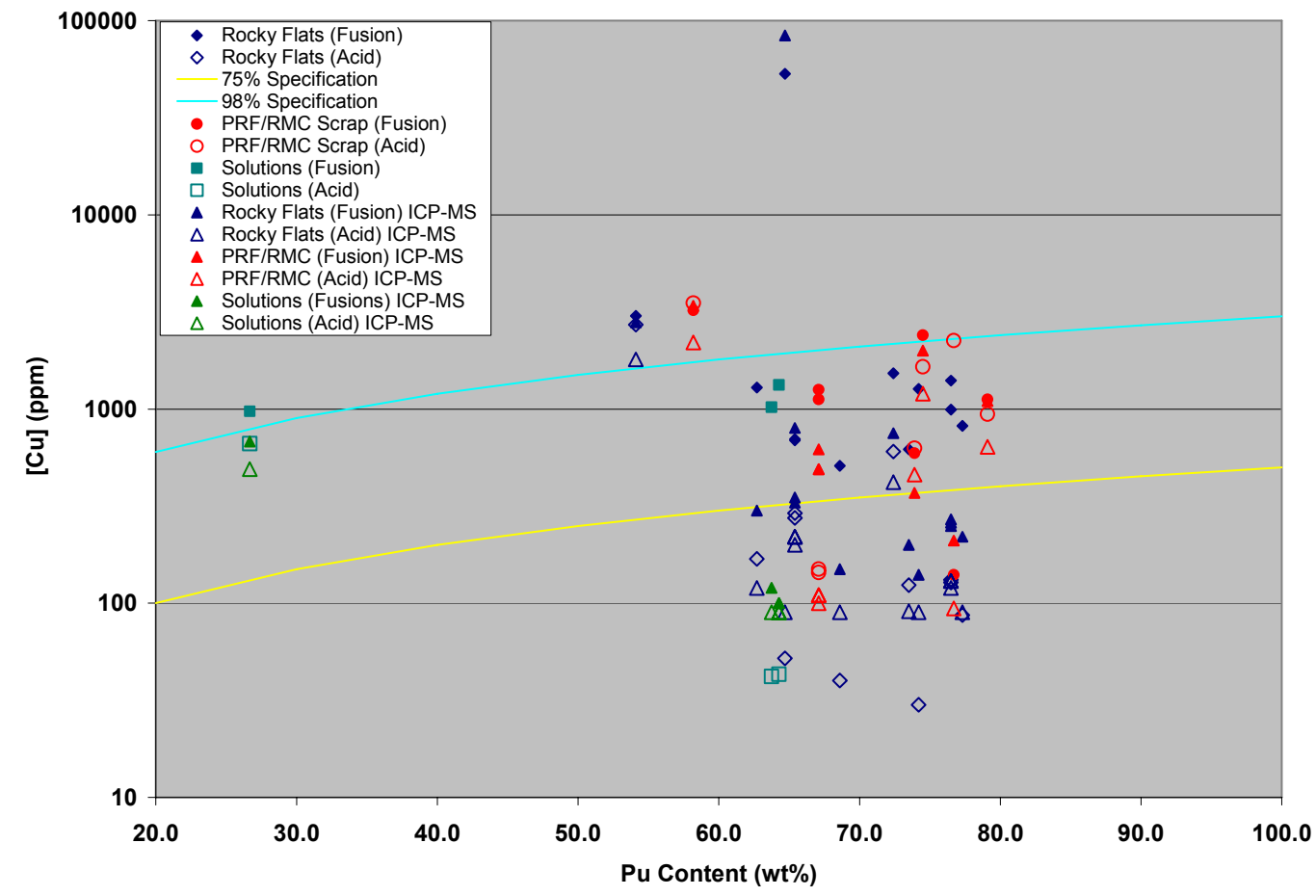

Figure 7.7. Copper Concentration as a Function of Plutonium Content. Concentrations are reported in $\mu \mathrm{g} / \mathrm{g}$ of sample and plotted on a log scale. 
Silicon was observed in all of the samples, but the measured values from the fusion were all less than the quantitation level for the measurement system. The acid-soluble silicon is well below the specification limits with the exception of one PRF/RMC scrap sample. The data from the fusion and acid fractions indicate that the majority of the silicon will be insoluble in nitric acid. Molybdenum concentrations in all but three of the samples are also below the quantitation levels for ICP-AES on the fusion fractions, but the data from ICP-AES on the acid fraction and the ICP-MS data are comparable and well above the quantitation level.

Several of the fusion samples also exceeded the boron specifications for 75 percent of the items. ICPAES data indicate that many of the samples may have exceeded the limits for thorium, but these values are probably due to an incomplete subtraction of the plutonium spectral lines that interfere with the thorium spectral lines. The ICP-MS data indicates that the thorium concentrations in these samples are well below the MOX specification.

Magnesium was observed at levels above the specification on the solution samples. This is expected because these samples were produced by a $\mathrm{Mg}(\mathrm{OH})_{2}$ precipitation process. The solution samples that were processed using an oxalate precipitation process will likely meet this specification.

\subsection{Prompt Gamma Analysis Compared to Destructive Analyses}

Items at PFP were screened by prompt gamma analysis (PGA) to measure sodium and chlorine concentrations. The ratio of these elements, measured by PGA, was used to identify items that had originated in an electrorefining (ER) process at RFETS and thus were candidates for lower-temperature $\left(750^{\circ} \mathrm{C}\right)$ thermal stabilization. The properties of the ER material had been evaluated and determined to achieve technical equivalency with the goals of the DOE 3013 storage standard when thermally stabilized at $750^{\circ} \mathrm{C}$, a temperature lower than the $950^{\circ} \mathrm{C}$ normally required by the DOE 3013 storage standard (Boak et al. 2003).

For most of the 3013 containers, two input items were combined into one storage item. Using the net weights and chlorine measured by PGA on input items, an estimate of the expected chlorine in the combined item was calculated. Chloride concentrations were measured on a subsample of the final 3013 items, constituted from the same pairs of input items used to estimate the expected chlorine concentration, by dissolving the salts in a water leach and analyzing for chloride ion by IC. The chloride value obtained by destructive analysis (IC) is compared to the prompt gamma analysis of the input items in Table 7.3, and the IC measurements are plotted as a function of the prompt gamma results in Figure 7.8. A line with unit slope and zero intercept is drawn to show the theoretical value for perfect agreement between the PGA and destructive analysis methods. These data show that the PGA results obtained by PFP credibly estimated the chlorine concentration for these types of material. Using PGA, the chlorine content of these items was underreported by an average of 12 percent.

Similar results were obtained when the destructive analysis for the total fluoride, as obtained from the fusion digests, was compared with the prompt gamma measurements. A linear curve fit with an intercept at zero was obtained for a plot of the fluoride concentration as a function of the normalized count rate for the $1274 \mathrm{keV}$ peak from the prompt gamma measurements (Figure 7.9). The results from sample B-5472 are not included because the ISE measurement is clearly biased as described in Section 7.1. 
Table 7.3. Chloride Analysis from PGA of Feed Items and IC of Product Wash Sample

\begin{tabular}{|c|c|c|c|c|c|c|c|}
\hline \multirow{3}{*}{$\begin{array}{l}\text { Sample } \\
\text { ID }\end{array}$} & \multirow{3}{*}{ Input Items } & \multirow{3}{*}{$\begin{array}{c}\mathbf{P u} \\
(\mathrm{wt} \%)\end{array}$} & \multicolumn{3}{|c|}{$\mathrm{Cl}^{-}\left(w \mathrm{wt}^{\circ} \%\right)$} & \multirow{3}{*}{ PGA/IC } & \multirow{3}{*}{ Material Type } \\
\hline & & & \multicolumn{2}{|c|}{ Prompt Gamma } & \multirow{2}{*}{ IC Analyzed } & & \\
\hline & & & Items & Averaged & & & \\
\hline \multirow{2}{*}{ B-5526 } & ARF-102-85-972 & \multirow{2}{*}{76.46} & 8.09 & \multirow{2}{*}{4.97} & \multirow{2}{*}{4.49} & \multirow{2}{*}{1.11} & \multirow{2}{*}{$\begin{array}{c}\text { Low-Chloride } \\
\text { Rocky Flats }\end{array}$} \\
\hline & ARF-102-85-730 & & 1.85 & & & & \\
\hline \multirow{2}{*}{ B-5680 } & ARF-102-86-192 & \multirow{2}{*}{74.24} & 4.99 & \multirow{2}{*}{4.86} & \multirow{2}{*}{5.40} & \multirow{2}{*}{0.90} & \multirow{2}{*}{$\begin{array}{c}\text { Low-Chloride } \\
\text { Rocky Flats }\end{array}$} \\
\hline & ARF-102-85-469 & & 4.72 & & & & \\
\hline \multirow{2}{*}{ B-5534 } & ARF-102-86-150 & \multirow{2}{*}{77.29} & 0.46 & \multirow{2}{*}{1.09} & \multirow{2}{*}{1.63} & \multirow{2}{*}{0.66} & \multirow{2}{*}{$\begin{array}{c}\text { Low-Chloride } \\
\text { Rocky Flats }\end{array}$} \\
\hline & ARF-102-85-665 & & 1.71 & & & & \\
\hline \multirow{2}{*}{ B-5497 } & ARF-102-86-416 & \multirow{2}{*}{54.07} & 5.42 & \multirow{2}{*}{5.81} & \multirow{2}{*}{8.58} & \multirow{2}{*}{0.68} & \multirow{2}{*}{$\begin{array}{c}\text { High-Chloride } \\
\text { Rocky Flats }\end{array}$} \\
\hline & ARF-102-85-181 & & 6.19 & & & & \\
\hline \multirow{2}{*}{ B-5524 } & ARF-102-85-719 & \multirow{2}{*}{72.36} & 6.54 & 5.40 & 769 & 070 & High-Chloride \\
\hline & ARF-102-85-731 & & 4.25 & 3.40 & 1.09 & 0.10 & Rocky Flats \\
\hline B-5439 & ARF-102-85-980 & 6466 & 11.70 & 922 & 6 & 082 & High-Chloride \\
\hline D-J459 & ARF-102-85-486 & 04.00 & 6.73 & & & & Rocky Flats \\
\hline & ARF-102-85-713 & & 6.73 & 66 & 79 & 08 & High-Chloride \\
\hline (32 & ARF-102-85-721 & 00.05 & 6.46 & 0.00 & 1.91 & 0.05 & Rocky Flats \\
\hline B-5495 & ARF-102-86-393 & 6274 & 12.80 & 1135 & 1202 & 094 & High-Chloride \\
\hline D-5495 & ARF-102-85-385 & 02.14 & 9.89 & 11.35 & 12.02 & 0.94 & Rocky Flats \\
\hline B- & ARF-102-86-376 & 6538 & 12.00 & & & & High-Chloride \\
\hline $\mathrm{D}^{-}$ & ARF-102-86-496 & 05.50 & 8.34 & 10.17 & 10.24 & 0.9 & Rocky Flats \\
\hline B-570 & PPSL-518 & & 9.27 & & & 1.17 & High-Chloride \\
\hline & ARF-102-86-116 & 15.0 & 3.15 & 0 & J & & Rocky Flats \\
\hline
\end{tabular}

Sodium was measured by PGA on the feed items and acid leach samples from the stabilized material that went into the 3013 containers. In Figure 7.10 the weight-averaged PGA data are compared with the acid leach ICP results. While there is more scatter in the results than in the chlorine analyses by IC, there is still a slope near 1 for this comparison with a method bias reporting values that are 45 percent low. The assumptions used to assign a sodium value to items measured by PGA may need adjustments. 


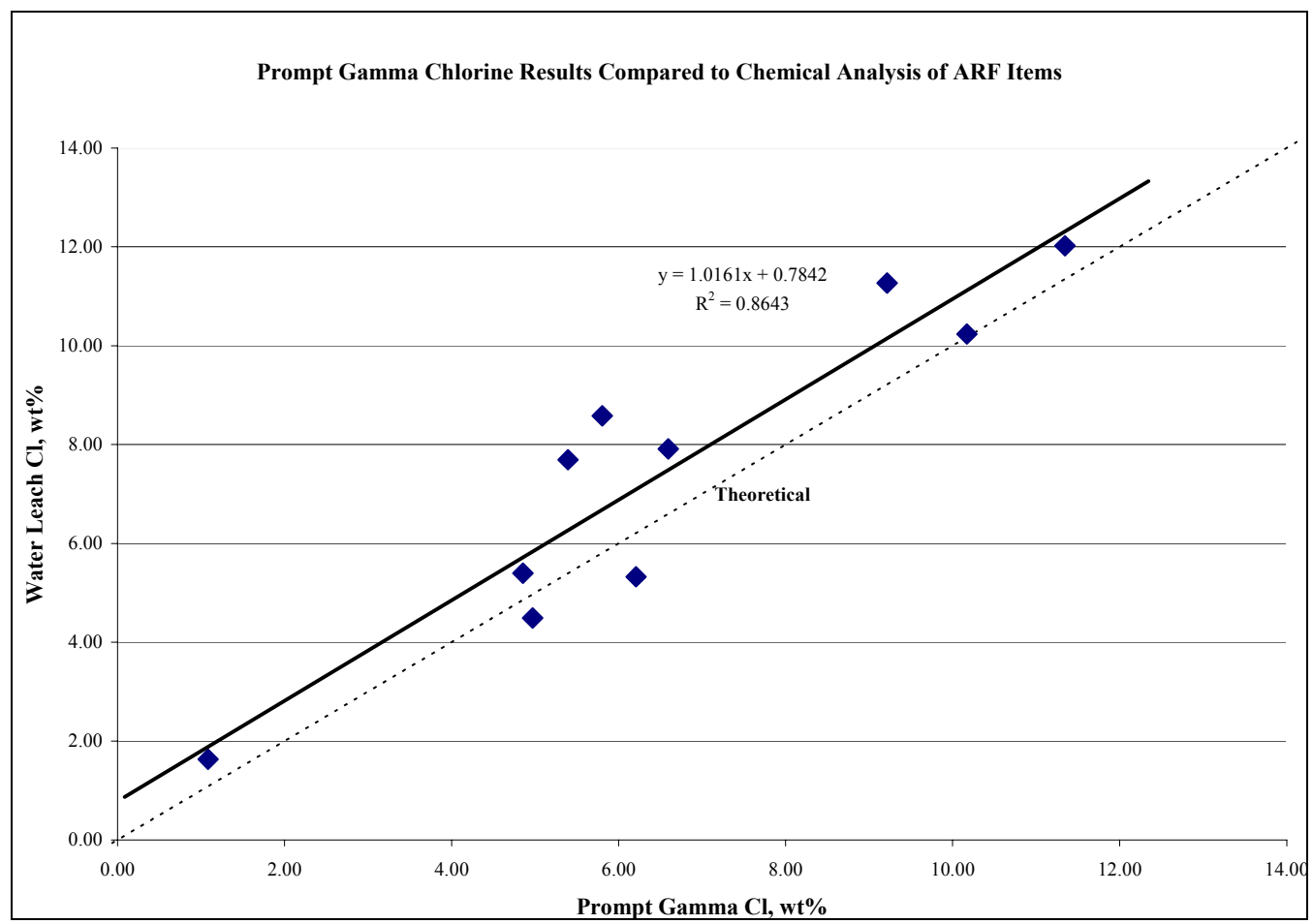

Figure 7.8. Chlorine Measured by PGA in wt $\%$ on Feed Items to 3013 Container Compared with Stabilized Product Sample Measured in Water Leachates

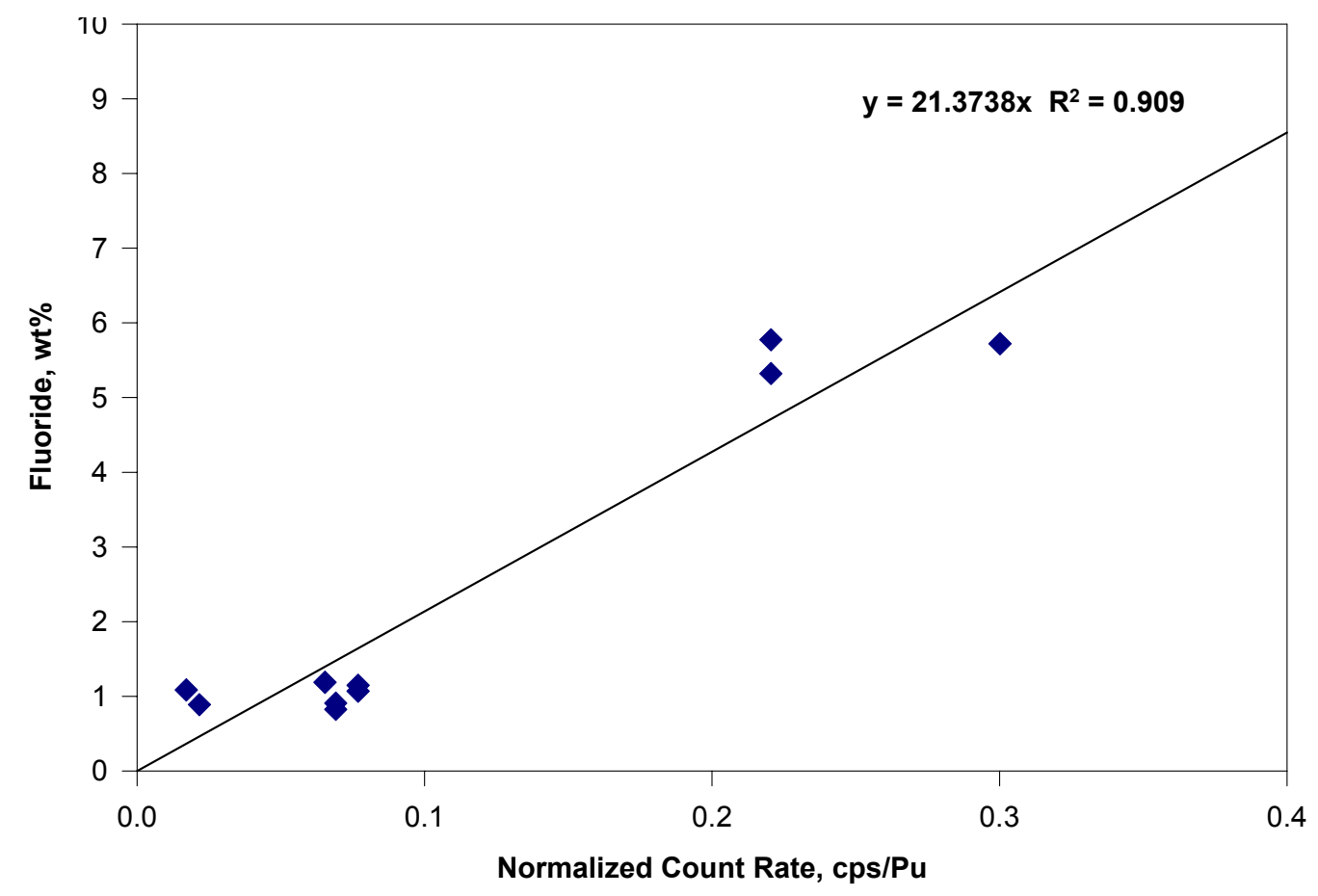

Figure 7.9. Normalized Count Rate for $1274 \mathrm{keV}$ Peak from Prompt Gamma Measurements on Feed Items to 3013 Container Compared with Fluoride Concentration Measured by ISE on the Fusion Digest of the Stabilized Product Sample 


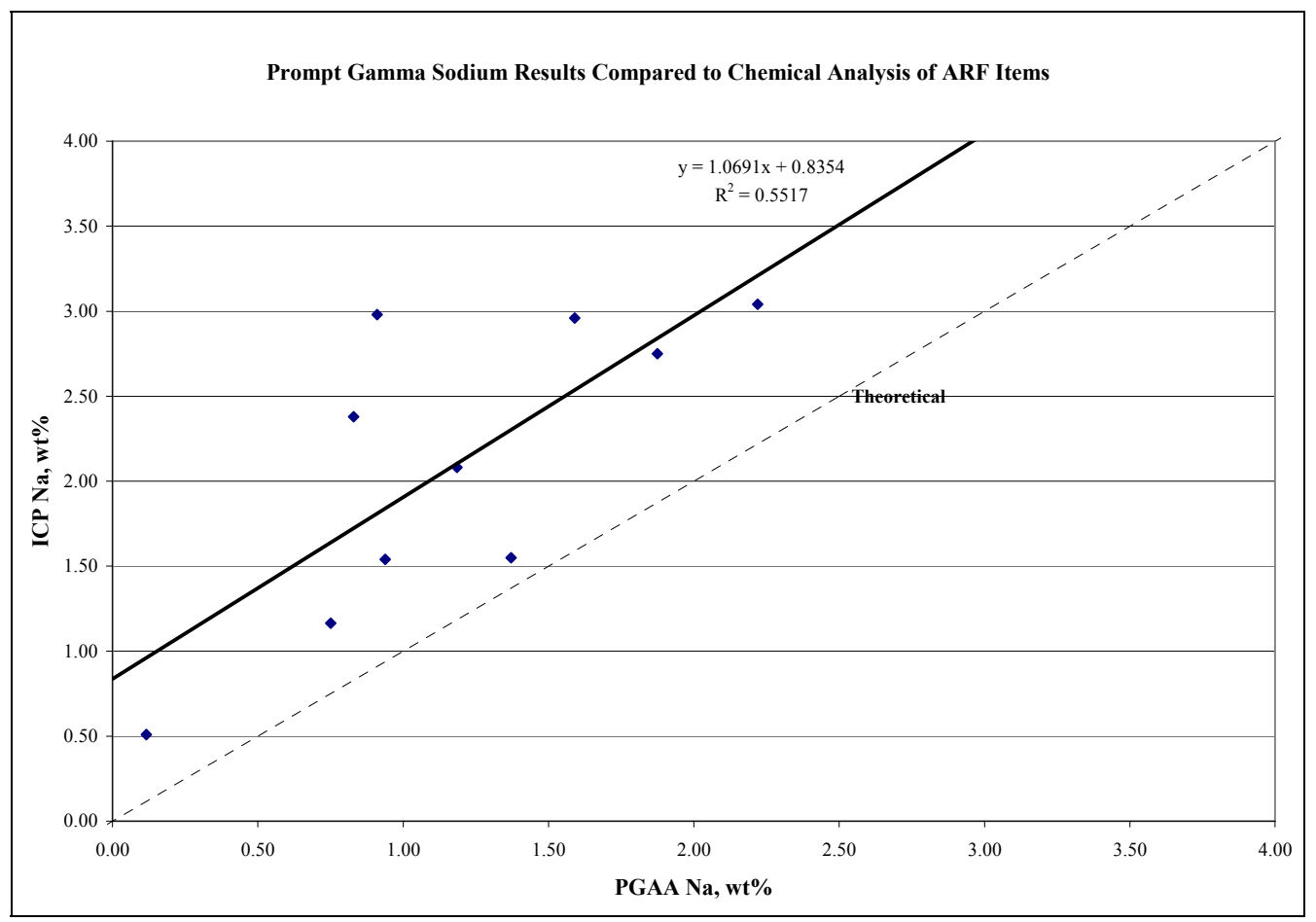

Figure 7.10. Sodium Measured by PGA in wt $\%$ on Feed Items to 3013 Container Compared with Stabilized Product Sample in Acid Leachates

\subsection{Moisture Measurement}

Samples were analyzed at PFP to qualify the material for packaging in DOE 3013 containers. The specification requires material to contain less than 0.5 percent moisture. Material was heated to $1000^{\circ} \mathrm{C}$ in a TGA. Total weight loss of all samples was less than 0.5 percent. Other volatile species may be evolved. Using a TGA equipped with a MS detection would give additional information on the identity of these volatile species. Table 7.4 lists results of the moisture analysis.

Figure 7.11 is a typical TGA scan for the chloride-containing material. An initial weight loss due to moisture is observed. Above $800^{\circ} \mathrm{C}$ there is a rapid weight loss that continues until the end of the analysis; this is loss of chloride salts. It is seen that nearly half of the weight loss occurs above $800^{\circ} \mathrm{C}$. 
Table 7.4. PFP Moisture Analysis Results

\begin{tabular}{|c|c|}
\hline Sample ID & TGA, \% Weight Loss \\
\hline \multicolumn{2}{|c|}{ Rocky Flats Oxide (low chloride) } \\
\hline B-5526 & 0.23 \\
\hline B-5534 & 0.121 \\
\hline B-5680 & 0.134 \\
\hline Rocky Flats Oxide (high chloride) \\
\hline B-5439 & 0.195 \\
\hline B-5495 & 0.196 \\
\hline B-5497 & 0.362 \\
\hline B-5524 & 0.18 \\
\hline B-5532 & 0.153 \\
\hline B-5701 & 0.178 \\
\hline B-5703 & 0.301 \\
\hline & PRF/RMC Scrap \\
\hline B-5456 & 0.058 \\
\hline B-5457 & 0.105 \\
\hline B-5470 & 0.052 \\
\hline B-5471 & 0.221 \\
\hline B-5472 & 0.269 \\
\hline B-5501 & 0.099 \\
\hline \hline
\end{tabular}

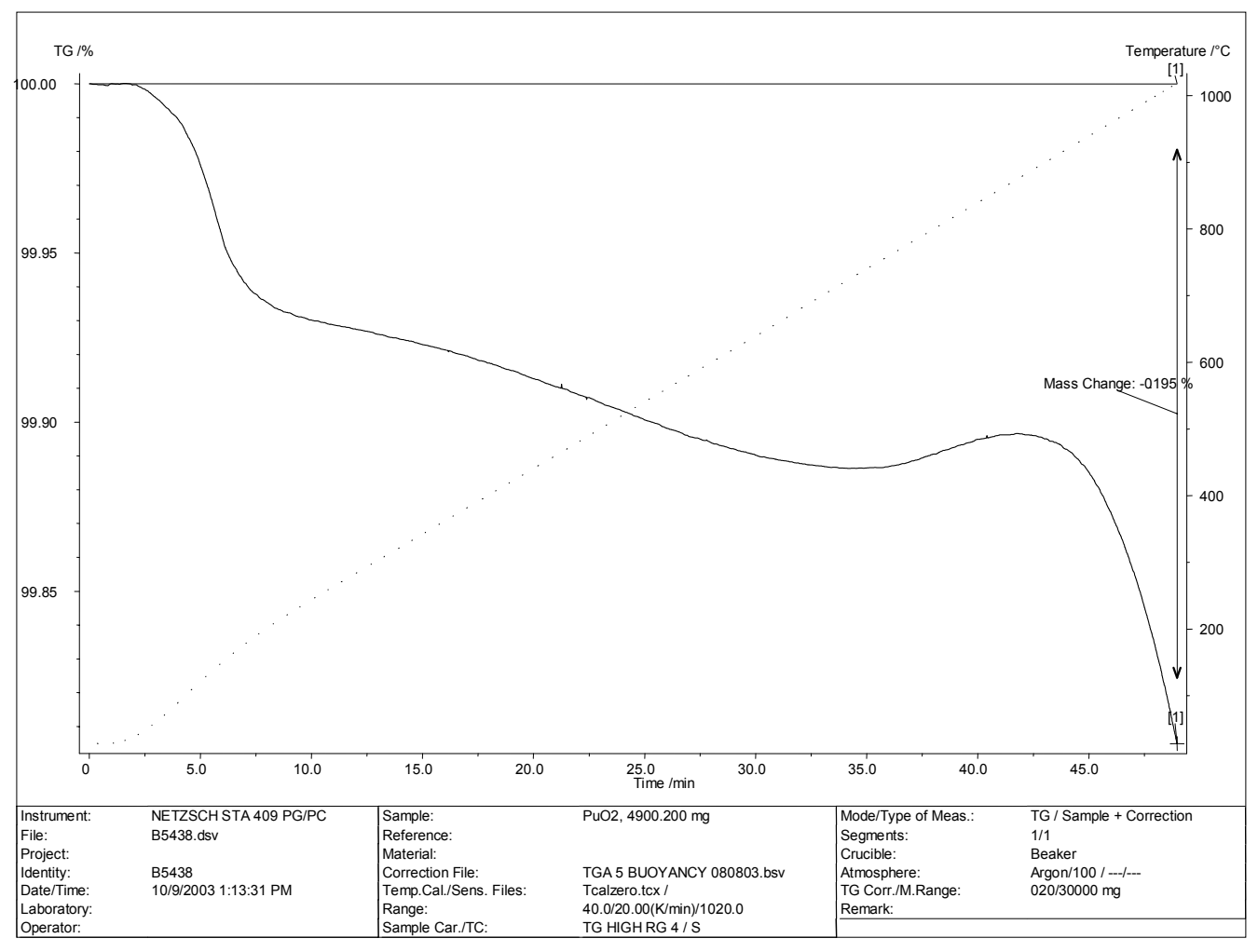

Figure 7.11. TGA Scan of Rocky Flats Chloride Sample Corresponding to Sample B-5439 


\subsection{Summary}

Major constituents (greater than $0.1 \mathrm{wt} \%$ ) found by analyses of the impure Hanford PFP oxides are listed in Tables 8.1 and 8.2. Sodium, potassium, and calcium were assumed to be chloride salts as long as sufficient chloride was available. Any excess of these metals above that satisfied by the available chloride was assumed to form the corresponding oxide. Similarly, all fluoride was assumed to be present as insoluble plutonium fluoride. The remainder of the plutonium beyond that present as $\mathrm{PuF}_{4}$ was assumed to be present as $\mathrm{PuO}_{2}$. It was assumed that all other metals were present as their respective oxide. Plutonium oxide and fluoride accounted for over 60 percent of the material composition for all items except R-418. Mass balances for these analyses ranged from 92 to 108 percent.

Concentrations of the metals were based on the most reliable data available. When more than one of the four methods (acid leach or fusion preparation followed by analysis by ICP-AES or ICP-MS) provided reliable results, the measured concentrations were averaged. Several analytes were only measured by a single method (ICP-AES or ICP-MS); therefore, the summary is based on those results. Many of the analytes were not soluble in the acid leach as identified by increases in the measured concentrations in the fusion digest compared to those reported in the acid leach. In such cases, only the data obtained from the fusion was incorporated in this summary. Concentrations of Rh, Sn, and Th as measured by ICP-AES appeared to be biased high due to interference from plutonium; therefore, ICP-MS data were used for these analytes. 
Table 8.1. Major Constituents of the Impure Rocky Flats Oxides Expressed as wt $\%$ of Total

\begin{tabular}{|c|c|c|c|c|c|c|c|c|c|c|}
\hline \multirow{2}{*}{$\begin{array}{c}\text { Chemical } \\
\text { Form }\end{array}$} & \multicolumn{7}{|c|}{ "High-Chloride Rocky Flats } & \multicolumn{3}{|c|}{ Low-Chloride Rocky Flats } \\
\hline & B-5439 & B-5495 & B-5497 & B-5524 & B-5532 & B-5701 & B-5703 & B-5526 & B-5534 & B-5680 \\
\hline $\mathrm{Al}_{2} \mathrm{O}_{3}$ & 0.7 & 1.0 & 1.3 & 0.6 & 0.4 & 0.5 & 0.5 & 1.0 & 0.6 & 1.0 \\
\hline $\mathrm{CrO}_{3}$ & 0.6 & 2.4 & 2.7 & 0.9 & 2.3 & 2.1 & 2.0 & 0.6 & 1.7 & 0.1 \\
\hline $\mathrm{CuO}$ & 8.6 & 0.1 & 0.4 & 0.1 & 0.0 & 0.1 & 0.1 & 0.1 & 0.1 & 0.1 \\
\hline $\mathrm{Fe}_{2} \mathrm{O}_{3}$ & 0.5 & 1.0 & 2.7 & 0.9 & 1.1 & 1.1 & 1.1 & 0.5 & 2.8 & 0.3 \\
\hline $\mathrm{Ga}_{2} \mathrm{O}_{3}$ & 0.4 & 0.0 & 0.3 & 0.9 & 1.7 & 4.4 & 2.2 & 0.3 & 0.2 & 1.3 \\
\hline $\mathrm{MgO}$ & 2.3 & 2.4 & 1.4 & 1.6 & 1.2 & 1.0 & 1.7 & 2.0 & 0.7 & 1.3 \\
\hline $\mathrm{MoO}_{3}$ & 0.2 & 0.2 & 0.2 & 0.2 & 0.3 & 0.2 & 0.2 & 0.2 & 0.2 & 0.0 \\
\hline $\mathrm{NaCl}$ & 7.6 & 7.7 & 6.1 & 7.5 & 5.3 & 3.9 & 7.0 & 3.0 & 1.3 & 3.9 \\
\hline $\mathrm{Ni}_{2} \mathrm{O}_{3}$ & 1.0 & 1.5 & 2.3 & 0.5 & 1.1 & 1.5 & 1.0 & 0.6 & 0.7 & 0.2 \\
\hline $\mathrm{SnO}_{2}$ & 0.0 & 0.0 & 0.3 & 0.0 & 0.0 & 0.0 & 0.0 & 0.0 & 0.0 & 0.0 \\
\hline $\mathrm{WO}_{3}$ & 0.3 & 0.5 & 0.5 & 1.1 & 0.4 & 0.3 & 0.4 & 0.1 & 0.1 & 0.0 \\
\hline $\mathrm{ZnO}$ & 0.0 & 0.0 & 0.2 & 0.0 & 0.1 & 0.0 & 0.0 & 0.1 & 0.0 & 0.0 \\
\hline $\mathrm{Cl}^{-}$ & 2.2 & 2.2 & 1.3 & 0.7 & 1.7 & 0.0 & 2.3 & 0.4 & 0.0 & 0.0 \\
\hline $\mathrm{PuF}_{4}$ & 2.1 & 4.5 & 9.9 & 3.7 & 1.7 & 2.9 & 3.6 & 4.6 & 7.0 & 1.8 \\
\hline $\mathrm{PuO}_{2}$ & 71.6 & 67.2 & 52.8 & 78.9 & 76.3 & 80.8 & 71.1 & 82.8 & 81.6 & 82.6 \\
\hline $\mathrm{H}_{2} \mathrm{O}$ & 0.2 & 0.2 & 0.4 & 0.2 & 0.2 & 0.2 & 0.3 & 0.2 & 0.1 & 0.1 \\
\hline Total & 107.7 & 102.0 & 97.3 & 103.7 & 99.7 & 105.9 & 100.3 & 103.0 & 100.5 & 101.2 \\
\hline
\end{tabular}


Table 8.2. Major Constituents of the Impure Plutonium Oxides from Scrap and Solutions Expressed as $\mathrm{wt} \%$ of Total

\begin{tabular}{|c|c|c|c|c|c|c|c|c|}
\hline \multirow[b]{2}{*}{ Chemical Form } & \multicolumn{6}{|c|}{ "PRF/RMC Scrap } & \multicolumn{2}{|c|}{ Solutions } \\
\hline & B-5456 & B-5457 & B-5470 & B-5471 & B-5472 & B-5501 & R-418 & R-419 \\
\hline $\mathrm{Al}_{2} \mathrm{O}_{3}$ & 2.1 & 0.3 & 0.1 & 0.3 & 0.1 & 0.7 & 2.5 & 1.0 \\
\hline $\mathrm{CaO}$ & 0.5 & 0.0 & 1.2 & 1.4 & 0.2 & 0.2 & 0.4 & 0.2 \\
\hline $\mathrm{CrO}_{3}$ & 4.2 & 0.5 & 3.1 & 1.4 & 4.3 & 3.0 & 1.5 & 0.1 \\
\hline $\mathrm{CuO}$ & 0.1 & 0.1 & 0.1 & 0.3 & 0.0 & 0.4 & 0.1 & 0.1 \\
\hline $\mathrm{Fe}_{2} \mathrm{O}_{3}$ & 6.6 & 4.5 & 4.2 & 6.8 & 2.3 & 5.6 & 5.1 & 0.6 \\
\hline $\mathrm{K}_{2} \mathrm{O}$ & 0.2 & 0.0 & 0.0 & 0.0 & 0.0 & 0.0 & 0.0 & 0.0 \\
\hline $\mathrm{MgO}$ & 2.3 & 0.2 & 0.3 & 0.2 & 1.4 & 3.3 & 46.1 & 22.3 \\
\hline $\mathrm{MnO}_{2}$ & 0.2 & 0.1 & 0.1 & 0.1 & 0.1 & 0.1 & 0.8 & 0.0 \\
\hline $\mathrm{MoO}_{3}$ & 0.3 & 0.1 & 0.1 & 0.1 & 0.1 & 0.3 & 0.1 & 0.0 \\
\hline $\mathrm{Na}_{2} \mathrm{O}$ & 0.8 & 0.1 & 0.1 & 0.2 & 0.1 & 0.8 & 1.0 & 0.0 \\
\hline $\mathrm{Ni}_{2} \mathrm{O}_{3}$ & 1.5 & 0.5 & 3.8 & 0.5 & 2.6 & 3.4 & 0.5 & 0.1 \\
\hline $\mathrm{P}_{2} \mathrm{O}_{5}$ & 0.6 & 0.0 & 0.1 & 0.1 & 0.5 & 0.2 & 0.6 & 0.2 \\
\hline $\mathrm{SiO}_{2}$ & 2.3 & 1.1 & 0.4 & 1.1 & 0.2 & 2.0 & 0.8 & 1.6 \\
\hline $\mathrm{TiO}_{2}$ & $\begin{array}{l}0.1 \\
\end{array}$ & 0.1 & 0.1 & 0.1 & 0.1 & $\begin{array}{l}0.1 \\
\end{array}$ & 0.1 & 0.1 \\
\hline $\mathrm{WO}_{3}$ & 0.5 & 0.0 & 0.0 & 0.1 & 0.0 & 0.2 & 0.0 & 0.0 \\
\hline $\mathrm{ZnO}$ & 0.1 & 0.2 & 0.1 & 0.2 & 0.0 & 0.2 & 0.2 & 0.0 \\
\hline $\mathrm{PuF}_{4}$ & 23.0 & 2.3 & 23.7 & 4.9 & (a) & 42.5 & 10.8 & 1.5 \\
\hline $\mathrm{PuO}_{2}$ & 56.3 & 87.7 & 63.4 & 80.2 & 87.0 & 29.4 & 20.9 & 71.3 \\
\hline $\mathrm{H}_{2} \mathrm{O}$ & 0.1 & 0.1 & 0.1 & 0.2 & 0.3 & 0.1 & (b) & (b) \\
\hline Total & 101.9 & 98.0 & 100.9 & 98.4 & 99.4 & 92.7 & 91.7 & 99.4 \\
\hline
\end{tabular}

(a) Fluoride analysis for this sample was biased high; therefore, no reliable fluoride value was available. Based on the prompt gamma results, a significant fraction of the $\mathrm{Pu}$ is present as $\mathrm{PuF}_{4}$.

(b) Moisture analysis was not performed on this sample. 


\subsection{Conclusions and Recommendations}

The plutonium concentration in the samples ranged from 26.7 to $77.2 \mathrm{wt} \%$. The double-pass filtrate material precipitated by the $\mathrm{Mg}(\mathrm{OH})_{2}$ process exhibited the lowest plutonium concentration. The $\mathrm{Mg}(\mathrm{OH})_{2}$ precipitation process generally yielded products with low plutonium concentrations, and of the solutions processed by this method, the double-pass filtrates generally contained the highest concentrations of impurities. All of the other plutonium oxide samples contained greater than $52 \mathrm{wt} \%$ plutonium. All four categories of plutonium scrap had material with less than $63 \mathrm{wt} \%$ plutonium and varied over a wide range of plutonium concentrations.

The plutonium isotopic compositions of these materials are fairly consistent, with 94.1 atom $\%{ }^{239} \mathrm{Pu}$ on average with a relative standard deviation of 0.7 percent. The greatest isotopic variation within an individual category of material was observed in the PRF/RMC scrap plutonium oxide samples. The ${ }^{238} \mathrm{Pu}$ ratio calculated from the AEA results varied significantly more than the ${ }^{239} \mathrm{Pu}$ and ${ }^{240} \mathrm{Pu}$ ratios. The average ${ }^{238} \mathrm{Pu}$ ratio was 0.014 atom\% with a relative standard deviation of 58 percent. These results are still consistent with weapons-grade plutonium.

Low uranium impurities were observed in these samples. The maximum uranium concentration measured was $0.14 \mathrm{wt} \%$ and is well below the MOX specification limit of 30 net $\mathrm{wt} \%$. The uranium isotopics ranged from 19 to 75 atom $\%{ }^{235} \mathrm{U}$. Uranium isotopic compositions were very dependent upon the category of material. The solution samples contained the lowest ${ }^{235} U$ concentration $(20 \pm 1$ atom\%), and the Rocky Flats oxides had the highest ${ }^{235} \mathrm{U}(72.1 \pm 1$ atom\%). No significant difference was observed between uranium isotopic ratios in the high chloride and low chloride oxides from Rocky Flats. The PRF/RMC scrap plutonium oxides had a wide range of uranium isotopics (33 to 74 atom $\%{ }^{235} \mathrm{U}$ ).

The principal water-soluble anions observed in these samples were chloride, nitrate, and phosphate. Chloride was the only anion observed at significant levels in the Rocky Flats oxides, with concentrations ranging from 1.6 to $12 \mathrm{wt} \%$. The boundary between high chloride and low chloride oxides was about $5 \mathrm{wt} \%$. One of the low chloride samples had a chloride concentration of $5.4 \mathrm{wt} \%$, and one of the high chloride samples had a chloride concentration of $5.3 \mathrm{wt} \%$. Comparison of the chloride concentrations measured by destructive analysis and prompt gamma analysis shows that prompt gamma measurements provide a good indication of the chloride present in the bulk sample. Accurate prompt gamma measurements on the plutonium oxide in the 3013 cans from which these samples were taken would provide a better comparison of these two measurement techniques.

The primary anions observed in the solution samples were nitrate and sulfate. The nitrate concentrations in these samples ranged from 1330 to $1480 \mathrm{ppm}$, and sulfate concentrations up to $4200 \mathrm{ppm}$ were observed. Nitrite was also observed in the solution samples, but the concentrations were fairly low $(<250 \mathrm{ppm})$ compared with the sulfate and nitrate concentrations.

The PRF/RMC scrap contained all of the observed anions (fluoride, chloride, nitrate, nitrite, phosphate, sulfate, and oxalate). The concentrations varied widely among these samples. Fluoride was observed at concentrations as high as $1680 \mathrm{ppm}$, but many of the samples had less than detectable levels of fluoride. Fluoride concentrations were also measured on a $\mathrm{pH}$-adjusted fraction of the caustic fusion to quantify fluoride included in water-insoluble plutonium fluoride present in these samples. These results 
indicate that in some samples, a significant amount of the fluoride was bound with plutonium and is water insoluble. Good correlation between the fluoride peak area in the PGA and the total fluoride concentration measured in the fusion digests by the ion selective electrode was observed. Chloride was also observed in the PRF/RMC samples, but the concentration was less than $300 \mathrm{ppm}$. Both nitrite and nitrate were observed in these samples. Nitrite was only observed in about half of the samples, and where it was observed the concentration was less than $65 \mathrm{ppm}$ and was 3 to 6 percent of the nitrate concentrations. Nitrate was observed in all of the PRF/RMC scrap samples and was the major anion observed at concentrations from 325 to $1200 \mathrm{ppm}$. Sulfate was also observed in all of the samples at measurable concentrations. The highest sulfate concentration measured was $1650 \mathrm{ppm}$, but most of the samples had concentrations less than $650 \mathrm{ppm}$. Phosphate was observed in half of the samples at concentrations less than $760 \mathrm{ppm}$. Oxalate was also observed above the quantitation limit of the system in a single PRF/RMC scrap sample. The oxalate concentration was $28 \mathrm{ppm}$. None of these anions in any of the categories exceeded the MOX specification limits.

The moisture content of these samples was below the MOX specification limit and 3013 criteria, and the highest moisture content was $0.36 \mathrm{wt} \%$ measured at PFP with TGA.

Metals and other elements above the MOX specification limit were observed in each of the samples. The elements of greatest concern were chromium, iron, nickel, silicon, aluminum, boron, molybdenum, and copper. Chromium was observed in all of the samples and exceeded the limit in at least one sample from each category. Twelve out of 18 samples exceeded the limit, and only two samples (a low-chloride Rocky Flats sample and the product nitrate sample) were well below the limit. Similar results were observed for iron. Two additional samples exceeded the MOX specification for iron. Fewer samples exceeded the specification for nickel. Only three samples, all from the PRF/RMC samples, exceeded the specification set for 98 percent of the items, but nine samples exceeded the specification for 75 percent of the items but were below the specification for 98 percent of the items. Neither of the solution samples exceeded this specification, and only one low chloride Rocky Flats sample exceeded the limit. The solution sample exceeded the specification by less than 5 percent.

Silicon was observed in all of the samples, but the measured values were all less than the quantitation level for the measurement system. Two samples, a PRF/RMC scrap sample and a low-chloride Rocky Flats sample, appear to have exceeded the specification for 98 percent of the items. Nine other samples appear to have exceeded the specification for 75 percent of the items but are lower than the specification for 98 percent of the items. Molybdenum concentrations in all but three of the samples are also below the quantitation levels for these measurements, but all of the samples exceeded the specification for 75 percent of the items. None of these samples exceeded the specification of 98 percent of the items. Only one measurement exceeded the quantitation level for manganese, and that sample exceeded the specification for 98 percent of the items. This sample was the double-pass filtrate sample with low plutonium content. Another sample (a PRF/RMC sample) appears to have exceeded the manganese specification for 75 percent of the items.

Several samples also exceeded the aluminum, boron, and copper specifications for 75 percent of the items. Six, nine, and 17 samples exceeded the specification for aluminum, boron, and copper, respectively. Three of the samples exceeded the copper specification for 98 percent of the items. ICPAES data indicate that many of the samples may have exceeded the limits for thorium, but these high thorium values are probably due to an incomplete subtraction of the plutonium spectral lines that interfere 
with the thorium spectral lines. The ICP-MS data indicates that the thorium concentrations in these samples are well below the MOX specification.

Magnesium was observed at levels above the specification on the solution samples. This is expected because these samples were produced by a $\mathrm{Mg}(\mathrm{OH})_{2}$ precipitation process. The solution samples that were processed using an oxalate precipitation process will likely meet this specification. Beryllium was also detected in two samples, but the concentrations were below the MOX specification of $100 \mathrm{ppm}$.

X-ray diffraction of the samples would give further detail on the chemical form of the impurities in these plutonium oxides. This analysis can be performed on existing samples. Accurate prompt gamma analysis of the 3013 cans from which these samples were taken would provide a more accurate determination of the feasibility of using prompt gamma to estimate chloride, sodium, and fluoride concentrations. 


\subsection{References}

Boak J, EA Conrad, CH Delegard, AM Murray, GD Roberson, and TJ Venetz. 2003. Recommendations on Stabilization of Plutonium Material Shipped to Hanford from Rocky Flats. LA-UR-03-3789, Los Alamos National Laboratory, Los Alamos, New Mexico. Available at http://lib-www.lanl.gov/cgibin/getfile?00937076.pdf.

Brossard MP. 2002. Interface Guidelines-Physical and Chemical Properties of $\mathrm{PuO}_{2}$ from Alternate Feedstocks. DCS01 AAJ CG NTE F 06900 B, Duke, Cogema, Stone \& Webster (DCS), Charlotte, NC.

Duke, Cogema, Stone \& Webster (DCS). October 2002. Mixed Oxide Fuel Fabrication Facility Construction Authorization Request. Docket Number 070-03098.

Fazzari DM, SA Jones, and CH Delegard. 2003. Application of Prompt Gamma-Ray Analysis to Identify Electrorefining Salt-Bearing Plutonium Oxide at the Plutonium Finishing Plant. PNNL-14409, Pacific Northwest National Laboratory, Richland, WA.

U.S. Department of Energy (DOE). Stabilization, Packaging, and Storage of Plutonium-Bearing Materials. DOE-STD-3013-2004, Section 6.1.2, U.S. DOE, Washington, D.C.

U.S. Environmental Protection Agency (EPA). Method 200.2, "Sample Preparation Procedure for Spectrochemical Determination of Total Recoverable Elements." EPA/600 4-91/010, US EPA Methods for Determination of Metals in Environmental Samples. EPA, Washington, D.C.

U.S. Nuclear Regulatory Commission (NRC). March 2005. Final Safety Evaluation Report on the Construction Authorization Request for the Mixed Oxide Fuel Fabrication Facility at the Savannah River Site, South Carolina, NUREG-1821, NRC, Washington, D.C. 


\section{Appendix}

\section{ICP-AES and ICP-MS Analyses on Acid Leach and Fusion Fractions}




\section{Appendix}

ICP-AES and ICP-MS Analyses on Acid Leach and Fusion Fractions

Table A.1. Analytes Targeted in ICP-AES Acid Leach Fraction (concentrations reported in $\mu \mathrm{g} / \mathrm{g}$ of sample)

\begin{tabular}{|c|c|c|c|c|c|c|c|c|c|c|c|c|c|c|c|c|c|c|c|c|c|c|}
\hline \multirow[b]{2}{*}{ Analyte } & \multicolumn{8}{|c|}{ High-Chloride Rocky Flats } & \multicolumn{4}{|c|}{ Low-Chloride Rocky Flats } & \multicolumn{7}{|c|}{ PRF/RMC Scrap } & \multicolumn{3}{|c|}{ Solutions } \\
\hline & B-5439 & B-5495 & B-5497 & B-5524 & B-5532 & B-5701 & B-5703 & B-5703-Dup & B-5526 & B-5526-Dup & B-5534 & B-5680 & B-5456 & B-5456-Dup & B-5457 & B-5470 & B-5471 & B-5472 & B-5501 & R-418 & R-419 & R-419-Dup \\
\hline $\mathrm{Al}$ & 87 & 233 & 2740 & 190 & 44 & 100 & 220 & 267 & 150 & 60 & 120 & 51 & 6380 & 6100 & 750 & 518 & 623 & 8690 & 6250 & 11200 & 295 & 436 \\
\hline$B$ & & & 24 & & & & & & & & 48 & & 23 & 26 & & & & 787 & 157 & 243 & 14 & 12 \\
\hline $\mathrm{Ca}$ & & 1060 & 2160 & 310 & & 140 & 62 & 44 & 240 & 230 & 1020 & 250 & 6620 & 8770 & 767 & 2130 & 1030 & 6220 & 19700 & 2970 & 586 & 658 \\
\hline $\mathrm{Ce}$ & & & & & & & & & & & & & & & & & & 836 & 110 & & & \\
\hline $\mathrm{Cr}$ & 891 & 1310 & 2480 & 740 & 748 & 692 & 712 & 785 & 442 & 484 & 729 & 174 & 1690 & 1830 & 535 & 930 & 687 & 235 & 2630 & 3760 & 302 & 296 \\
\hline $\mathrm{Cu}$ & 52 & 169 & 2720 & 605 & 40 & 124 & 275 & 291 & 132 & 128 & 87 & 30 & 144 & 150 & 942 & 629 & 1650 & 2250 & 3520 & 664 & 43 & 42 \\
\hline $\mathrm{Fe}$ & 1420 & 944 & 5680 & 1950 & 1600 & 1420 & 3060 & 3350 & 857 & 1200 & 1540 & 675 & 7890 & 7890 & 13300 & 6020 & 12800 & 3890 & 24500 & 32000 & 2040 & 2120 \\
\hline K & 49400 & 48500 & 41400 & 17400 & 34600 & 25500 & 45400 & 44000 & 19200 & 18000 & 7520 & 25600 & 1900 & 920 & & & & & & & & \\
\hline $\mathrm{La}$ & & & & & & & & & & & & & 7 & 10 & & & & 2180 & 367 & & 7 & 12 \\
\hline $\mathrm{Mg}$ & 10600 & 9140 & 8100 & 5940 & 5840 & 4130 & 8710 & 9530 & 7530 & 6730 & 1700 & 3240 & 9910 & 8230 & 1090 & 2690 & 1260 & 15900 & 24700 & over-range & 129000 & 117000 \\
\hline $\mathrm{Mn}$ & 82 & 55 & 284 & 67 & 100 & 60 & 80 & 83 & 81 & 87 & 75 & 37 & 694 & 617 & 526 & 348 & 408 & 831 & 755 & 5330 & 330 & 270 \\
\hline Mo & 833 & 581 & 865 & 389 & 919 & 748 & 370 & 378 & 435 & 464 & 1200 & 37 & 1950 & 2620 & 661 & 1530 & 289 & 1220 & 1910 & 667 & 27 & 27 \\
\hline $\mathrm{Na}$ & 29800 & 30400 & 23800 & 29600 & 20800 & 15500 & 27900 & 27100 & 12000 & 11300 & 5090 & 15400 & 6260 & 6250 & 480 & 1000 & 1750 & 910 & 5790 & 7590 & 180 & 380 \\
\hline $\mathrm{Ni}$ & 8930 & 8500 & 11800 & 5790 & 8660 & 6910 & 6980 & 7000 & 4310 & 4860 & 6330 & 1940 & 9070 & 7190 & 5280 & 25400 & 2020 & 9510 & 20500 & 3990 & 622 & 698 \\
\hline $\mathrm{Si}$ & 110 & 200 & 214 & 130 & 85 & 86 & 130 & 130 & 110 & 90 & 190 & 60 & 399 & 812 & 130 & 259 & 236 & 13200 & 2940 & & & \\
\hline $\mathrm{Sr}$ & & 5 & 12 & & & & 1 & 1 & & & 3 & 4 & 19 & 24 & 19 & 12 & 8 & 16 & 33 & 6 & 2 & 2 \\
\hline $\mathrm{Y}^{*}$ & & 4 & 18 & 8 & & & 5 & 10 & 2 & & & & & & & & & 163 & 27 & & & \\
\hline $\mathrm{Zn}$ & & & 1680 & 71 & & & & & & & & & 90 & 110 & 1640 & 588 & 1030 & 54 & 1470 & 1960 & & 52 \\
\hline $\mathrm{Zr}$ & & & & & & & & & & & & & 5 & & & & & & & 18 & & \\
\hline
\end{tabular}



Table A.2. Additional Analytes Detected in ICP-AES Acid Leach Fraction (concentrations reported in $\mu \mathrm{g} / \mathrm{g}$ of sample)

\begin{tabular}{|c|c|c|c|c|c|c|c|c|c|c|c|c|c|c|c|c|c|c|c|c|c|c|}
\hline \multirow[b]{2}{*}{ Analyte } & \multicolumn{8}{|c|}{ High Chloride Rocky Flats } & \multicolumn{4}{|c|}{ Low Chloride Rocky Flats } & \multicolumn{7}{|c|}{ PRF/RMC Scrap } & \multicolumn{3}{|c|}{ Solutions } \\
\hline & B-5439 & B-5495 & B-5497 & B-5524 & B-5532 & B-5701 & B-5703 & B-5703-Dup & B-5526 & B-5526-Dup & B-5534 & B-5680 & B-5456 & B-5456-Dup & B-5457 & B-5470 & B-5471 & B-5472 & B-5501 & $\mathrm{R}-418$ & R-419 & R-419-Dup \\
\hline $\mathrm{Ag}$ & & & 40 & & & & & & & & & & 45 & 37 & 86 & 6 & 24 & 334 & 369 & 31 & & \\
\hline As & & & 36 & & & 18 & & & & & & & 22 & & & & & 705 & 150 & 98 & 68 & 56 \\
\hline $\mathrm{Be}$ & 0 & & 19 & 1 & 0 & 3 & 13 & 12 & 1 & 3 & 1 & 6 & 105 & 113 & & 0 & 0 & 18 & 11 & 4 & & \\
\hline $\mathrm{Bi}$ & & & & 23 & & & & & & & & & 20 & 21 & & 27 & & 1350 & 262 & 140 & 78 & 75 \\
\hline $\mathrm{Cd}$ & & & 213 & 4 & & & & & & & & & 8 & 8 & 6 & 11 & 23 & 116 & 42 & 136 & 9 & 10 \\
\hline Co & 128 & 63 & 97 & 70 & 157 & 92 & 93 & 93 & 125 & 129 & 45 & 56 & 80 & 57 & 58 & 440 & 23 & 867 & 193 & 77 & 12 & 13 \\
\hline Dy & & & & & & & & & & & & & & & & & & 624 & 104 & 8 & & \\
\hline $\mathrm{Eu}$ & & & & & & & & & & & & & & & & & & 185 & 29 & & & \\
\hline $\mathrm{Nd}$ & & & & & & & & & & & & & & & & & & 1130 & 180 & & & \\
\hline $\mathrm{P}$ & & & 2070 & & & 30 & 30 & 35 & & & & & 3060 & 3400 & 150 & 399 & 641 & 1980 & 1210 & 5370 & & 22 \\
\hline $\mathrm{Pb}$ & 28 & 59 & $\begin{array}{l}\text { over- } \\
\text { range }\end{array}$ & 150 & 32 & 40 & 49 & 52 & 33 & 29 & 66 & & 171 & 88 & 110 & 254 & 428 & 2270 & 1050 & 209 & 42 & 44 \\
\hline $\mathrm{Pd}^{*}$ & & & & & & & & & & & & & & & & & & 5910 & 987 & 130 & & \\
\hline $\mathrm{Rh}$ & & & & & & & & & & & & & & 39 & & 46 & & 13800 & 2280 & & 31 & \\
\hline $\mathrm{Ru}$ & & & & & & & & & & & & & & & & & & 1560 & 231 & & & \\
\hline $\mathrm{Sb}$ & & & 212 & & & & & & & & & & & & & & & 1200 & 182 & & & \\
\hline $\mathrm{Se}$ & & & & & & 21 & & 29 & & & & & & & & & & 2030 & 360 & 130 & 91 & 80 \\
\hline $\mathrm{Sn}^{*}$ & & & & & & & & & & & & & & & & & & 19800 & 3400 & & & \\
\hline Th & 22 & & & 25 & & 12 & 16 & 18 & 22 & 21 & 53 & & 13 & 77 & 32 & 89 & 52 & 15500 & 2560 & & & 18 \\
\hline $\mathrm{Ti}$ & 2 & 8 & 79 & 5 & 2 & 3 & 13 & 10 & 2 & 3 & 3 & & 77 & 79 & 135 & 39 & 51 & 264 & 173 & 245 & 336 & 301 \\
\hline $\mathrm{Tl}$ & & 14 & 33 & & & 17 & & 21 & & & & & & & & & & 877 & 171 & 182 & 130 & 120 \\
\hline $\mathrm{U}$ & & & & & & & & & & & & & & & & & & \begin{tabular}{|l|}
20500 \\
\end{tabular} & 3380 & & & \\
\hline $\mathrm{V}$ & 4 & 3 & 15 & 3 & & 2 & 3 & 4 & & & 9 & & 30 & 34 & 4 & 15 & 8 & 1280 & 235 & 53 & 28 & 26 \\
\hline $\mathrm{W}$ & 176 & 292 & 1170 & 202 & 202 & 169 & 171 & 177 & 22 & & 47 & 47 & 2200 & 2800 & & 172 & 67 & 700 & 508 & 115 & 65 & 62 \\
\hline
\end{tabular}



Table A.3. Analytes Targeted in ICP-AES Fusion Fraction (concentrations reported in $\mu \mathrm{g} / \mathrm{g}$ of sample)

\begin{tabular}{|c|c|c|c|c|c|c|c|c|c|c|c|c|c|c|c|c|c|c|c|c|c|c|}
\hline \multirow[b]{2}{*}{ Analyte } & \multicolumn{8}{|c|}{ High-Chloride Rocky Flats } & \multicolumn{4}{|c|}{ Low-Chloride Rocky Flats } & \multicolumn{7}{|c|}{ PRF/RMC Scrap } & \multicolumn{3}{|c|}{ Solutions } \\
\hline & B-5439 & B-5495 & B-5497 & B-5524 & B-5532 & B-5701 & B-5703 & B-5703-Dup & B-5526 & B-5526-Dup & B-5534 & B-5680 & B-5456 & B-5456-Dup & B-5457 & B-5470 & B-5471 & B-5472 & B-5501 & $\mathrm{R}-418$ & $\mathrm{R}-419$ & R-419-Dup \\
\hline Al & 3800 & 5040 & 6670 & 3260 & 2000 & 2410 & 2870 & 2000 & 5540 & 5010 & 3050 & 5070 & 11000 & 11100 & 1400 & 570 & 1500 & 530 & 3510 & 13400 & 5680 & 4380 \\
\hline$B$ & 290 & 380 & & 260 & & & & & 440 & 290 & 310 & 410 & 280 & 210 & & & & & & 340 & 470 & 370 \\
\hline $\mathrm{Ca}$ & 3600 & 4500 & 3400 & 3600 & 2400 & 3500 & 2600 & 2400 & 5100 & 3900 & 4600 & 4300 & 8690 & 9890 & 1700 & 1600 & 2600 & 1400 & 16300 & 5600 & 5600 & 5000 \\
\hline $\mathrm{Cd}$ & & & 170 & & & 130 & & & & 46 & & & & & & & & & & 160 & 76 & 57 \\
\hline \multicolumn{23}{|l|}{$\mathrm{Ce}$} \\
\hline $\mathrm{Cr}$ & 2890 & 8310 & 8760 & 2790 & 7650 & 7050 & 7570 & 5710 & 2060 & 2790 & 5800 & 630 & 12600 & 14200 & 2260 & 14900 & 5210 & 14700 & 9280 & 5090 & 687 & 620 \\
\hline $\mathrm{Cu}$ & 53300 & 1290 & 3020 & 1530 & 510 & 620 & 700 & 690 & 1400 & 994 & 820 & 1270 & 1260 & 1120 & 1120 & 593 & 2400 & 140 & 3220 & 973 & 1330 & 1020 \\
\hline $\mathrm{Fe}$ & 3350 & 7280 & 18600 & 6370 & 7470 & 7600 & 8060 & 6660 & 3210 & 3390 & 19800 & 2130 & 42300 & 50200 & 31600 & 29300 & 47800 & 16300 & 39300 & 35600 & 4650 & 3710 \\
\hline $\mathrm{K}$ & 22000 & 34000 & 18000 & & 11000 & & 12000 & 12000 & 14000 & 9700 & & & & & & & & & & & & \\
\hline $\mathrm{La}$ & 800 & 950 & & 710 & 380 & 410 & 370 & 320 & 1100 & 740 & 620 & 1100 & 780 & 570 & & & & & & 230 & 1200 & 900 \\
\hline \multicolumn{23}{|l|}{$\mathrm{Li}$} \\
\hline $\mathrm{Mg}$ & 17700 & 19700 & 9140 & 13200 & 9190 & 7810 & 11400 & 11700 & 18500 & 14700 & 6970 & 12900 & 19500 & 18800 & 1200 & 1400 & 1100 & 400 & 14500 & 278000 & 145000 & 147000 \\
\hline $\mathrm{Mn}$ & 290 & 320 & 440 & 250 & 260 & 210 & 200 & 190 & 360 & 270 & 480 & 300 & 1300 & 1500 & 750 & 520 & 850 & 370 & 780 & 5330 & 330 & 270 \\
\hline Mo & 1600 & 1300 & 1440 & 950 & 1600 & 1400 & 1400 & 1000 & 1200 & 1100 & 1400 & 390 & 1500 & 1830 & 600 & 640 & 530 & 460 & 1950 & 980 & 330 & 270 \\
\hline $\mathrm{Ni}$ & 6380 & 11500 & 13100 & 3040 & 8430 & 9640 & 7430 & 7260 & 4710 & 4860 & 5220 & 1860 & 8960 & 10900 & 3070 & 25400 & 5970 & 21500 & 15800 & 4480 & 1020 & 890 \\
\hline $\mathrm{Si}$ & 6900 & 7400 & 3600 & 6200 & 4000 & 4400 & 4000 & 3900 & 11000 & 8700 & 6100 & 9200 & 12000 & 9100 & 5300 & 1700 & 5100 & 1100 & 9300 & 3800 & 8300 & 7000 \\
\hline $\mathrm{Sr}$ & & & & & & & 80 & & & & & & & & & & & & & & & \\
\hline $\mathrm{Y}^{*}$ & & & & & & & & & & & & & & & & & & & & & & \\
\hline $\mathrm{Zn}$ & & & 2210 & & & & & & 360 & 710 & & & 460 & 490 & 1920 & 530 & 1530 & 230 & 1560 & 2090 & & \\
\hline
\end{tabular}



Table A.4. Additional Analytes Detected in ICP-AES Fusion Fraction (concentrations reported in $\mu \mathrm{g} / \mathrm{g}$ of sample) High-Chloride Rocky Flats Low-Chloride Rocky Flats PRF/RMC Scrap

\begin{tabular}{|c|c|c|c|c|c|c|c|c|c|c|c|c|c|c|c|c|c|c|c|c|c|c|}
\hline Analyte & B-5439 & B-5495 & B-5497 & B-5524 & B-5532 & B-5701 & B-5703 & B-5703-Dup & B-5526 & B-5526-Dup & B-5534 & B-5680 & B-5456 & B-5456-Dup & B-5457 & B-5470 & B-5471 & B-5472 & B-5501 & R-418 & R-419 & R-419-Dup \\
\hline $\mathrm{Ag}$ & & 100 & & & & & & & 150 & 88 & & 98 & & & & & & & 170 & & 150 & 100 \\
\hline \multicolumn{23}{|l|}{ As } \\
\hline $\mathrm{Ba}$ & & & 402 & 46 & & & & & 67 & 73 & & & 39 & 51 & 47 & 24 & 149 & & 64 & 420 & & \\
\hline $\mathrm{Be}$ & & & & 29 & & & & & & & & & 86 & 100 & & & & & & & & \\
\hline $\mathrm{Bi}$ & & 530 & & 330 & & & & & 700 & 460 & & 560 & & & & & & & & & 810 & 560 \\
\hline $\mathrm{Cd}$ & & & 170 & & & 130 & & & & 46 & & & & & & & & & & 160 & 76 & 57 \\
\hline $\mathrm{Co}$ & 300 & 330 & & 210 & 240 & 210 & & & 420 & 320 & 210 & 290 & 360 & 360 & & 670 & & 880 & 200 & & 300 & 230 \\
\hline Dy & & 240 & & 160 & & & & & 310 & 200 & & 270 & 160 & & & & & & & & 320 & 240 \\
\hline \multicolumn{23}{|l|}{ Er } \\
\hline \multicolumn{23}{|l|}{$\mathrm{Eu}$} \\
\hline $\mathrm{Nd}$ & & & & & & & & & 440 & & & & & & & & & & & & 360 & \\
\hline $\mathrm{P}$ & 530 & 630 & 1900 & 580 & & & & & 1200 & 960 & 930 & 760 & 2600 & 2600 & & & 470 & & 740 & 2700 & 1100 & 850 \\
\hline $\mathrm{Pb}$ & 440 & 780 & 23900 & 420 & & & & & 1100 & 690 & & 780 & 370 & & & & & & 480 & 410 & 1000 & 720 \\
\hline $\mathrm{Pd}$ & & & & & & & & & 3000 & & & & & & & & & & & & 2800 & \\
\hline $\mathrm{Rh}$ & 5100 & 6400 & & 4600 & 2400 & 2600 & 2200 & 2100 & 7400 & 4800 & 3900 & 7300 & 4900 & 3400 & & & & & & 1400 & 8000 & 6100 \\
\hline \multicolumn{23}{|c|}{$\mathrm{Ru}$} \\
\hline $\mathrm{Sb}$ & & & 2000 & & & & & & & & & & & & & & & & & & & \\
\hline $\mathrm{Se}$ & & & & & & & & 29 & 1100 & & & 840 & & & & & & & & 1800 & 11000 & 7900 \\
\hline Sn & 6100 & 11000 & & 6000 & & 2000 & & & 11000 & 7100 & 4800 & 9700 & 5400 & 3700 & & & & & & 1800 & 11000 & 7900 \\
\hline $\mathrm{Te}$ & & & & & & & & & & & & & & & & & & & & & 1600 & \\
\hline Th & 6700 & 7300 & & 5800 & 3600 & 3800 & 3500 & & 8500 & 5700 & 5300 & 9000 & 6200 & 4500 & & & & & & & 9000 & 7100 \\
\hline $\mathrm{Ti}$ & & 140 & 470 & 73 & & & & & 120 & 89 & & 92 & 450 & 550 & 400 & 390 & 310 & 430 & 260 & 300 & 690 & 670 \\
\hline \multicolumn{23}{|l|}{ T1 } \\
\hline $\mathrm{U}$ & & & & & & & & & 8200 & & & & & & & & & & & & 7200 & \\
\hline $\mathrm{V}$ & 480 & 590 & & 420 & 240 & 250 & 230 & 210 & 680 & 450 & 390 & 660 & 480 & 360 & & & & & & 210 & 740 & 580 \\
\hline W & 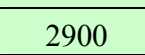 & 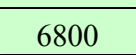 & 2400 & 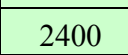 & 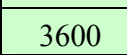 & 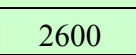 & - & 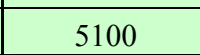 & & & & & 2500 & 2200 & & & & & & & & \\
\hline
\end{tabular}



Table A.5. Analytes Targeted in ICP-MS Acid Leach Fraction (concentrations reported in $\mu \mathrm{g} / \mathrm{g}$ of sample)

\begin{tabular}{|c|c|c|c|c|c|c|c|c|c|c|c|c|c|c|c|c|c|c|c|c|c|c|c|c|c|c|}
\hline \multirow[b]{2}{*}{ Analyte } & \multicolumn{9}{|c|}{ High-Chloride Rocky Flats } & \multicolumn{5}{|c|}{ Low-Chloride Rocky Flats } & \multicolumn{8}{|c|}{ PRF/RMC Scrap } & \multicolumn{4}{|c|}{ Solutions } \\
\hline & B-5439 & B-5495 & B-5497 & B-5524 & B-5532 & B-5701 & B-5703 & B-5703-Rep & B-5703-Dup & B-5526 & B-5526-Rep & B-5526-Dup & B-5534 & B-5680 & B-5456 & B-5456-Rep & B-5456-Dup & B-5457 & B-5470 & B-5471 & B-5472 & B-5501 & R-418 & $\mathrm{R}-419$ & R-419-Rep & R-419-Dup \\
\hline $\mathrm{Ag}$ & & & & & & & & & & & & & & & & & & 94 & & & 76 & 330 & & & & \\
\hline \multicolumn{27}{|l|}{ As } \\
\hline $\mathrm{Au}$ & 0.11 & & 0.73 & 0.23 & 0.06 & 0.19 & 0.27 & 0.31 & 0.30 & 0.11 & 0.11 & 0.18 & 0.04 & 0.38 & 0.02 & & 0.02 & & & & 0.03 & & & & & \\
\hline \multicolumn{27}{|l|}{$\mathrm{B}$} \\
\hline $\mathrm{Ba}$ & & & 402 & 46 & & & & & & 67 & & 73 & & & 39 & & 51 & 47 & 24 & 149 & & 64 & 420 & & & \\
\hline \multirow{2}{*}{\multicolumn{27}{|c|}{$\frac{B e}{B i}$}} \\
\hline & & & & & & & & & & & & & & & & & & & & & & & & & & \\
\hline $\mathrm{Cd}$ & & & 150 & & & & & & & & & & & & & & & & & 18 & 20 & 22 & 94 & & & \\
\hline \multicolumn{27}{|l|}{$\mathrm{Ce}$} \\
\hline $\mathrm{Co}$ & 110 & 56 & 86 & 59 & 140 & 80 & 82 & 89 & 86 & 130 & 120 & 140 & 39 & 48 & 72 & 68 & 54 & 51.0 & 410 & 23.0 & 320 & 95 & 72 & 11 & 10 & 12 \\
\hline Er & & 0.11 & \begin{tabular}{|l|}
0.044 \\
\end{tabular} & & & & & & & & & & 0.098 & & 0.24 & 0.22 & 0.23 & & & & & 0.057 & & & & \\
\hline $\mathrm{Ga}$ & 1800 & 140 & 1300 & 1900 & 5100 & 19000 & 13000 & 14000 & 15000 & 1300 & 1200 & 1300 & 1100 & 7400 & 110 & 110 & 110 & & & & & & & & & \\
\hline $\mathrm{Hg}$ & 2 & 2 & 10 & 2 & 2 & 1 & 1 & 2 & 2 & & & & & & 7 & 7 & 10 & & & & & 1 & & & & \\
\hline $\mathrm{La}$ & 800 & 950 & & 710 & 380 & 410 & 370 & & 320 & 1100 & & 740 & 620 & 1100 & 780 & & 570 & & & & & & 230 & 1200 & & 900 \\
\hline Mo & 740 & 520 & 770 & 350 & 830 & 650 & 330 & 360 & 350 & 420 & 410 & 470 & 1100 & 42 & 1600 & 1500 & 2300 & 580 & 1400 & 270 & 810 & \begin{tabular}{ll|l}
1700 \\
\end{tabular} & 640 & & & \\
\hline $\mathrm{Nb}$ & & & & & & & & & & 0.23 & 0.15 & & & & 0.22 & 0.22 & 0.14 & 0.26 & 1.1 & & 11 & 3 & 0.54 & & & \\
\hline $\mathrm{Np}$ & 3 & 0.6 & 3 & 7 & 4 & 2 & 4 & 5 & 6 & 1 & 0.9 & 0.9 & 7 & 0.7 & 1 & 0.9 & 1 & 0.9 & 11 & 1 & 57 & 9 & 2 & 7 & 6 & 6 \\
\hline $\mathrm{Sb}$ & 1 & & 90 & & 2 & & & & & & & & & & & & & 1 & 1 & & 7 & 2 & 1 & & & \\
\hline Sn & & & 110 & & & & & & & 18 & & & & & 14 & & 19 & 29 & & & 55 & 240 & 17 & & & 20 \\
\hline $\mathrm{Sr}$ & & & & & & & & & & & & & & & 20 & 19 & 25 & 21.0 & & & & 33 & & & & \\
\hline $\mathrm{Ta}$ & & & & & & & & & & & & & & & & & & & & & 2.6 & & & & & \\
\hline Th & & & 0.6 & & & & & & & & & & & & & & & 3 & 10 & 1 & 22 & 8 & 1 & 3 & 2 & 2 \\
\hline $\mathrm{Ti}$ & & 13 & 77 & 10 & & & 16 & 18 & 15 & 10 & 15 & 8 & 10 & & 94 & 89 & 100 & 130 & 46 & 55 & 72 & 190 & 250 & 350 & 340 & 330 \\
\hline $\mathrm{Tl}$ & & & & & & & & & & & & & & & & & & & & & & & & & & \\
\hline $\mathrm{W}$ & 180 & 330 & 1300 & 210 & 210 & 180 & 170 & 180 & 180 & & & & 46 & 44 & 2300 & 2400 & 3200 & & 170 & 71 & 120 & 420 & & & & \\
\hline
\end{tabular}



Table A.6. Additional Analytes Detected in ICP-MS Acid Leach Fraction (concentrations reported in $\mu \mathrm{g} / \mathrm{g}$ of sample)

\begin{tabular}{|c|c|c|c|c|c|c|c|c|c|c|c|c|c|c|c|c|c|c|c|c|c|c|c|c|c|c|}
\hline \multirow[b]{2}{*}{ Analyte } & \multicolumn{9}{|c|}{ High-Chloride Rocky Flats } & \multicolumn{5}{|c|}{ Low-Chloride Rocky Flats } & \multicolumn{8}{|c|}{ PRF/RMC Scrap } & \multicolumn{4}{|c|}{ Solutions } \\
\hline & B-5439 & B-5495 & B-5497 & B-5524 & B-5532 & B-5701 & B-5703 & B-5703-Rep & B-5703-Dup & B-5526 & B-5526-Rep & B-5526-Dup & B-5534 & B-5680 & B-5456 & B-5456-Rep & B-5456-Dup & B-5457 & B-5470 & B-5471 & B-5472 & B-5501 & R-418 & R-419 & R-419-Rep & R-419-Dup \\
\hline $\mathrm{Cr}$ & 740 & 1100 & 2100 & 580 & 650 & 570 & 580 & 660 & 690 & 520 & 450 & 530 & 590 & & 1500 & 1400 & 1700 & 410 & 830 & 600 & & 3800 & 6800 & 350 & 290 & 310 \\
\hline $\mathrm{Cu}$ & & 120 & 1800 & 420 & & 91 & 200 & 220 & 220 & 120 & 130 & 130 & & & 110 & 100 & 110 & 640 & 460 & 1200 & 94 & 2200 & 490 & & & \\
\hline Dy & & & 0.02 & 0.02 & & & & & & & & & & & & & & & 0.11 & & & & 0.05 & & & \\
\hline $\mathrm{Mn}$ & 74 & 49 & 270 & 58 & 97 & 56 & 72 & 82 & 81 & 99 & 87 & 100 & 66 & 32 & 680 & 640 & 620 & 490 & 360 & 410 & 380 & 670 & 9200 & 58 & 51 & 50 \\
\hline $\mathrm{Ni}$ & 6300 & 9600 & 15000 & 3900 & 6300 & 6200 & 5000 & 5500 & 5200 & 3300 & 3300 & 4300 & 4400 & 1300 & 8600 & 8100 & 5600 & 3600 & 34000 & 1600 & 7200 & \begin{tabular}{|l|l|}
27000 \\
\end{tabular} & 3100 & & & \\
\hline $\mathrm{Pb}$ & & & 47000 & 210 & & & & & & & & & & & 160 & 160 & 87 & 120 & 240 & 480 & 400 & 780 & 200 & & & \\
\hline $\mathrm{Pd}$ & & & 0.35 & 0.61 & & & & & & 0.27 & & 0.95 & & & & & & & & & & & & & & \\
\hline $\mathrm{Pt}$ & 3.6 & 0.09 & & 6.9 & 1.9 & 4.7 & 1.1 & 1.2 & 1.1 & 1.4 & 1.5 & 1.6 & 0.24 & 2.2 & 0.5 & 0.48 & 0.48 & & & & & 0.10 & 1.5 & & & \\
\hline $\mathrm{Rh}$ & & & 0.74 & 0.12 & & 0.72 & & & & 0.31 & 0.32 & 0.28 & & & 0.11 & 0.11 & 0.12 & 0.11 & & 0.13 & & 0.17 & & & & \\
\hline $\mathrm{Ru}$ & & & & & & & & & & 0.20 & 0.18 & & & & 0.23 & 0.33 & 0.31 & & & 0.22 & & 0.16 & & & & \\
\hline$\underline{U}$ & & & & & & & & & & 8200 & & & & & & & & & & & & & & 7200 & & \\
\hline $\mathrm{V}$ & 1 & 1 & 10 & 1 & 1 & 1 & 1 & 2 & 2 & 1 & 1 & 1 & 6 & & 23 & 22 & 24 & 2.8 & 7.7 & 4.9 & 6 & 15 & 14 & & & \\
\hline$\underline{W}$ & 180 & 330 & 1300 & 210 & 210 & 180 & 170 & 180 & 180 & & & & 46 & 44 & 2300 & 2400 & 3200 & & 170 & 71 & 120 & 420 & & & & \\
\hline$\underline{Y}$ & 2 & 5.2 & 19 & 9 & 2 & & 6 & 6 & 11 & 5 & 5 & 4 & & & 1 & 1 & 2 & & & & & & & & & \\
\hline $\mathrm{Zn}$ & & & 740 & & & & & & & & & & & & & & & 740 & 320 & 530 & & 700 & 920 & & & \\
\hline
\end{tabular}



Table A.7. Analytes Targeted in ICP-MS Fusion Fraction (concentrations reported in $\mu \mathrm{g} / \mathrm{g}$ of sample)

\begin{tabular}{|c|c|c|c|c|c|c|c|c|c|c|c|c|c|c|c|c|c|c|c|c|c|c|c|c|c|c|}
\hline \multirow[b]{2}{*}{ Analyte } & \multicolumn{9}{|c|}{ High-Chloride Rocky Flats } & \multicolumn{5}{|c|}{ Low-Chloride Rocky Flats } & \multicolumn{8}{|c|}{ PRF/RMC Scrap } & \multicolumn{4}{|c|}{ Solutions } \\
\hline & B-5439 & B-5495 & \begin{tabular}{|l|} 
B-5497 \\
\end{tabular} & \begin{tabular}{|l|l|} 
B-5524 \\
\end{tabular} & B-5532 & B-5701 & B-5703 & B-5703-Rep & B-5703-Dup & B-5526 & B-5526-Rep & B-5526-Dup & B-5534 & B-5680 & \begin{tabular}{|l|} 
B-5456 \\
\end{tabular} & B-5456-Rep & B-5456-Dup & B-5457 & B-5470 & B-5471 & B-5472 & B-5501 & R-418 & R-419 & R-419-Rep & R-419-Dup \\
\hline $\mathrm{Ag}$ & & & & & & & & & & & & & & & 73 & 83 & 63 & 170 & & 67 & & 370 & & & & 60 \\
\hline \multicolumn{27}{|c|}{ As } \\
\hline $\mathrm{Au}$ & 0.2 & 6 & 0.4 & 3 & 0.9 & 0.1 & 0.2 & 0.2 & 0.3 & 0.4 & 0.5 & 0.3 & 0.4 & 0.3 & 16 & 16 & 9 & 2 & 0.4 & 0.9 & 0.4 & 7 & & 0.1 & 0.1 & 0.1 \\
\hline \multicolumn{27}{|l|}{$B$} \\
\hline \multirow{2}{*}{\multicolumn{27}{|c|}{$\frac{\mathrm{Ba}}{\mathrm{Be}}$}} \\
\hline \multicolumn{23}{|l|}{$\mathrm{Be}$} & & & & \\
\hline $\mathrm{Bi}$ & & & 11 & 40 & 20 & & 45 & 8 & 7 & 14 & & & 8 & & & & & & & & & & & & & \\
\hline $\mathrm{Cd}$ & & & 180 & & & 120 & & & & & & & & & & & & & & 39 & & 31 & 100 & & & \\
\hline $\mathrm{Ce}$ & & & & & & & & & & 14 & & & & & & & & & & & & & 75 & & & \\
\hline Co & 180 & 120 & 190 & 93 & 240 & 190 & 130 & 130 & 140 & 140 & 140 & 160 & 120 & 57 & 300 & 300 & 340 & 110.0 & 480 & 180.0 & 1100 & 340 & 120 & 17 & 17 & 16 \\
\hline Er & & 1.0 & 0.5 & 0.2 & & & 0.5 & 0.4 & 0.5 & & & & 0.2 & & 1.0 & 1.0 & 1.2 & & & & & 0.5 & 0.5 & & & \\
\hline $\mathrm{Ga}$ & 2700 & 370 & 2600 & 6800 & \begin{tabular}{|l|l|}
13000 \\
\end{tabular} & 33000 & 16000 & 16000 & 17000 & 2200 & 2200 & 2400 & 1800 & \begin{tabular}{|l|}
10000 \\
\end{tabular} & 760 & 760 & 790 & & & 130 & & 160 & & & & \\
\hline $\mathrm{Hg}$ & 14 & 17 & 30 & 73 & 24 & 25 & 10 & 10 & 17 & 3 & 3 & 4 & 5 & 3 & 31 & 32 & 36 & 2 & 2 & 8 & 2 & 12 & 2 & & & \\
\hline $\mathrm{La}$ & & & & & & & & & & & & & & & & & & & & & & & 22 & & & \\
\hline Mo & 1700 & 1200 & 1800 & 1100 & 1800 & 1700 & 1400 & 1500 & 1100 & 960 & 960 & 1100 & 1500 & 210 & 1900 & 1900 & 2200 & 760 & 470 & 640 & 580 & 2700 & 1000 & 110 & 110 & 95 \\
\hline $\mathrm{Nb}$ & & 2.4 & 2.4 & & & & & & & & & & & & 45 & 45 & 32 & 11 & 9.5 & 9.7 & 36 & 28 & & 4.3 & 4.2 & 3.9 \\
\hline $\mathrm{Np}$ & 170 & & 160 & 240 & 400 & 150 & 220 & 220 & 200 & 140 & 140 & 140 & & 160 & & & & & & & & & & 260 & 260 & 270 \\
\hline $\mathrm{Sb}$ & & 4 & 1200 & 7 & 4 & 4 & 6 & 6 & 6 & 5 & 5 & 5 & 6 & 5 & 10 & 11 & 12 & 17 & 5 & 11 & 8 & 11 & 6 & 9 & 9 & 10 \\
\hline Sn & & 120 & 2200 & & 130 & 100 & 110 & 160 & 120 & 120 & 160 & 120 & & & 310 & 320 & 440 & 170 & 140 & 230 & 170 & 1100 & & & & \\
\hline $\mathrm{Sr}$ & 34 & 52.0 & 44 & 37 & 45 & 54 & 130 & 120 & 41 & 55 & 56 & 34 & 47 & 39 & 67 & 65 & 74 & 73.0 & & 60.0 & & 73 & 45 & 34 & & 46 \\
\hline Th & 1 & 2 & 2 & 2 & 1 & 2 & 5 & 5 & 5 & 2 & 2 & 2 & 6 & 2 & 11 & 10 & 14 & 14 & 12 & 48 & 25 & 44 & 22 & 32 & 32 & 28 \\
\hline $\mathrm{Ti}$ & 48 & 85 & 590 & 60 & 56 & 35 & 100 & 74 & 92 & 41 & 48 & 51 & 60 & 42 & 500 & 510 & 650 & 500 & 270 & 350 & 490 & 450 & 320 & 610 & 610 & 630 \\
\hline $\mathrm{Tl}$ & & & & & & & & & & & & & & & & & & & & & & & & & & \\
\hline $\mathrm{W}$ & \begin{tabular}{|l|l|}
1500 \\
\end{tabular} & 1700 & 6000 & \begin{tabular}{|l|l}
15000 \\
\end{tabular} & 2400 & 2600 & 1000 & 1700 & 1700 & 370 & 370 & 450 & 580 & 310 & 4300 & 6600 & 7300 & 240 & 230 & 830 & 220 & 1200 & 230 & 38 & 34 & 33 \\
\hline
\end{tabular}



Table A.8. Additional Analytes Detected in ICP-MS Fusion Fraction (concentrations reported in $\mu \mathrm{g} / \mathrm{g}$ of sample)

\begin{tabular}{|c|c|c|c|c|c|c|c|c|c|c|c|c|c|c|c|c|c|c|c|c|c|c|c|c|c|c|}
\hline \multirow[b]{2}{*}{ Analyte } & \multicolumn{9}{|c|}{ High-Chloride Rocky Flats } & \multicolumn{5}{|c|}{ Low-Chloride Rocky Flats } & \multicolumn{8}{|c|}{ PRF/RMC Scrap } & \multicolumn{4}{|c|}{ Solutions } \\
\hline & B-5439 & B-5495 & B-5497 & B-5524 & B-5532 & B-5701 & B-5703 & B-5703-Rep & B-5703-Dup & B-5526 & B-5526-Rep & B-5526-Dup & B-5534 & B-5680 & $\mid$ B-5456 & B-5456-Rep & B-5456-Dup & B-5457 & B-5470 & B-5471 & B-5472 & B-5501 & R-418 & R-419 & R-419-Rep & R-419-Dup \\
\hline $\mathrm{Cr}$ & 3200 & 17000 & 19000 & 6200 & 16000 & 15000 & 16000 & 16000 & 12000 & 1900 & 1900 & 6000 & 12000 & 680 & 28000 & 29000 & 32000 & 2600 & 17000 & 9800 & 30000 & 22000 & 10000 & 540 & 550 & 540 \\
\hline $\mathrm{Cu}$ & 84000 & 300 & 2800 & 750 & 150 & 200 & 330 & 800 & 350 & 260 & 270 & 250 & 220 & 140 & 490 & 490 & 620 & 1100 & 370 & 2000 & 210 & 3400 & 680 & 100 & 100 & 120 \\
\hline Dy & & & & & & & & & & & & & & & & & & & & & & & 1 & & & \\
\hline $\mathrm{Eu}$ & & & & 1 & & & & & & & & & & & & & & & & & & & & & & \\
\hline $\mathrm{Mn}$ & 150 & 130 & 580 & 110 & 210 & 140 & 140 & 140 & 140 & 120 & 140 & 130 & 430 & 70 & 1500 & 1500 & 1800 & 990 & 380 & 990 & 480 & 1100 & 11000 & 120 & 70 & 78 \\
\hline $\mathrm{Nd}$ & & & & & & & & & & & & & & & & & & & & & & & 2 & & & \\
\hline $\mathrm{Ni}$ & 6200 & 13000 & 25000 & 2800 & 8300 & 19000 & 8300 & 8300 & 7600 & 3300 & 3300 & 4300 & \begin{tabular}{|l|}
4600 \\
\end{tabular} & 1400 & 17000 & 17000 & 20000 & 2700 & 24000 & 4900 & \begin{tabular}{|l|l|}
37000 \\
\end{tabular} & 32000 & 3800 & & & \\
\hline $\mathrm{Pb}$ & & & 62000 & & & & & & & & & & & & & & & & & 930 & 500 & 1200 & 280 & & & \\
\hline $\mathrm{Pd}$ & 5 & & & 2 & & 1 & & & & 2 & 2 & 1 & & & & & & & 1 & & & & & & & \\
\hline $\mathrm{Pt}$ & 4 & & 2 & 17 & 3 & 6 & 2 & 2 & 2 & 3 & 4 & 4 & & 3 & 3 & 3 & 3 & & 1 & 1 & & & 2 & & 0.9 & 0.9 \\
\hline $\mathrm{Rh}$ & 2.10 & & 1.00 & 0.46 & & 0.29 & & & 0.33 & 0.59 & 0.55 & 0.42 & & & 1.00 & 1.00 & 1.20 & & & 0.35 & & 0.41 & & & & \\
\hline $\mathrm{Ru}$ & 0.35 & 0.34 & 0.34 & 0.54 & & 1.10 & & 0.38 & 0.69 & 0.67 & 0.37 & 0.84 & & & $\begin{array}{ll}0.48 \\
\end{array}$ & 0.52 & 1.70 & 0.41 & 0.49 & 0.35 & 0.30 & 0.48 & 0.33 & 0.42 & 0.32 & 0.53 \\
\hline $\mathrm{Ta}$ & 3 & 140 & 12 & 69 & 34 & 3 & 6 & 7 & 12 & 15 & 8 & 10 & 11 & 4 & 2400 & 2500 & 2200 & 180 & 31 & 71 & 28 & 510 & 2 & 4 & 4 & 3 \\
\hline $\mathrm{Te}$ & & 0.17 & 0.24 & & & & & & & & & & & & & & & 0.15 & & 0.21 & 0.13 & & & $\begin{array}{l}0.15 \\
\end{array}$ & 0.15 & \\
\hline $\mathrm{U}$ & & & & & & & & & & 8200 & & & & & & & & & & & & & & \begin{tabular}{|l|}
7200 \\
\end{tabular} & & \\
\hline $\mathrm{V}$ & 8 & 17 & 31 & 7 & 10 & 13 & 14 & 12 & 10 & 4 & 5 & 7 & 24 & & 31 & 32 & 34 & 7.1 & 7.3 & 15.0 & 14 & 24 & 19 & 2 & 2 & 2 \\
\hline$Y$ & 23 & 28.0 & 28 & 25 & 10 & 7 & 38 & 37 & 38 & 32 & 33 & 34 & 3 & & 7 & 8 & 9 & & & & & & 7 & & & \\
\hline $\mathrm{Zn}$ & & & 1500 & & 570 & & & & & & & & & & 670 & 650 & 600 & 1300 & & 960 & & 1200 & 1200 & & & \\
\hline
\end{tabular}

